\title{
Honeycomb fiber-reinforced polymer sandwich composites for development of aquaculture raceway systems
}

\author{
Avinash Vantaram \\ West Virginia University
}

Follow this and additional works at: https://researchrepository.wvu.edu/etd

\section{Recommended Citation}

Vantaram, Avinash, "Honeycomb fiber-reinforced polymer sandwich composites for development of aquaculture raceway systems" (2004). Graduate Theses, Dissertations, and Problem Reports. 1514. https://researchrepository.wvu.edu/etd/1514

This Thesis is protected by copyright and/or related rights. It has been brought to you by the The Research Repository @ WVU with permission from the rights-holder(s). You are free to use this Thesis in any way that is permitted by the copyright and related rights legislation that applies to your use. For other uses you must obtain permission from the rights-holder(s) directly, unless additional rights are indicated by a Creative Commons license in the record and/ or on the work itself. This Thesis has been accepted for inclusion in WVU Graduate Theses, Dissertations, and Problem Reports collection by an authorized administrator of The Research Repository @ WVU. For more information, please contact researchrepository@mail.wvu.edu. 


\title{
Honeycomb Fiber-Reinforced Polymer Sandwich Composites for Development of Aquaculture Raceway Systems
}

\author{
By \\ Avinash Vantaram \\ Thesis submitted to the \\ College of Engineering and Mineral Resources \\ At \\ West Virginia University \\ In partial fulfillment of the requirements for the degree of \\ Master of Science \\ In \\ Mechanical Engineering
}

\author{
Julio F. Davalos, Ph.D., Chair \\ Jacky C. Prucz, Ph.D., Co- Chair \\ Thomas M. Damiani, Ph.D.
}

\author{
West Virginia University \\ Morgantown, West Virginia
}

2004

Keywords: Honeycomb Fiber Reinforced Polymers (HFRP), Sandwich Composites, Aquaculture, Raceways, Finite Element Modeling 


\title{
ABSTRACT \\ Honeycomb Fiber- Reinforced Polymer Sandwich Composites for Development of Aquaculture Raceway Systems
}

\author{
Avinash Vantaram \\ Advisor: Dr. Julio F. Davalos
}

It is argued that the utilization of impaired mine waters abundant in WV and other mid-Appalachian states for fish culture can substantially increase aquaculture economic development. The primary limitation to the effective utilization of discharged waters is the lack of suitable fish culture tanks that can be easily installed in rugged terrains surrounding mine water treatment plants, where cast-in-place concrete tanks cannot be constructed. Therefore, Fiber-Reinforced Polymer (FRP) sandwich materials offer an economical option for production of light, transportable and durable fish culture raceway systems. This study is concerned with the development and evaluation of prototype fish culture tanks using a Honeycomb FRP, termed HFRP, sandwich panel with sinusoidal core geometry, which is produced by Kansas Structural Composites Inc., (KSCI) by a contactmolding process.

Based on defined functional requirements, a raceway system consisting of staggered tanks is designed, and each tank has a longitudinal partition wall to carry out parallel aquaculture studies. Representative panel samples of the side and bottom walls are tested within the linear range and eventually to failure. Also two different designs for the side-to-bottom panel connections are tested in the linear range for rotational stiffness. Elastic equivalent properties for the face and core laminates are calculated. The linear response of the samples is analyzed by the finite element method, first using actual core geometry and then using the equivalent properties, and the predictions are compared with the experimental results. Based on these results, modifications to the existing design are suggested. Failure loads and modes are analyzed and used to determine possible failures of raceway units in use. A finite element $(\mathrm{FE})$ model of the entire tank is developed and several expected loading combinations during use of the system are considered. Factors of safety during various installation conditions are estimated based on the results of the system FE model. Finally, an overview of three current field projects using HFRP raceways is presented. 


\section{ACKNOWLEDGEMENTS}

First and foremost, I would like to thank Dr. Julio F. Davalos, who has been more than a guide to me during this research. He provided valuable insight into all areas of the project. His invaluable moral support during the course of the research will never be forgotten.

Special thanks also to Justin Robinson. My gratitude to him not only for aiding in completing the project, but also for being a close friend and guide cannot be expressed in words.

I would also like to thank Dr. Jacky C. Prucz and Dr. Thomas M. Damiani for serving on the advisory committee. Dr. Pizhong Qiao from the University of Akron provided valuable suggestions in obtaining equivalent properties. I deeply appreciate Dr. Ken Semmens from WVU for his help in aquaculture issues. Thanks are also owed to Vinod Ramayanam, An Chen and Waiqiao Wang for participating in invaluable technical discussions with me.

Funding for this project was provided by the NSF Partnerships for Innovation Program (NSF-PFI), while the fielded implementation of the product was supported by the USDA-AFMDP. The test samples were generously provided by Kansas Structural Composites Inc. Special thanks is due to these two organizations as this research could not have been conducted without adequate funding and test samples.

Finally, I would like to express my deepest gratitude to my family for their love and support during the work. Without their encouragement, the work would not have been a success. 


\section{TABLE OF CONTENTS}

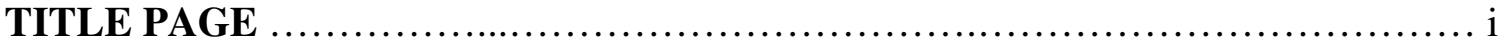

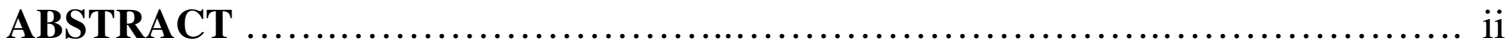

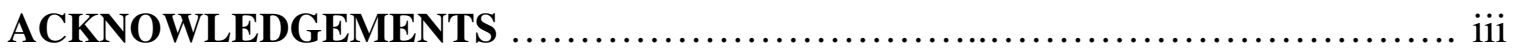

TABLE OF CONTENTS ......................................................... iv

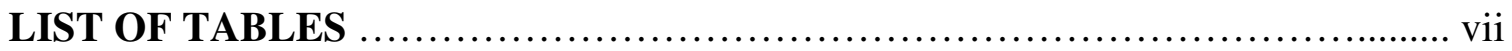

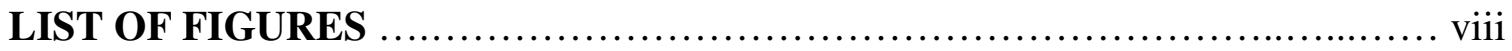

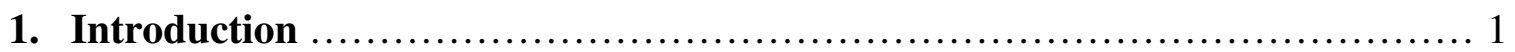

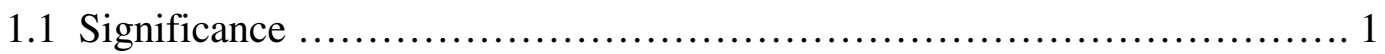

1.2 Background- Review On Existing Raceway Units ........................ 2

1.2.1 Introduction ................................................... 2

1.2.2 Materials for Raceway Construction ................................. 3

1.2.3 Description of Sandwich Materials ............................... 7

1.2.4 Cost Comparison of Raceways from Various Manufacturers ......... 9

1.3 Objective and scope ................................................. 11

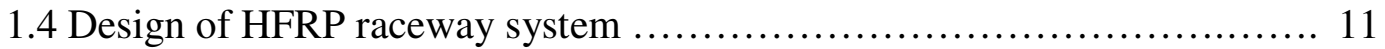

1.5 Thesis Overview ........................................................ 14

\section{HFRP Sandwich Material}

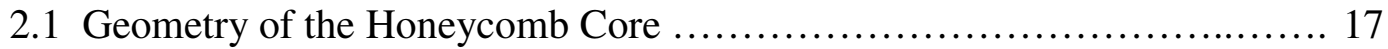

2.2 Properties of Chopped Strand Mat ...................................... 18

2.3 Formulation of equivalent properties ................................... 20

3 Evaluation of components

3.1 Test Samples ..................................................... 22

3.2 Finite Element Modeling ….......................................... 25

3.2.1 Actual Core Geometry .......................................... 25

3.2.2 Equivalent Plate Modeling ..................................... 29

4 Stiffness Evaluation of Beam Samples in Bending

4.1 Experimental Testing of Beam Samples .................................... 30

4.1.1 Testing Procedure ................................................ 32

4.1.2 Results of Experimental Testing .................................... 33

4.2 Finite Element Modeling of Beam Samples ............................. 33

4.2.1 Actual Core Geometry .............................................. 34

4.2.2 Equivalent Core Plate........................................... 35

4.2.3 Finite Element Analysis Results ................................. 36

4.3 Comparison of Results ............................................... 37

$5 \quad$ Testing and Analysis of Connection Samples

5.1 Experimental Testing of Connection Samples ............................ 39

5.2 Finite Element Modeling of Connection Samples .......................... 42

5.2.1 Actual Core Geometry .......................................... 42

5.2.2 Equivalent Core Plate.......................................... 44 
5.2.3 Cantilever Beam FE Modeling ................................ 45

5.3 Comparison of Experimental and FE Results ............................ 46

$6 \quad$ Failure Testing of Beam Samples

6.1 Experimental Setup ............................................... 50

6.2 Failure Testing of Beam Samples ..................................... 51

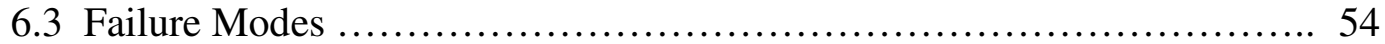

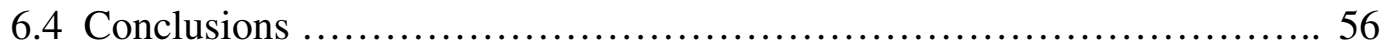

$7 \quad$ Modeling of Complete Raceway

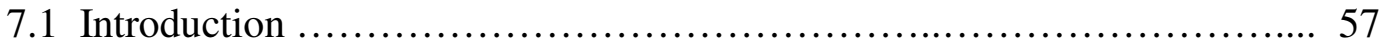

7.2 Finite Element Modeling of the Raceway …............................. 58

7.2.1 Model Dimensions .................................................... 58

7.2.2 Connection Design .............................................. 59

7.2.3 Mesh Selection ................................................. 59

7.2.4 Loads ................................................................. 60

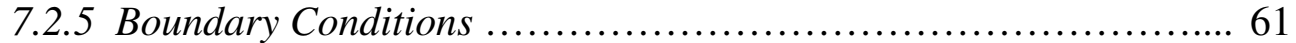

7.2.6 Reported Results ................................................ 62

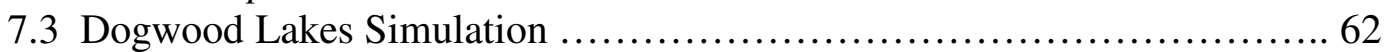

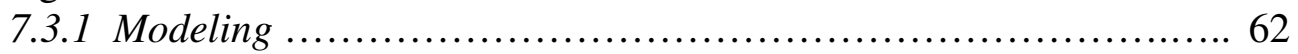

7.3.2 Discussion of Results ........................................... 64

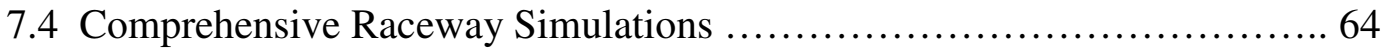

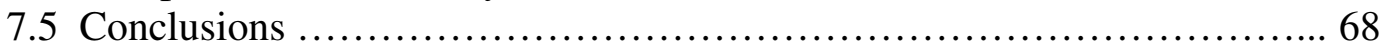

8 Field Implementation of HFRP Raceway Systems

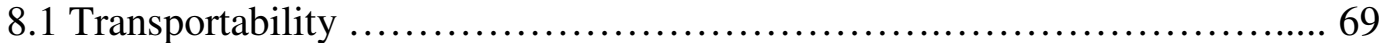

8.2 Accomplished Projects ........................................... 70

8.2.1 Dogwood Lakes ............................................... 71

8.2.2 Reymann Memorial Farms ..................................... 74

8.2.3 Floating Raceways ............................................ 76

9 Recommendations

9.1 Overview of the Project ............................................ 80

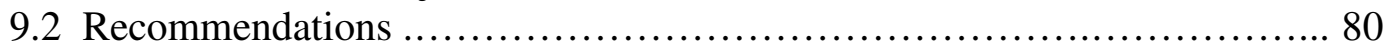

9.2.1 Based on Experimental Testing .............................. 81

9.2.2 Based on Experience from Field Implementation ................... 81

9.2.3 To Decrease the Manufacturing and Assembly Costs .............. 83

9.3 Future Work ............................................................... 83

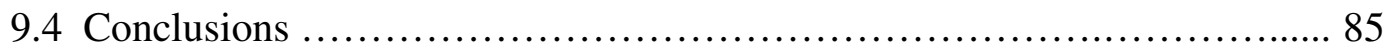

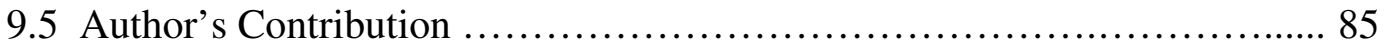

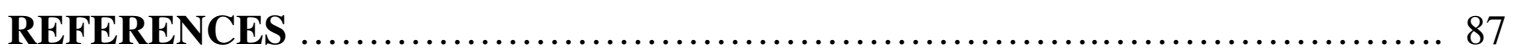

LIST OF PUBLICATIONS ON THE PROJECT _............................ 89 


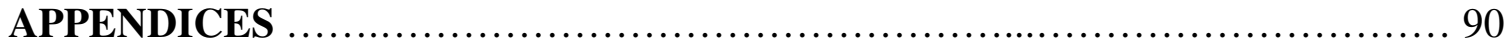

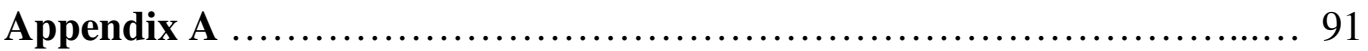

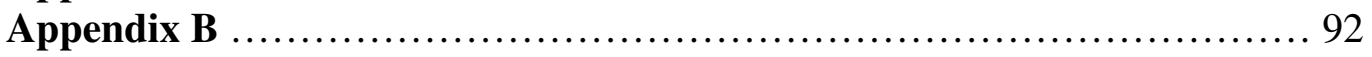

Appendix C …......................................................... 95

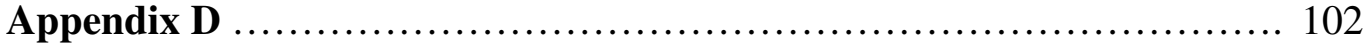




\section{LIST OF TABLES}

Table 2.1 Properties of E-glass Fiber and Polyester Resin .................... 18

Table 2.2 Properties of Chopped Strand Mat in Bending ....................... 19

Table 2.3 Equivalent Properties of the Honeycomb Core Geometry ............. 21

Table 4.1 Deflection Results for Beam Samples ............................ 36

Table $4.2 \quad$ Strain Results for Beam Samples ................................ 37

Table 5.1 Comparison of Results for the Stiffened and Unstiffened Connection

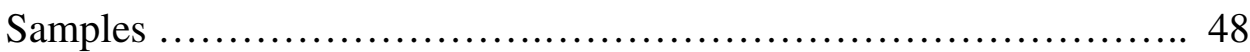

Table $6.1 \quad$ Failure Information for Beam Samples ........................... 52

Table 6.2 In-Service Values for Deflection and Strain Obtained from the Finite Element Modeling .......................................... 52

Table $6.3 \quad$ Factors of Safety for Various Samples ........................... 52

Table 7.1 Comparison of Results for a Side Panel Transverse Section for Central

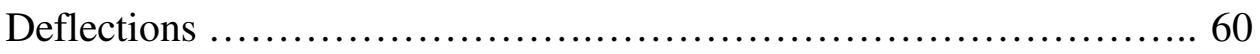

Table 7.2 Results of FE Model Simulation of Dogwood Lakes Raceway Units ..... 63

Table 7.3 Behavior of the Tank under various Loading and Boundary Conditions ..65 


\section{LIST OF FIGURES}

Figure 1.1 Open Ended Earthen Raceways with Concrete Water Control Structure .. 3

Figure $1.2 \quad$ Open Ended Concrete Raceways $\ldots \ldots \ldots \ldots \ldots \ldots \ldots \ldots \ldots \ldots \ldots \ldots \ldots \ldots \ldots$

Figure $1.3 \quad$ Wear and Tear of Concrete Raceways .............................. 5

Figure 1.4 Closed Ended Rectangular Tank with Liner and Supporting Braces ...... 5

Figure 1.5 Closed Ended Fiberglass Tank with Supporting Braces ................. 6

Figure 1.6 Closed Ended Sandwich Tanks without Braces ........................ 7

Figure 1.7 Balsa Wood Core Sandwich Material $\ldots \ldots \ldots \ldots \ldots \ldots \ldots \ldots \ldots \ldots \ldots \ldots . . . . \ldots$

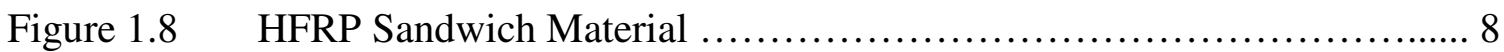

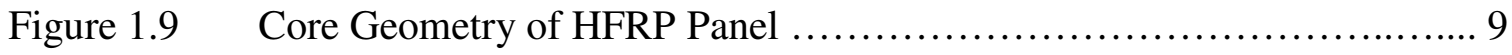

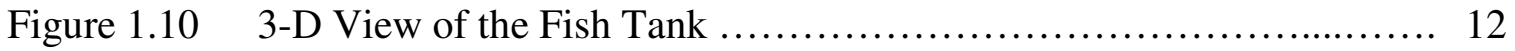

Figure 2.1 A Unit Cell (RVE) of Sinusoidal Core - Plan View ................. 18

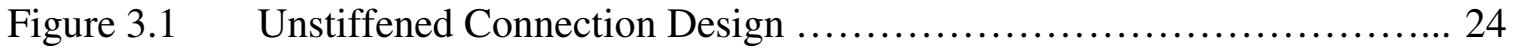

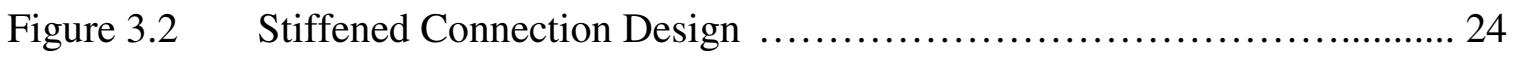

Figure 3.3 2"x2" Quarter Cell Core Configuration ........................... 27

Figure 3.4 Quarter Cell with Top Face Sheet Containing Automatic Mesh Elements.................................................. 27

Figure $3.5 \quad$ Face Sheet Elements on the Core Deleted ............................ 27

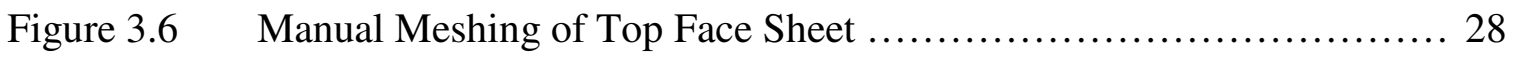

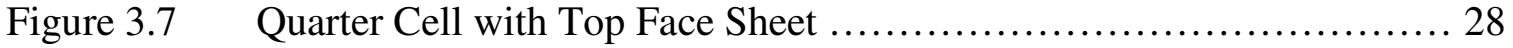

Figure 3.8 2"x2" Quarter Cell ......................................... 28

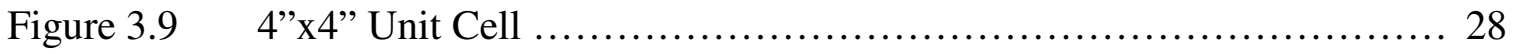


Figure 3.10 Equivalent Core FE Model (4"x4" Section) ........................ 29

Figure 4.1 Typical Test Setup for a Beam Sample in Bending ................... 31

Figure 4.2 Load Vs Deflection Data for a 4' Transverse Sample of a Side Panel ... 32

Figure 4.3 Deflection Shape for Actual Geometry Transverse Sample of a Side Panel ..................................................... 34

Figure 4.4 Deflection Shape for the Equivalent Side Panel Transverse Sample .... 35

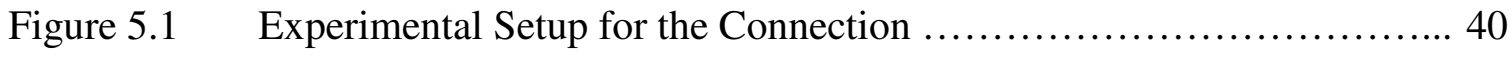

Figure 5.2 Location of Strain Gages on

(a) Bottom- Panel .............................................. 41

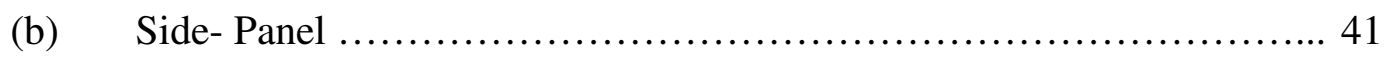

Figure 5.3 Actual Geometry Model of the Unstiffened Connection .............. 42

Figure 5.4 Actual Geometry Model of the Stiffened Connection ................ 43

Figure 5.5 Equivalent Core Geometry Model of the Unstiffened Connection ...... 44

Figure 5.6 Equivalent Core Geometry Model of the Stiffened Connection ......... 45

Figure $5.7 \quad$ Cantilever Beam FE Model .................................. 46

Figure 5.8 Connector Selection for the Raceway ........................... 49

Figure 5.9 Placement of a Unidirectional Fabric at the Connection .............. 49

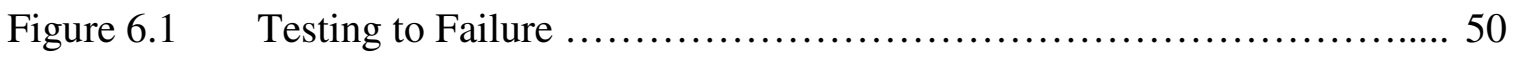

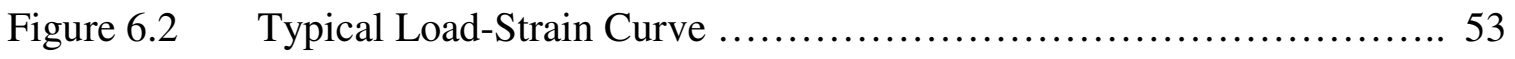

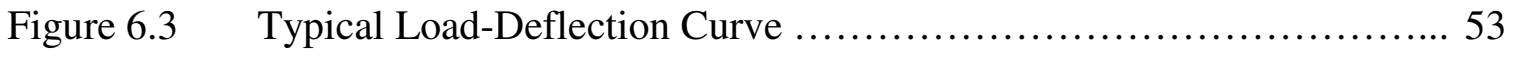

Figure 6.4 Delamination of Face Sheet From Core ............................ 54

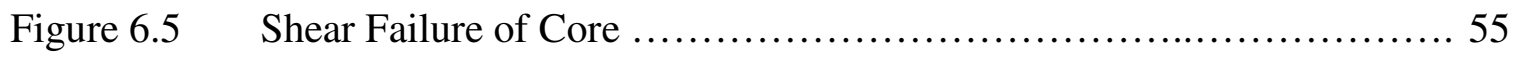

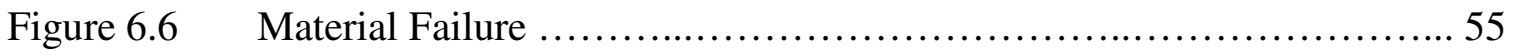


Figure 7.1 Complete Raceway Unit

Figure $7.2 \quad$ Finite Element Model of the Raceway .............................. 58

Figure 7.3 Main Tank-to-Quiescent Zone Connection at Dogwood Lakes .......... 63

Figure 7.4 Transverse Stress at the Top Bolt When only Two Bolts are Used at the

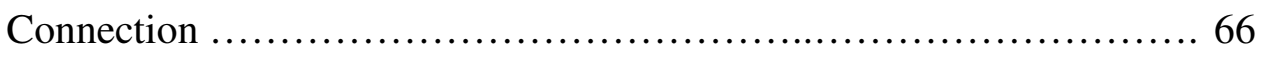

Figure 7.5 Maximum Deflection and Maximum Opening at Water Level at the

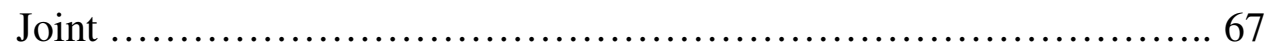

Figure 7.6 Strains and Deflections when Water Flows Through a Single Channel .. 67

Figure 8.1 Transportation of Fish Raceways …............................... 69

Figure 8.2 Unloading of Tanks from the Trailers ........................... 70

Figure 8.3 Terrain at Dogwood Lakes …................................... 72

Figure $8.4 \quad$ Tanks After Installation ........................................... 73

Figure $8.5 \quad$ Project Complete …................................................. 73

Figure 8.6 Installation of Raceways at Wardensville ............................ 75

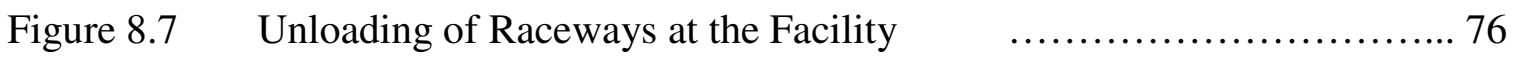

Figure 8.8 Net-Pens Used at Warwick Mine Water Treatment Plant ................ 77

Figure 8.9 Installation of Floating Raceways at the Warwick Mine Water Treatment

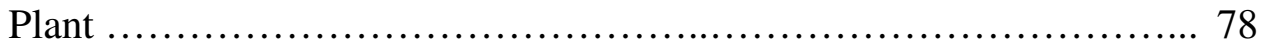

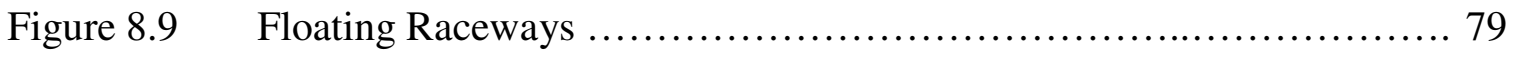

Figure 9.1 Main Tank-to-Quiescent Zone Joint

(a) Dogwood Lakes ................................................ 82

(b) Reymann Memorial Farms ........................................ 82

Figure 9.2 Mechanical Connector Joining the Two Central Panels ................. 82 
Figure 9.3 Initial Design of the New Connector Joining the Side and Bottom Panels

(a) Solid Model of the Proposed Connection ........................... 84

(b) Wire Frame Model of the Proposed Connection ..................... 84

(c) Assembled Connection Sample .................................. 84

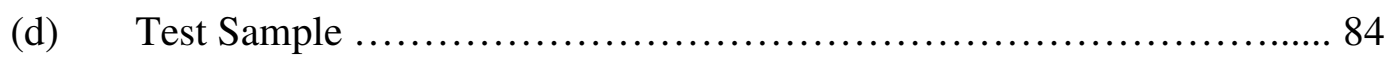




\section{Chapter 1}

\section{Introduction}

\subsection{Significance}

It is estimated that 232 million gallons of water per day are discharged in West Virginia from both active and abandoned mines. If only $30 \%$ of these water resources were used for aquaculture, the expansion of this industry in WV is expected to increase by more than $\$ 12$ million. However, the primary limitation for the effective utilization of discharged waters is the lack of suitable fish culture tanks that can be easily installed in rugged terrains surrounding mine water treatment plants. Such topographical constraints do not easily permit the construction of cast-in-place concrete tanks, and therefore, advanced composite materials offer an alternative for production of modular, transportable, lightweight, and durable fish culture raceway systems. This thesis discusses the development of a fish raceway system manufactured from Honeycomb Fiber-Reinforced Polymer (HFRP) sandwich panels, using E-glass fibers and a polyester resin. HFRP is being extensively used for highway bridge decks because of its high strength to weight ratio and versatility of manufacturing. Since sandwich panels can be manufactured of any thickness and any material architecture, it was envisioned that HFRP can be efficiently used to construct mobile fish raceway systems. Thus, a raceway system was proposed to mainly facilitate aquaculture research in and around West Virginia. Upon successful implementation of these tanks, modifications to the design will be suggested to accommodate fish mass production at other locations. 


\subsection{Background - Review of Existing Raceway Systems}

\subsubsection{Introduction}

According to the FishBase Glossary of terms, a fish raceway is defined as "A long narrow channel with a continuous flow of water for growing fish" [1]. The three general classifications of the existing fish culture systems are rectangular tanks, circular tanks and oval tanks. For this discussion, a review of functionality and construction methods of rectangular raceways is given.

Rectangular tanks are divided into open-ended raceways and closed tanks. A raceway is an open-ended tank where water enters continuously at one end and leaves at the other. This is a proven design for trout culture. The raceways are usually placed in series to obtain maximum utilization of water before discharge. They usually have a plug flow with velocity of about $0.05 \mathrm{ft} / \mathrm{sec}$. Waste is swept by the action of fish and water flow to a quiescent zone where it settles out allowing for removal. Thus raceways are labor efficient compared to other tanks. They also have a small footprint and occupy less space than closed tanks. One of the main advantages with raceways is that gravity flow can be exploited and no pumping is needed saving investment and expenditure. Due to various aquaculture considerations, a modular, rectangular raceway system is used in this project as a design of choice. This section briefly describes the various materials being used for the construction of rectangular raceways. 


\subsubsection{Materials for Raceway Construction}

Various construction materials are used to produce raceways. Generally raceways are made of the following: earth (earthen raceways), concrete, cement block, wood lined with plastic, metal, fiberglass and sandwich materials. The advantages and disadvantages of the different systems are discussed in the following sections.

\section{Earthen Raceways:}

Earthen raceways were the first type to be built, because of low cost and ease of construction. They usually have water control devices made of concrete. Though they are generally suited to grow healthy fish, they have certain disadvantages. The irregular geometries of side walls and bottom present challenges during crowding and grading of fish and difficulty in the removal of waste products. Plant growth also creates undesirable

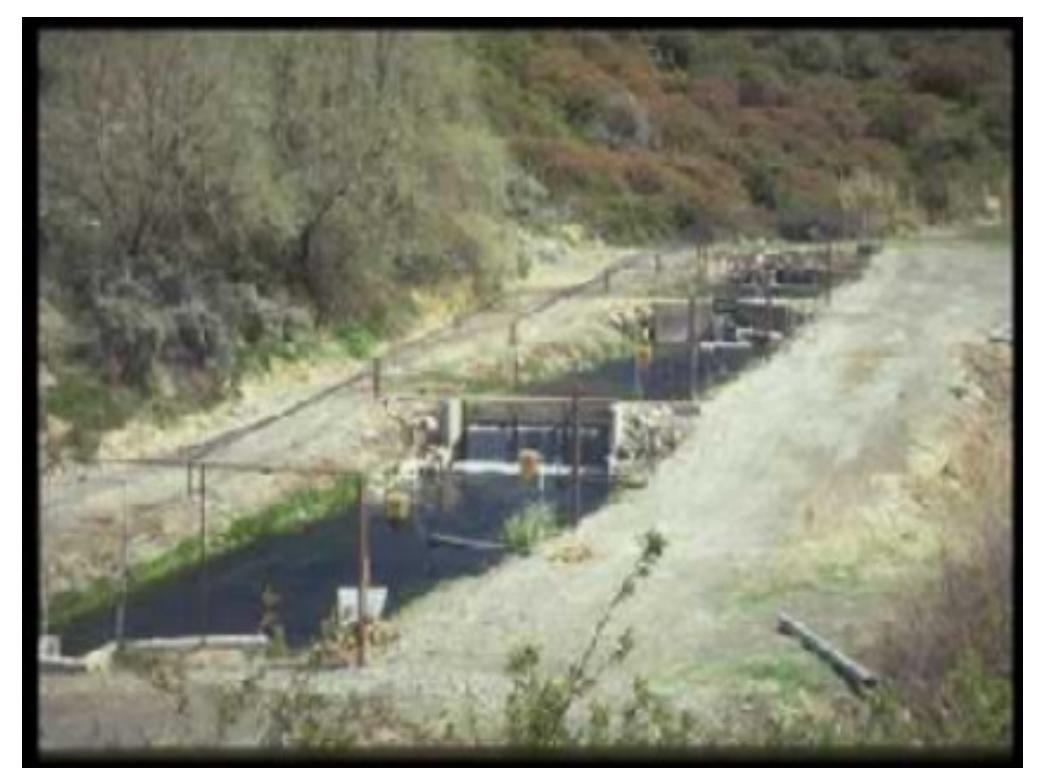

Figure 1.1 Open Ended Earthen Raceways with Concrete Water Control Structure 
effects, and certain diseases, like the whirling disease, are more prevalent in earthen raceways, raising concerns about fish health.

\section{Concrete Raceways:}

The most commonly used material for raceway construction is concrete. While the manufacturing costs of these units are lower compared to most other materials, the construction of concrete raceways is not suitable for rugged terrains because of difficulties in transporting materials and casting concrete at the site. With sufficient care, plant growth can be eliminated in concrete raceways, and because of the regular geometry with well-defined corners, crowding and grading of fish is easily accomplished. Concrete is best suited for large raceways. But concrete shows marked wear and tear over a period of time, particularly due to freezing-and-thawing within the pore structure of the material, leading to cracking and deterioration. The main disadvantage of these tanks is that they are permanent structures and cannot be transported to other places.

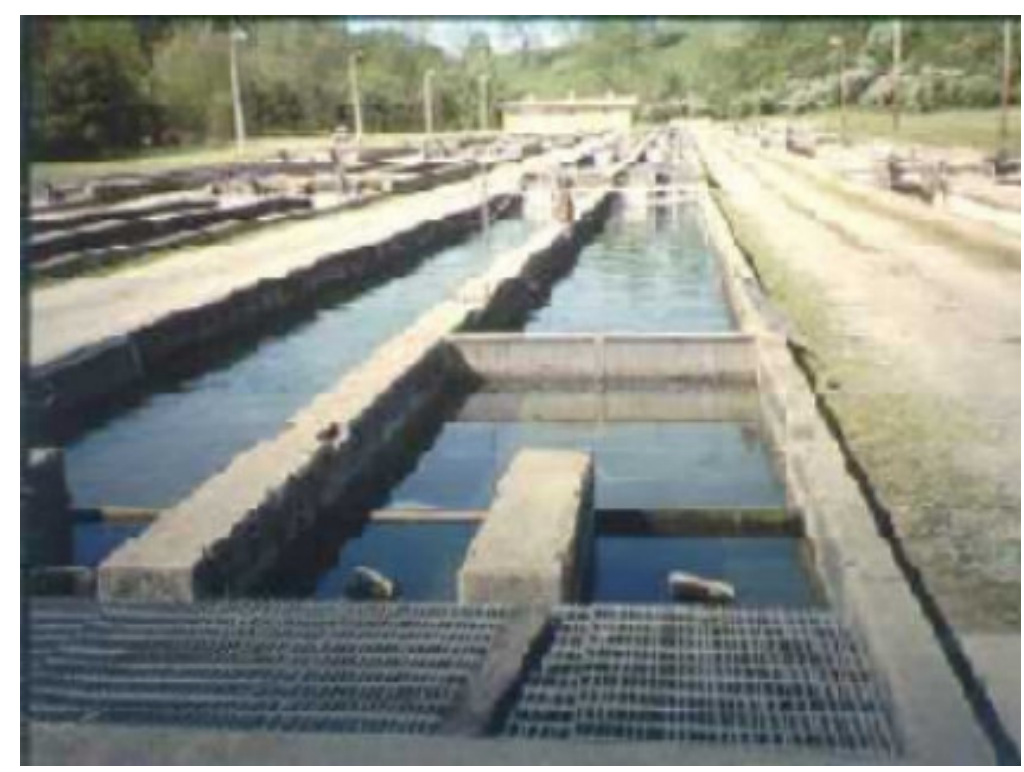

Figure 1.2 Open Ended Concrete Raceways 


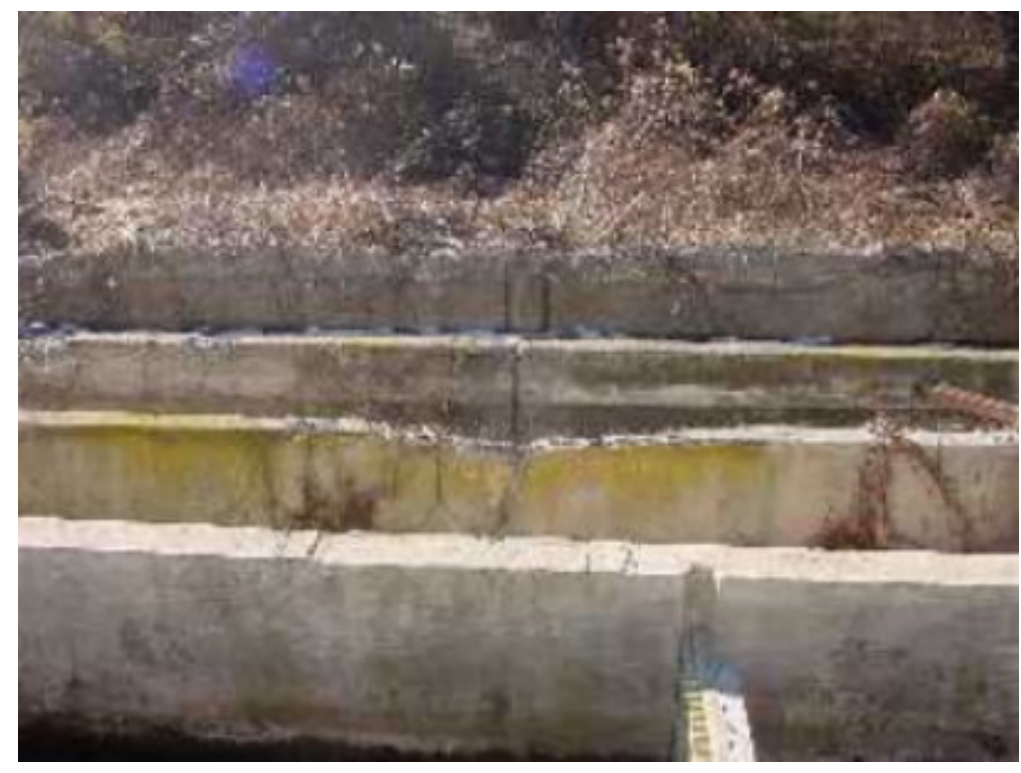

Figure 1.3 Wear and Tear of Concrete Raceways

\section{Metal Raceways:}

Metal raceways, such as those made of aluminum, are lightweight and can be easily manufactured. However they are not stiff enough to stand alone and hence need

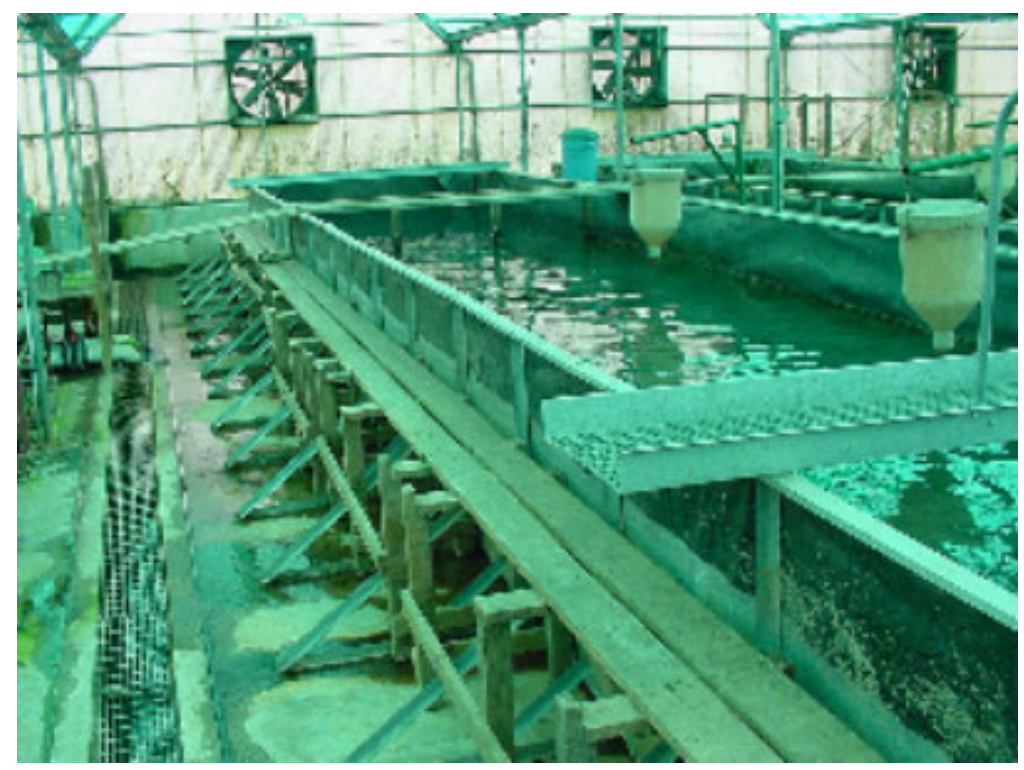

Figure 1.4 Closed Ended Rectangular Tank with Liner and Supporting Braces 
supporting braces. They have a tendency to occupy more space, thus creating concerns regarding safety and convenience. Material etching could also be a problem resulting in a decrease in the effective life of the tank.

\section{Fiberglass Raceways:}

Fiberglass raceways are lightweight, durable and transportable. They can be used as temporary structures and can be installed in rugged terrains. They need supporting braces, which result in the same concerns with safety as in a metal raceway. They are usually smaller than concrete raceways. They are generally manufactured as closed ended tanks and may require an expensive mold. Manufacturing parallel flow systems is also difficult because of stiffness limitations. These systems are not as durable as concrete.

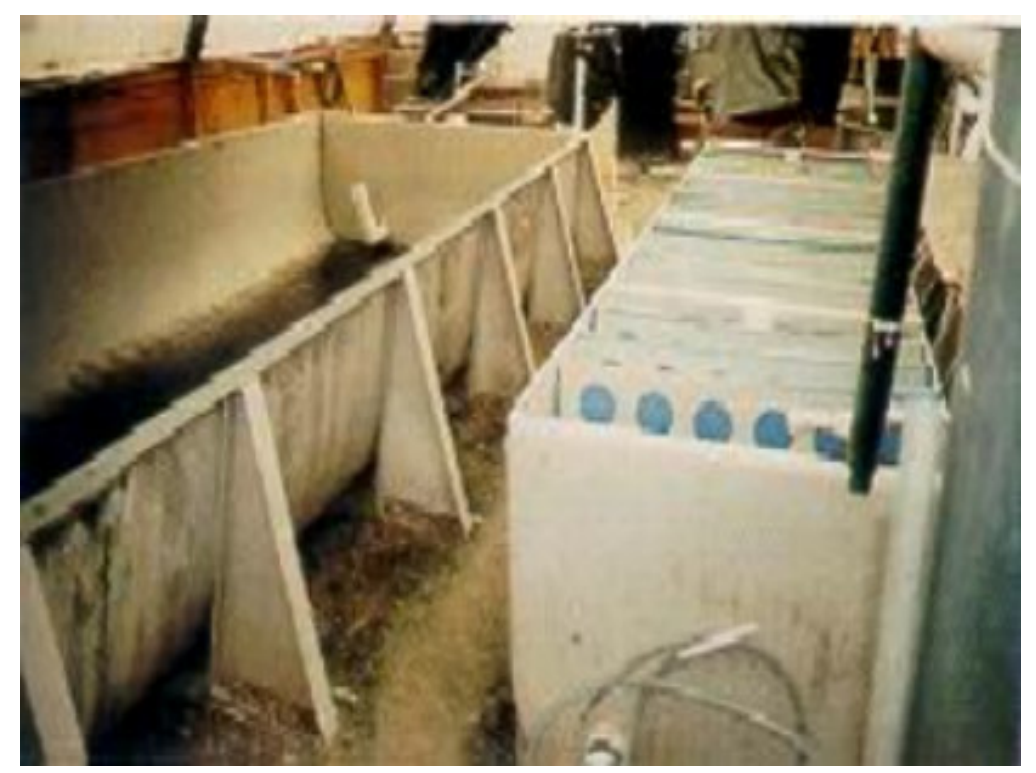

Figure 1.5 Closed Ended Fiberglass Tank with Supporting Braces

\section{Sandwich Material:}

Sandwich materials have high strength to weight ratio, which makes them highly suitable for transportable raceways. Their high stiffness enables the construction of stand- 
alone raceways needing no external braces and hence can easily be constructed in parallel. They are easily installed and relocated because of their lightweight. The main disadvantage with this material is that it is relatively expensive compared to concrete.

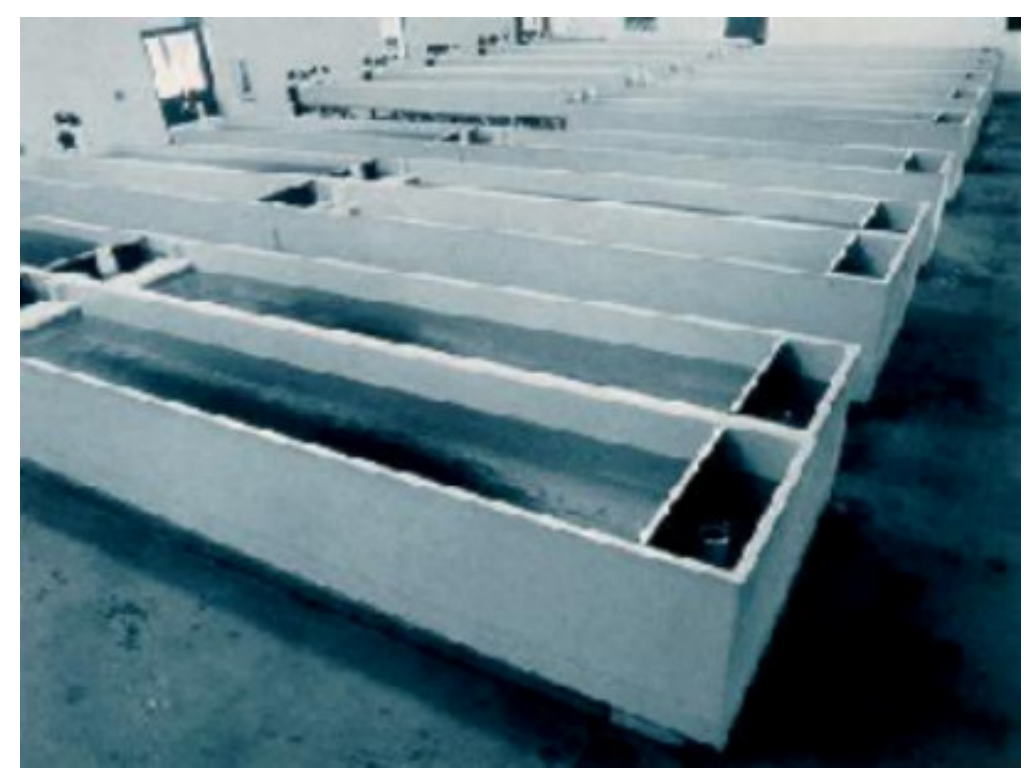

Figure 1.6 Closed Ended Sandwich Tanks Without Braces

\subsubsection{Description of Sandwich Materials}

As the name indicates, sandwich materials have two face sheets separated by a core. Sandwich configurations differ in the material and shape of the core, which can be either solid, like wood or foam, or honeycomb geometry. The thickness of the core determines the distance of separation of the two face sheets; the increase in core- height increases the bending stiffness of the sandwich. A sandwich panel under transverse loads acts in a similar way as an I-beam, with the stiff facesheets (representing the flanges of the I- beam) resisting bending and the core (representing the web) resisting mainly shear. 
A brief discussion on some of the sandwich materials being used in the construction of aquaculture tanks is given below.

Fiberglass with wooden core has a solid balsa wood or plywood core, sandwiched between two layers of fiberglass plies (Figure 1.7). This sandwich construction is being used in the manufacturing of stand-alone raceways by companies such as Gemini Fiberglass Inc., and also by several companies in the manufacturing of lightweight race boats.
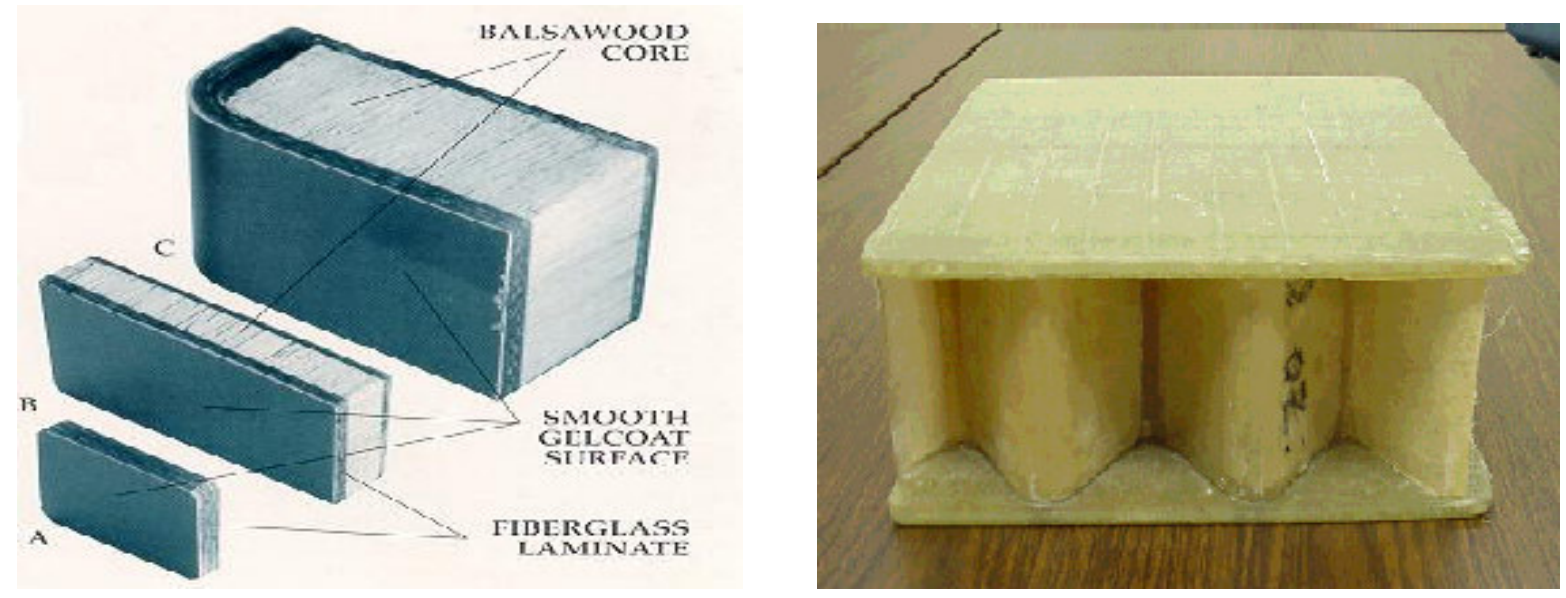

Figure 1.7 Balsa Wood Core Sandwich Material Figure 1.8 HFRP Sandwich Material

Honeycomb Fiber Reinforced Polymer (HFRP) sandwich panels have a cellular core geometry sandwiched between two face sheets (Figure 1.8). As the core is not solid material, the unit weight of an HFRP sandwich panel is much less than of a comparable solid core sandwich panel. The typical weight of HFRP panels for fish tanks is approximately 4 to $6 \mathrm{lb} / \mathrm{ft}^{2}$, which is about 12 times less than the weight of a comparable 
concrete material. HFRP sandwiches also differ in the shape of the honeycomb core, which can be circular, sinusoidal, triangular, and others. In this project, the core consists of sinusoidal corrugations and straight components sandwiched between the face sheets (Figure 1.9); this product is manufactured by Kansas Structural Composites Inc., Russell, KS.

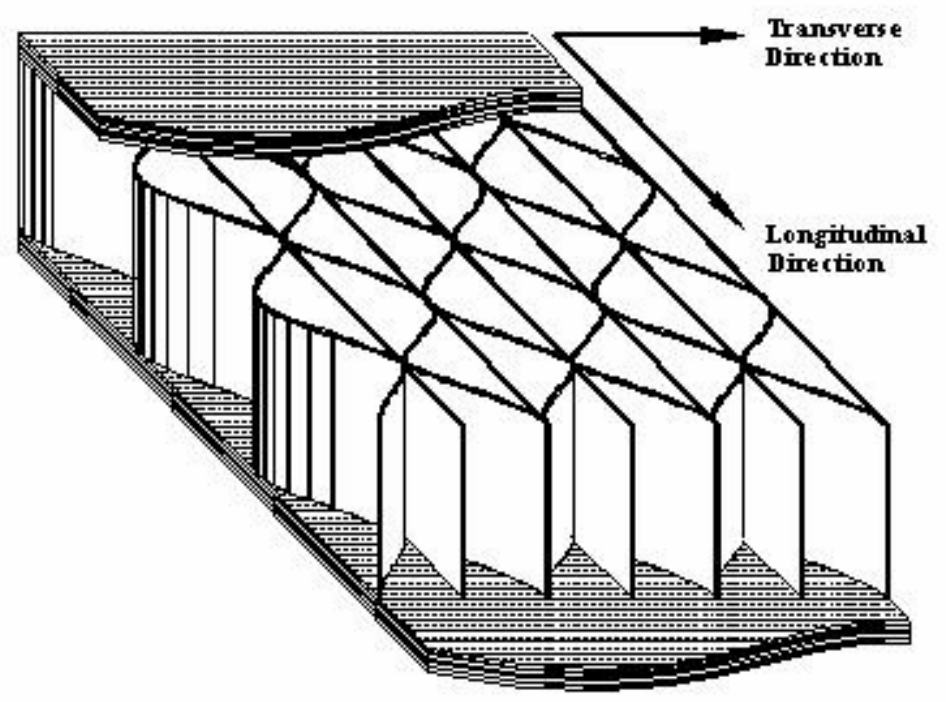

Figure 1.9 Core Geometry of HFRP Panel

\subsubsection{Cost Comparison of Raceways from Various Manufacturers}

Several companies manufacture fiberglass raceways in the country, with various stiffness and core configurations. To compare the cost of manufacture of the HFRP raceways with other products available in the market, seven of the major manufacturers of fiberglass raceways were contacted and unofficial quotations for production of raceways of required dimensions were requested. While some of the manufacturers do not manufacture tanks big enough for the comparison, quotations for custom built tanks 
were requested. The cost of the raceways varied among manufacturers depending on the material used and labor intensity of the raceways. While comparing the costs of the raceways, it should also be considered that the quotations were not official bids and the dimensions were approximations to the actual design requested, and hence there could be significant differences in the actual costs of the raceways produced by these manufacturers.

From the information provided in the quotations, it was observed that the cost of raceways produced by manufacturers using other sandwich cores varied from 1.16 to 2.0 times the price of HFRP raceways produced by KSCI. Fiberglass raceways which require external braces were also considered for the comparisons, and the costs were found out to vary from 0.5 to 0.7 times that of the HFRP raceways. These tanks have lower stiffness and strength values compared to the sandwich raceways. Also, the central dividing panel in most of the cases was not water-tight. One of the manufacturers also produces free standing raceways, which include all the necessary piping and aerators, priced about 2.3 times that of the HFRP raceways.

From the above data, it can be observed that the cost of the raceways provided by $\mathrm{KSCI}$ is comparable to that of other manufacturers for the required configuration, in which the central divider is water-tight and the raceway requires no external bracing. It should be noted, however, that only the KSCI tank developed through this study was capable of satisfying structural and functional requirements of this project. Modifications 
to the current design will be suggested at the end of the study, which is expected to further decrease unit cost of the raceways.

\subsection{Objective and Scope}

This study is concerned with the design, manufacturing, experimental and numerical evaluations of HFRP sandwich panels and panel-to-panel connections used in the development of fish culture tanks, to be installed in West Virginia. The component panels are tested as beams and their measured displacements and strains are correlated with finite element analyses using ABAQUS (1998) [2]. Similarly, two designs of sideto-bottom panel connections are evaluated experimentally and modeled to study their relative rotational stiffness of the connection joints. The beam samples are subsequently tested to failure and the failure loads and modes are evaluated. The complete raceway is modeled using finite elements and tested numerically under various conditions to predict the behavior of the tank in the field. Factors of safety for various loading and boundary conditions are calculated. General details of the design of the fish tank are presented, and an overview of three field projects is given.

\subsection{Design of HFRP Raceway System}

The design of the HFRP raceway system is based on requirements established by the users of the system, who defined the height, length and width of the tanks. The 
strength and stiffness of the HFRP structural components was then determined jointly by the WVU research team and the manufacturer, Kansas Structural Composites Inc.

The requirements of the raceways were based on current concrete raceway systems and also on specific needs of the future users. A schematic view of the raceway is shown in Figure 1.10. It has two parallel channels of constant cross-section, allowing for simultaneous comparative aquaculture studies. The channels are 3 feet wide by $3 \frac{1}{1 / 2}$ feet high, which allows for a depth of water of 3 feet. The raceway is divided into two separate components, the main raceway unit and a quiescent zone. The main raceway unit is 24 feet long and is used for raising fish. Separation screens are placed along the channels to accommodate the possibility of raising different species or sizes of fish. The second part of the tank is a quiescent zone. The fish are restricted from this area, which is used for collecting and disposing of fish waste and debris, using a drain located on the

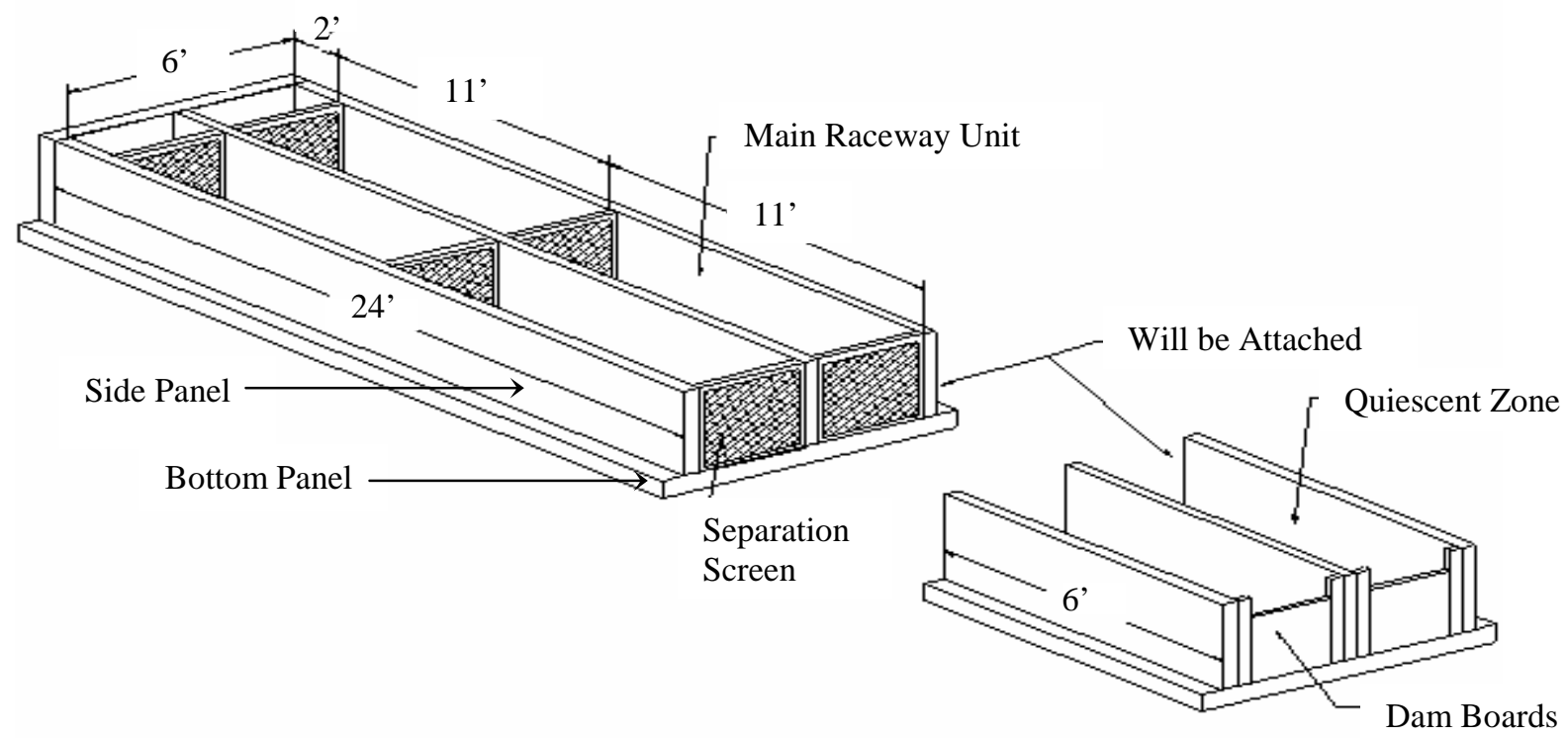

Figure 1.10 3-D View of the Fish Tank 
bottom panel of the quiescent zone. Dam boards are placed at the end to control the elevation of the water in the tank. The two sections of the tank are connected using a structural fastening system, which may be modified in future designs based on results of the present research.

In order to establish appropriate stiffness and strength properties for the component panels, several functionality requirements had to be considered. The tanks should not have any obstructions on the outside that would impede easy access. Also, the interior cross-section of the channels must have normal corners. Thus, the connection of the bottom-to-side panels must be stiff enough to meet deflection and strength criteria, while also satisfying the prescribed functionality requirements. There are two connection designs, which are discussed in a following section.

After the initial design of the raceway, the required structural capacity of the panels was established. Based on past experience, the research team and the manufacturer determined an appropriate size and lay-up. The loads were based on 3 feet of water pressure and other forces possibly from people leaning against the side panels. The deflection limit is based on the separation screen openings, which was determined to be $3 / 8$ of an inch.

A 3-D view of the sandwich panel geometry is given in Figure 1.9, showing the top and bottom face sheets and the core consisting of sinusoidal and straight components. The constituent materials are chopped E-glass fibers and polyester resin. The side panels 
have a total thickness of 2 inches with the top and bottom face sheets consisting of three layers of chopped strand mat (ChSM), each being 0.03 inches thick. The corrugated and straight core components are produced from two layers of ChSM. The facesheets and core components of the bottom panels are manufactured using the same materials and thicknesses as for the side panels, but the panel total thickness is 4 inches.

\subsection{Thesis Overview}

The purpose of this study is to design, develop and implement Honeycomb FiberReinforced Polymer Sandwich raceways for aquaculture applications in West Virginia. In this study, we first discuss in Chapter 2 the significance of HFRP and its micro- and macro-mechanics, followed by formulation of equivalent properties.

Characterization of stiffness and strength properties for individual raceway components is critical. Experimental testing and finite element analysis is used to examine panel beam samples as well as panel to panel connections. A description of the test samples and finite element modeling methods is presented in Chapter 3, followed by Chapter 4, which describes the experimental testing of beam samples in the linear range. The purpose of this testing is to evaluate the stiffness of the HFRP sandwich. The results are used to verify finite element models which are formulated using both actual core geometry and equivalent properties calculated in Chapter 2. 
The connection of the side to bottom panel is critical in the performance of the raceways. Adequate stiffness and strength of the connection is vital for the successful implementation of the raceway. Experimental testing and finite element modeling of the connection is discussed in Chapter 5, including a comparison of results. At this stage, modifications to the design are suggested.

A study of the failure loads and modes provides us information on strength capacity and type of failure of the HFRP sandwich that can be expected in the field. By using the ultimate strength of the beam samples, we can estimate the factors of safety under working conditions for field applications. Chapter 6 discusses the experimental study of failure of the representative beam samples.

Based on the results from Chapters 4, 5 and 6, the entire raceway is modeled in Chapter 7 using equivalent core properties. Because of the large number of elements and computational limitations, selection of mesh size is of vital importance. Justification of the mesh size selected is given. Calculation of expected loads including miscellaneous loads is discussed. Several levels of integral connectivity for the main raceway to the quiescent zone are considered and modeled. The entire model is tested under various boundary conditions and loads and the results are discussed. The results are used to approximately assess the behavior of the tank in the field. Using the failure values for component panels in Chapter 6, factors of safety for different boundary conditions and loading conditions are estimated for the entire tank. 
Current field projects are briefly discussed in Chapter 8, with more descriptive information on the installation of tanks at Dogwood Lakes, a mine water treatment facility near Morgantown, WV.

Finally, in Chapter 9, an overview of the thesis is presented, with emphasis on recommendations based on the laboratory testing, finite element modeling results, and experiences gained from the field implementation of the HFRP raceways. 


\section{Chapter 2}

\section{Honeycomb Fiber- Reinforced Polymer Sandwich Material}

In the finite element modeling of the HFRP test samples and complete raceway discussed in later chapters, both actual geometry and equivalent core geometry are used. This chapter discusses the geometry of the honeycomb core, presents actual material properties, and reviews the formulation of equivalent core properties.

\subsection{Geometry of the Honeycomb Core}

The core provides primarily shear stiffness and supports the face sheet panels. It consists of closed honeycomb-type cells. The sinusoidal wave component of the core is manufactured by forming the FRP sheet into a corrugated mold. The shape of the corrugated component, shown in Figure 2.1, can be defined using the following equation:

$$
y=h\left(1-\cos \left(\frac{\pi x}{b}\right)\right)
$$

where, $\mathrm{h}$ and $\mathrm{b}$ are the geometric dimensions shown in Fig. 2.1. 


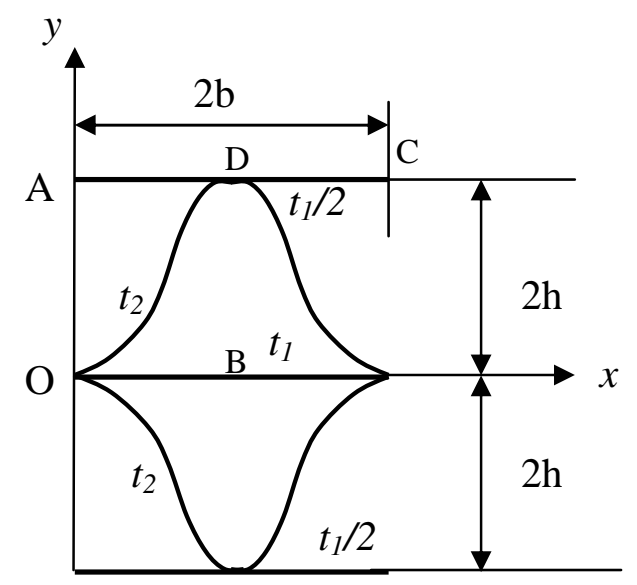

Figure 2.1 A Unit Cell (RVE) of Sinusoidal Core - Plan View

\subsection{Properties of Constituent Materials}

The Honeycomb FRP panels in this study are manufactured from layers of $3 \mathrm{oz}$ chopped strand mat (ChSM). The panel is symmetric about the mid-height, and the face sheet has 3 layers, while each core laminate has 2 layers of ChSM. The constituents of the ChSM are E-glass fibers and isophthalic polyester resin, with properties as given in Table 2.1.

Table 2.1 Properties of E-glass Fiber and Polyester Resin

\begin{tabular}{|c|c|c|c|c|}
\hline & $\mathrm{E}, \times 10^{6} \mathrm{psi}$ & $\mathrm{G}, \times 10^{6} \mathrm{psi}$ & $\mathrm{N}$ & $\rho, \mathrm{lb} / \mathrm{in}^{3}$ \\
\hline E- glass Fiber & 10.5 & 4.183 & 0.255 & 0.092 \\
\hline Polyester Resin Matrix & 0.734 & 0.237 & 0.3 & 0.041 \\
\hline
\end{tabular}


The stiffness properties of the laminate are directly related to the fiber-volume fraction, which can be expressed using the following equation:

$\mathrm{V}_{\mathrm{f}}=\mathrm{W} /(\rho \mathrm{xt})$

Where, $\mathrm{W}=$ nominal weight of the fabric,

$\rho=$ density of the fibers, and $t=$ thickness of the layer

Using the above equation, the fiber-volume fraction of the chopped strand mat is found out to be 0.472 , which is used to calculate the elastic properties of the material. Using a micromechanics model for composites with periodic microstructure [3], the elastic properties of a fictitious unidirectional composite with the above volume fraction are first calculated (Appendix A).

The isotropic properties of the random composite can be obtained from the known properties of a unidirectional material with the same fiber volume fraction using the equations proposed by Barbero [3]. Using these formulations, the values of the layer stiffnesses are obtained in Appendix B and summarized in Table 2.2. It is assumed that the material is isotropic in the ply plane.

Table 2.2 Properties of Chopped Strand Mat in Bending

\begin{tabular}{|c|c|c|c|c|c|}
\hline $\begin{array}{c}\mathrm{E}_{1}, \mathrm{x} 10^{6} \\
\mathrm{psi}\end{array}$ & $\begin{array}{c}\mathrm{E}_{2}, \mathrm{x} 10^{6} \\
\mathrm{psi}\end{array}$ & $\begin{array}{c}\mathrm{G}_{12}, \times 10^{6} \\
\mathrm{psi}\end{array}$ & $\begin{array}{c}\mathrm{G}_{23}, \mathrm{x} 10^{6} \\
\mathrm{psi}\end{array}$ & $v_{12}$ & $v_{23}$ \\
\hline 3.03043 & 3.03043 & 1.14842 & 605614 & 0.3194 & 0.5072 \\
\hline
\end{tabular}




\subsection{Formulation of Equivalent Properties}

To decrease computational effort for the finite element models, a set of equivalent laminate moduli are defined which represent the stiffness of a fictitious, equivalent, orthotropic plate that behaves like the actual laminate under various loads. The formulations to evaluate the equivalent properties of the face laminates and the honeycomb core with a sinusoidal configuration are presented by Davalos et al. (2001) [4]. Further modifications to the in-plane formulations were suggested by Qiao and Wang (2005) [5]. Formulations to calculate the in-plane properties of the equivalent laminate are obtained from [5] and the out-of-plane laminate properties are calculated using formulations proposed in [4]. A brief overview on the calculation of equivalent laminate moduli is presented in this section.

The equivalent properties of the face laminate are obtained using a micro/macromechanics approach [3] (see Appendix D). The elastic equivalence analysis of the sinusoidal honeycomb core structure is based on a homogenization concept by a combined energy method and mechanics of materials approach. The homogenization process of periodic structures requires defining a Representative Volume Element (RVE) (Figure 2.1), for which the global properties can be obtained by periodic geometric conditions and kinematical assumptions which are as follows: (1) the material behaves linear-elastically; (2) perfect bond exists at face-to-core and core wall-to-wall contacts;

and (3) the ratio of the thickness of core wall to the radius of core wall is small and therefore, classical beam theory can be applied. Skin effects between the face sheet and 
the core wall are also not considered while calculating the equivalent properties. Chen (2004) [6] studied this effect for sinusoidal honeycomb core configurations and concluded that it becomes prominent as the thickness of the sandwich core decreases.

Based on the formulations proposed in [4] and [5], the equivalent properties of FRP honeycomb core are computed in Appendix C (in-plane properties for equivalent core) and Appendix D (out-of-plane properties for equivalent core and elastic equivalent properties for the face sheet) and given in Table 2.1. These properties represent an equivalent core plate, the thickness of which depends on the thickness of the honeycomb core. These properties are used in the equivalent-property finite element modeling, which is discussed later in this thesis.

Table 2.3 Equivalent Properties of the Honeycomb Core Geometry

\begin{tabular}{|c|c|c|c|c|c|c|c|c|}
\hline $\begin{array}{c}\mathrm{E}_{\mathrm{x}}, \mathrm{x} 10^{6} \\
\mathrm{psi}\end{array}$ & $\begin{array}{c}\mathrm{E}_{\mathrm{y}}, \mathrm{x} 10^{6} \\
\mathrm{psi}\end{array}$ & $\begin{array}{c}\mathrm{E}_{\mathrm{z}}, \mathrm{x} 10^{6} \\
\mathrm{psi}\end{array}$ & $\begin{array}{c}\mathrm{G}_{\mathrm{xy}}, \mathrm{x} 10^{6} \\
\mathrm{psi}\end{array}$ & $\begin{array}{c}\mathrm{G}_{\mathrm{yz}}, \mathrm{x} 10^{6} \\
\mathrm{psi}\end{array}$ & $\begin{array}{c}\mathrm{G}_{\mathrm{xz}}, \mathrm{x} 10^{6} \\
\mathrm{psi}\end{array}$ & $v_{x y}$ & $v_{\mathrm{yz}}$ & $v_{\mathrm{xz}}$ \\
\hline 90721.1 & 6522.347 & 211174.9 & 3430.142 & 54710.2 & 22208.33 & 0.7907 & 0.01566 & 0.21777 \\
\hline
\end{tabular}




\section{Chapter 3}

\section{Background for Component Evaluations}

In this chapter we discuss the details of experimental testing and finite element modeling of the raceway samples, including descriptions of geometry and dimensions of samples.

The structural components of the HFRP raceway unit evaluated in this thesis consist of representative beam-type samples of the side and bottom panels, as well as proposed panel-to-panel connections. Beam samples representative of actual raceway panels are experimentally tested within the elastic limit to evaluate stiffness properties and to correlate results with finite element analyses. Subsequently, the same samples are tested to failure in bending. Also, two proposed side-to-bottom panel connections are evaluated for rotational stiffness of the joint using experimental and finite element methods.

\subsection{Test Samples}

The test samples consist of beams with longitudinal and transverse core orientations (see Figure 1.9). In the following chapters, a beam is referred to as having longitudinal core orientation, if the orientation of the sinusoidal wave is along the length 
of the beam and as having transverse core orientation if the sine wave is directed across the width.

The beam samples used in the experimental testing consist of five bottom panel samples and five side panel samples. For both types of panels, there are two longitudinal samples and two transverse samples, each 8-inch wide by five-foot long. In addition, there are two 12-inch wide samples, one with transverse core orientation for the side panel, which is 6-foot long, and one with longitudinal core orientation for the bottom panel, which is 7-foot long.

The experimental testing program also includes the evaluation of two proposed panel-to-panel connection designs. The unstiffened connection, shown in Figure 3.1, is designed for the side panel to be embedded the distance of one-inch into the bottom panel. The panels are then joined with a polyester resin. The bottom panel extends four inches beyond the outside face of the side panel to allow for a better distribution of stresses at the corner. The stiffened connection, shown in Figure 3.2, is similar to the previous connection, with the exception of a triangular stiffener placed on the outside edge of the embedded panels. The diagonal stiffener, which extends four inches up the side wall and four inches out to the edge of the bottom panel, is produced by a core section of triangular cross-section covered by a face sheet. The stiffener is co-cured to the side and bottom panels. In both cases, the inside corner remains normal as required by the design. Each of the two connection samples is 12 inches wide. The bottom panel extends 18 inches from the interior edge of the side panel, with the longitudinal core 
orientation along its length. The side panel extends 42 inches from the top of the bottom panel, with the longitudinal core orientation along its length.

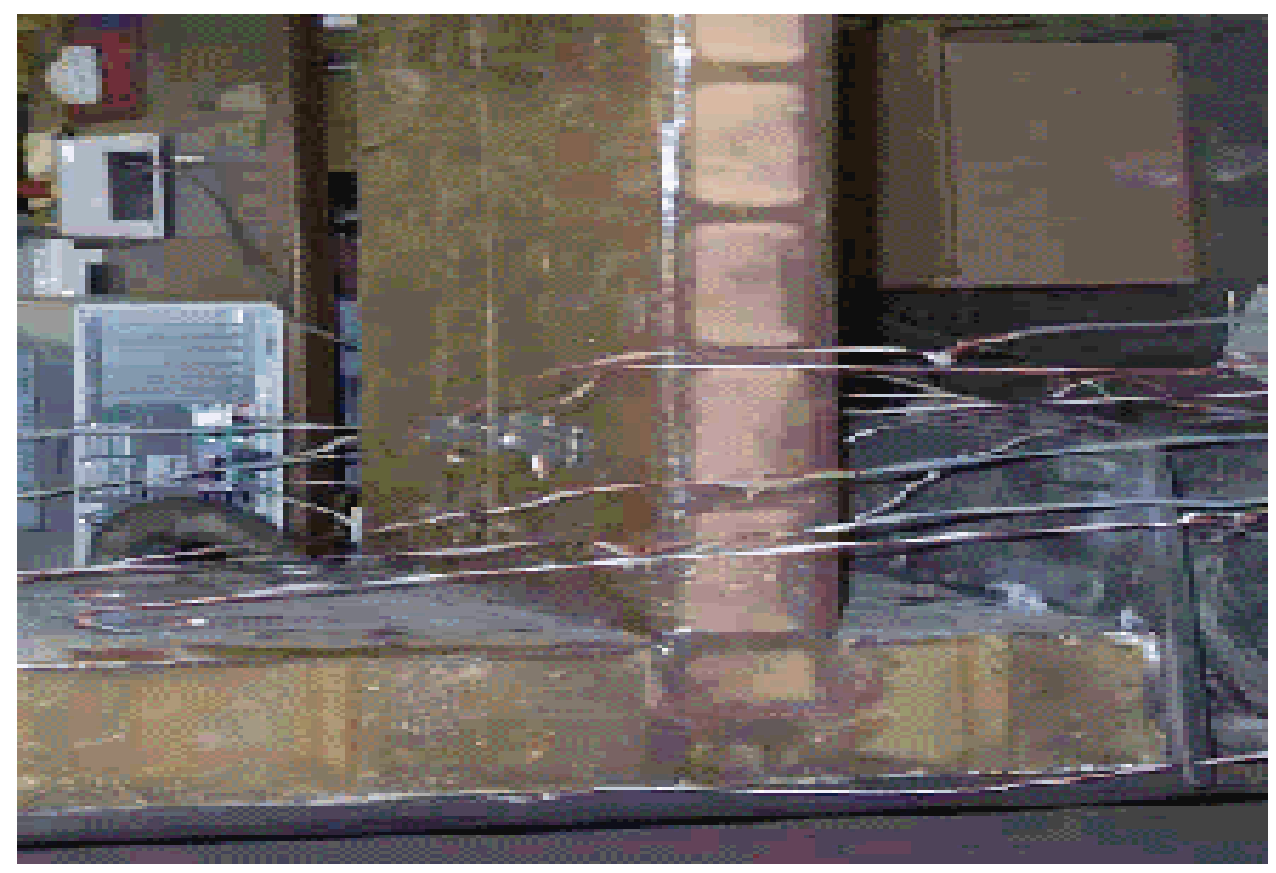

Figure 3.1 Unstiffened Connection Design

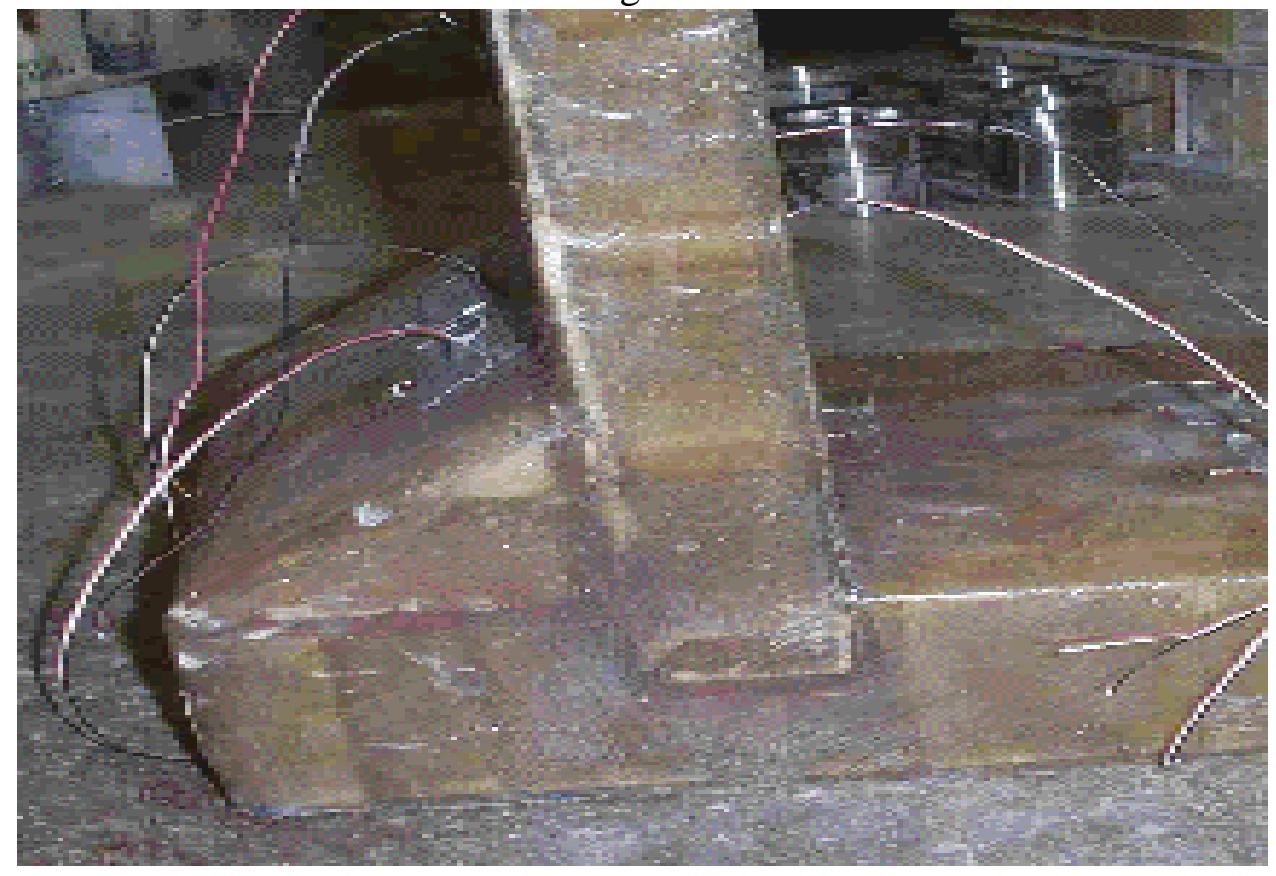

Figure 3.2 Stiffened Connection Design 


\subsection{Finite Element Modeling}

The experimental results are used to verify finite element evaluations through comparison of results. Two different models are evaluated based on two methods to represent the core: (1) actual core-geometry model, in which the sinusoidal and straight core components of the actual geometry are modeled, and the actual properties of the material are used; and (2) equivalent core-geometry model, in which properties for an equivalent plate which would replace the actual geometry are calculated and used in the analysis. The calculations of actual and equivalent core properties were discussed in Chapter 2. FEMAP (1999) [7] is used as a pre- and post-processor for the finite element analysis program ABAQUS (1998). A brief description of the two models follows.

\subsubsection{Actual Core-Geometry}

The actual core-geometry model is intended to simulate the actual configuration of the sandwich beam samples. Each face sheet is composed of three layers of quasiisotropic chopped strand mat, while the core wall is composed of two layers of ChSM. A 2"x2" quarter cell is first created as discussed below, which is used to create a 4" $\mathrm{x} 4$ " unit cell, which is copied and pasted to create the beam and connection samples in the later sections.

The sinusoidal shape of the core is first generated using spline functions, and the vertical projection of the in-plane shape is defined by the height of the core, which is 
1.91 " for the side panel and 3.91" for the bottom panel. The core geometry is meshed using 4-node shell elements as shown in Figure 3.3. Though the core consists of 2 plies of ChSM 0.06" thick, the straight core is modeled using only single layered shell elements with 0.03 " thickness. This is to accommodate copying and mirroring of elements about the outer vertical faces to create the 4" 4 " unit cell and the beam samples with symmetric straight laminae (0.06" thick) equivalent to two-layered laminae.

An automatic mesh is generated for the top face sheet of the quarter unit cell as shown in Figure 3.4 using 3-node shell elements. From Figure 3.4 (b), it can be seen that there is no continuity of strains and displacements between the face sheet and the core laminae. Hence, elements on top of the sinusoidal core are deleted as shown in Figure 3.5 and 3-node shell elements are manually created as shown in Figure 3.6 and Figure 3.7, connecting nodes on the face sheet to those on the vertical core. Once the top face sheet is modeled, elements are copied to create the bottom face sheet (Figure 3.8). All the coincident nodes on the core and the face sheet are merged leading to continuity in deflections and strains. After the 2"x2" quarter cell is modeled, elements are mirrored about planes efgh and aehd (shown in Figure 3.8) to create the 4"x4" unit cell shown in Figure 3.9. This 4" 4 " cell can be copied across the length and width to obtain the desired dimensions and core orientation for the beam samples. 


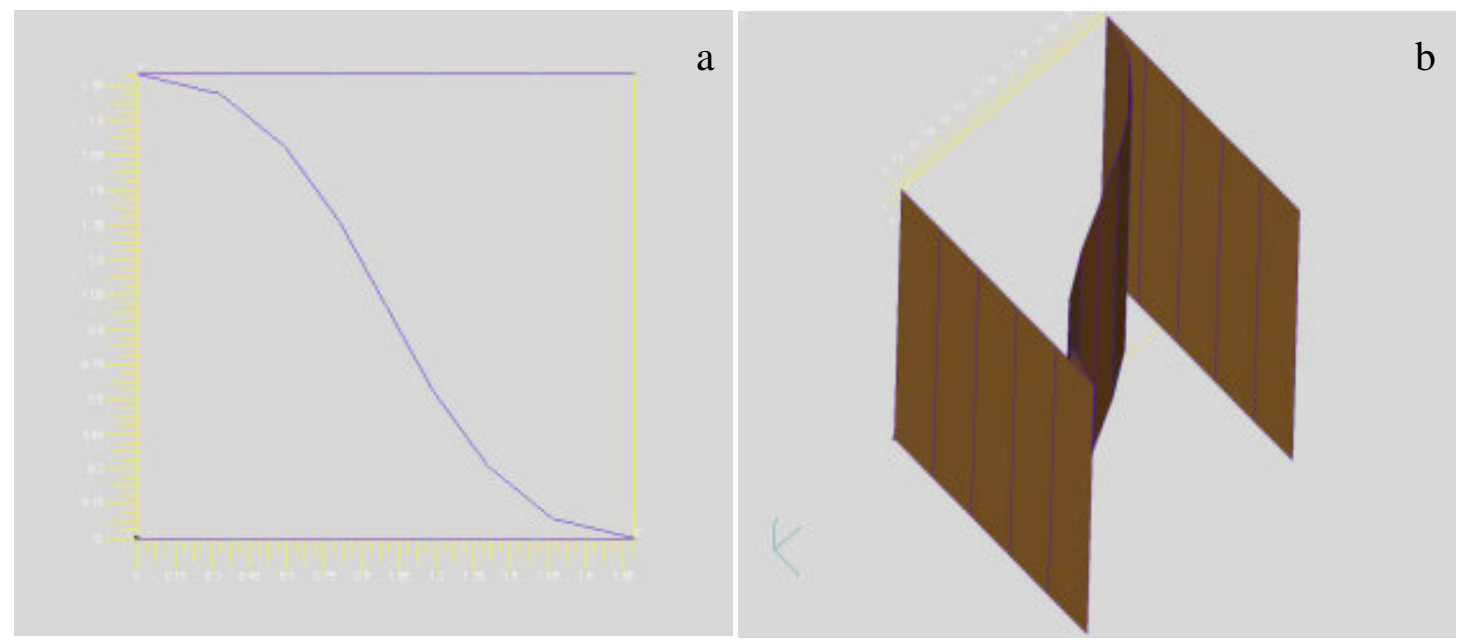

Figure 3.3 2"x2" Quarter Cell Core Configuration

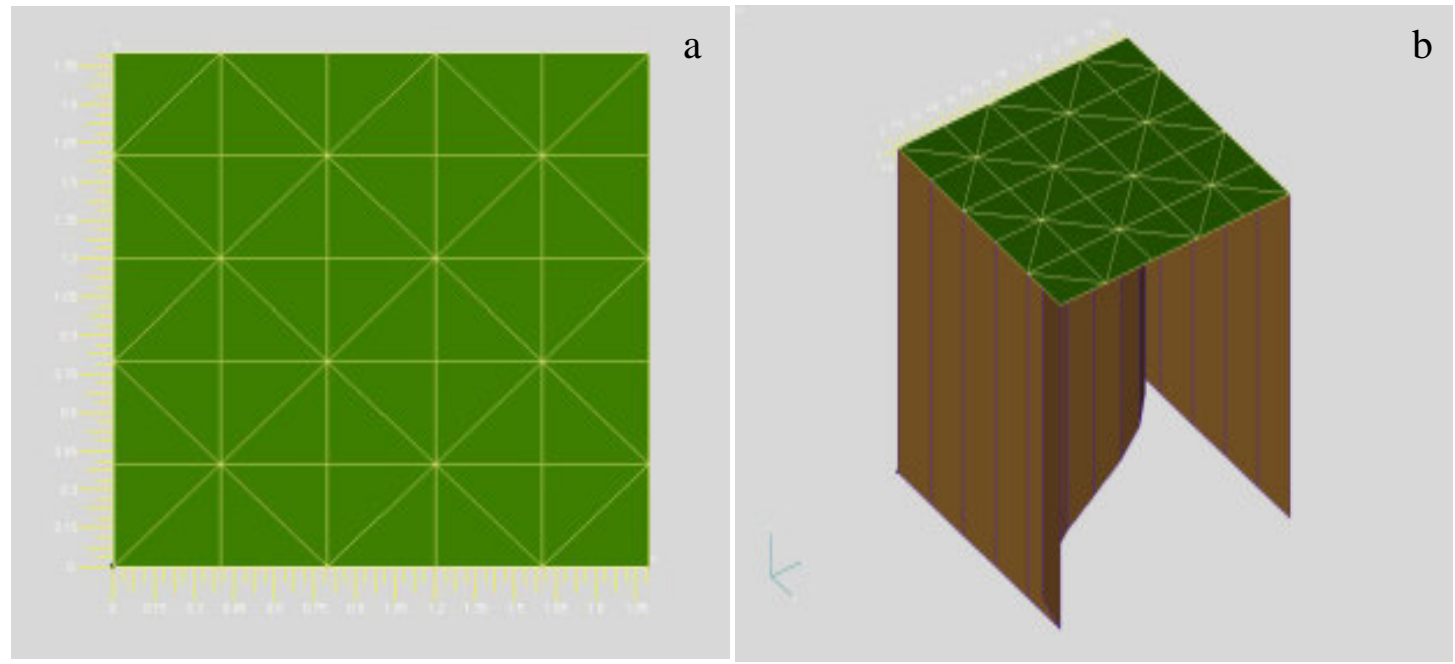

Figure 3.4 Quarter Cell with Top Face Sheet Containing Automatic Mesh Elements

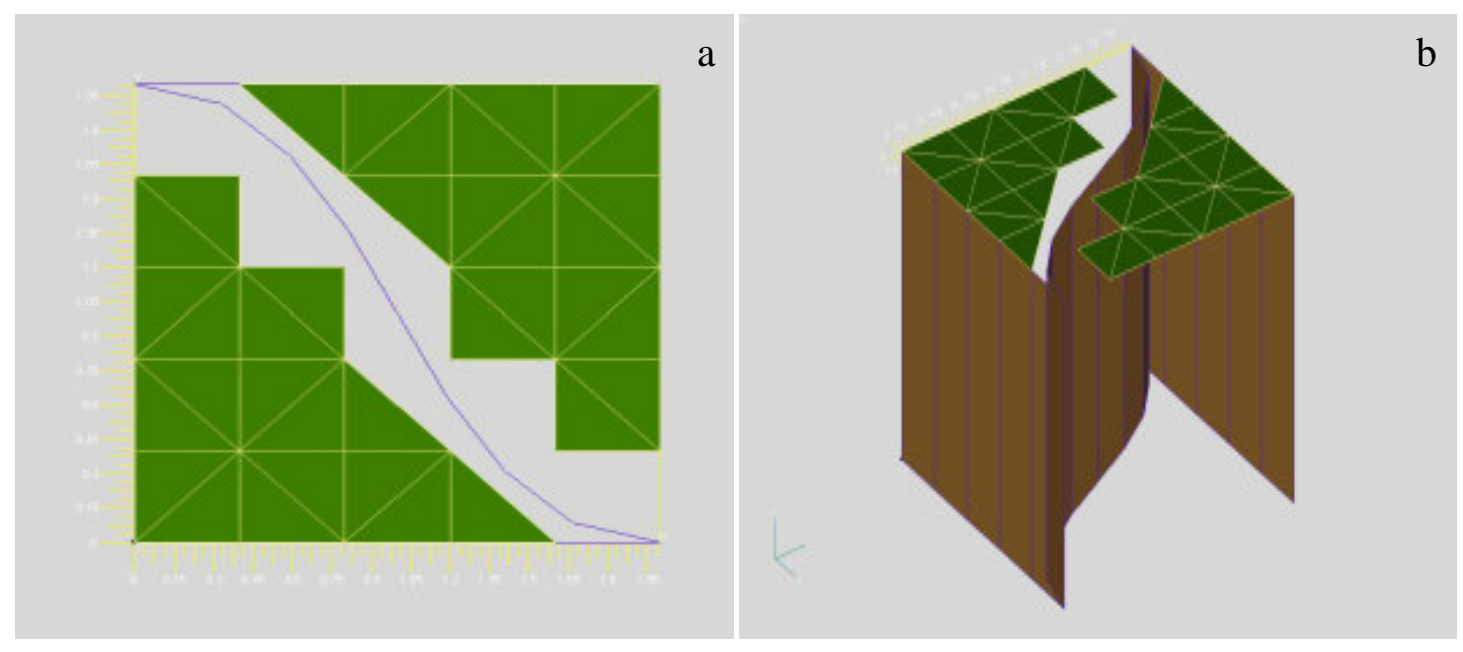

Figure 3.5 Face Sheet Elements on the Core Deleted 


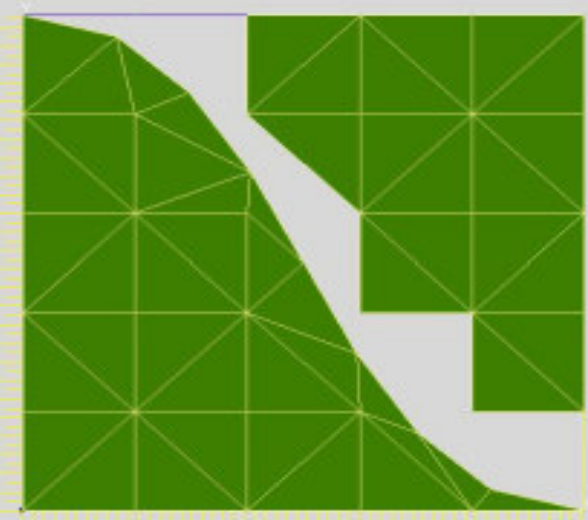

a

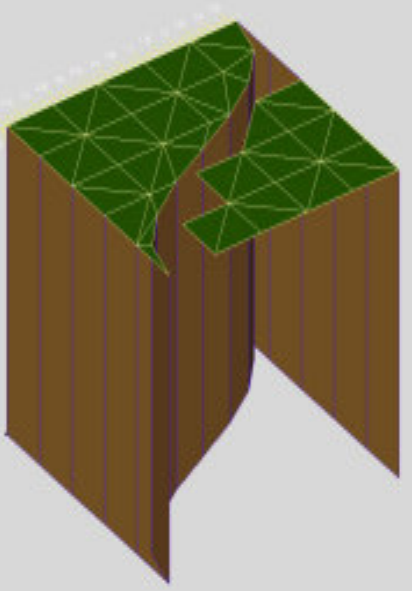

Figure 3.6 Manual Meshing of Top Face Sheet

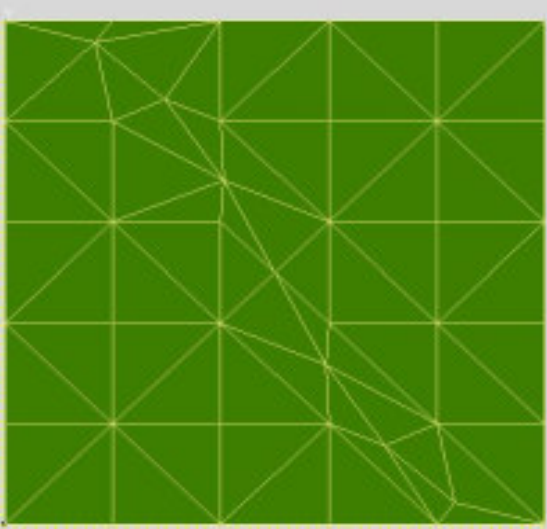

a

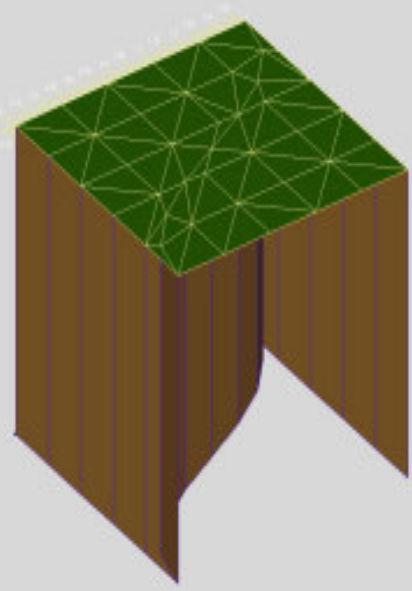

Figure 3.7 Quarter Cell with Top Face Sheet
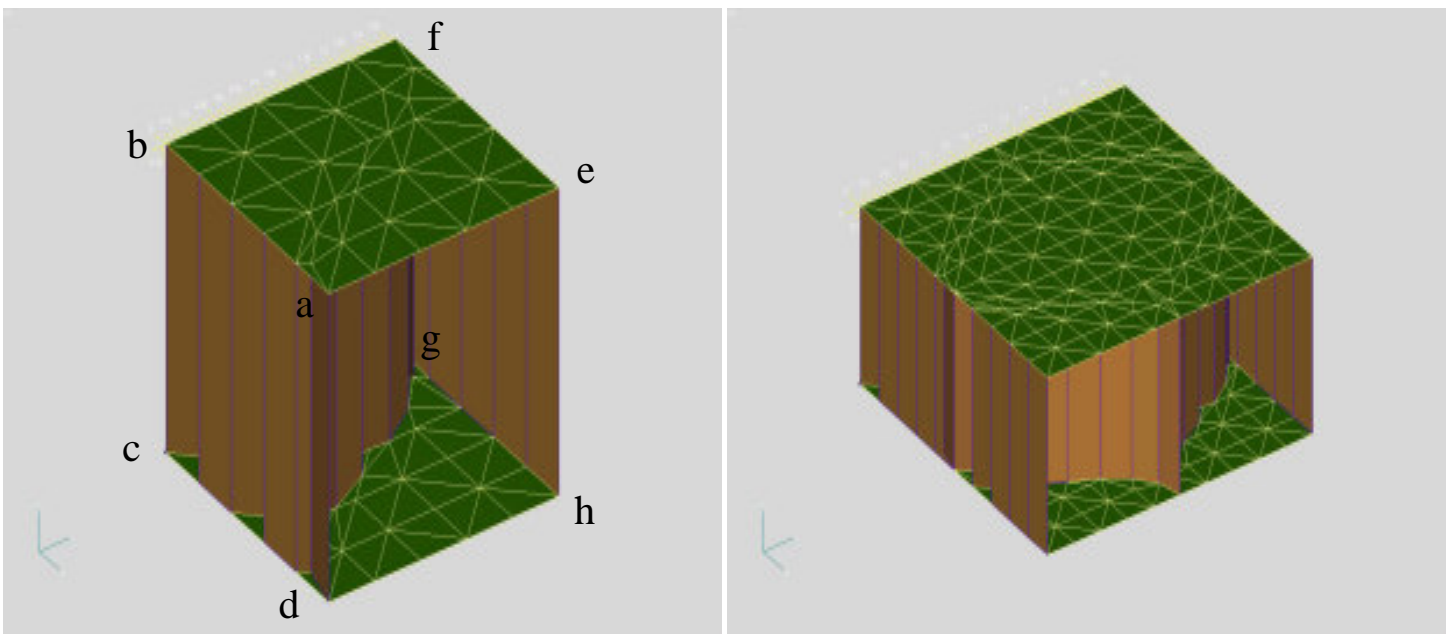

Figure 3.8 2"x2" Quarter Cell

Figure 3.9 4"x4" Unit Cell 


\subsubsection{Equivalent Plate Modeling}

The elastic equivalent properties for the HFRP panels are obtained using a micro/macro-mechanics approach for the face laminates and a homogenization concept with a combined energy method and mechanics of materials approach for the honeycomb core, as discussed previously in Chapter 2 .

Based on the formulations given by Davalos et al. [4], the equivalent properties of the FRP honeycomb core and the face sheet are computed. Finite element models based on equivalent properties for longitudinal and transverse core orientations are created using a three layered laminated plate with the top and bottom layers representing the face sheets and the middle layer representing the core (Figure 3.10). The thickness of the middle layer (core) is 1.91 " for the side panel and 3.91" for the bottom panel, all other properties remaining the same. The mesh consists of 3-node layered shell elements, and the analysis is conducted with ABAQUS (1998).

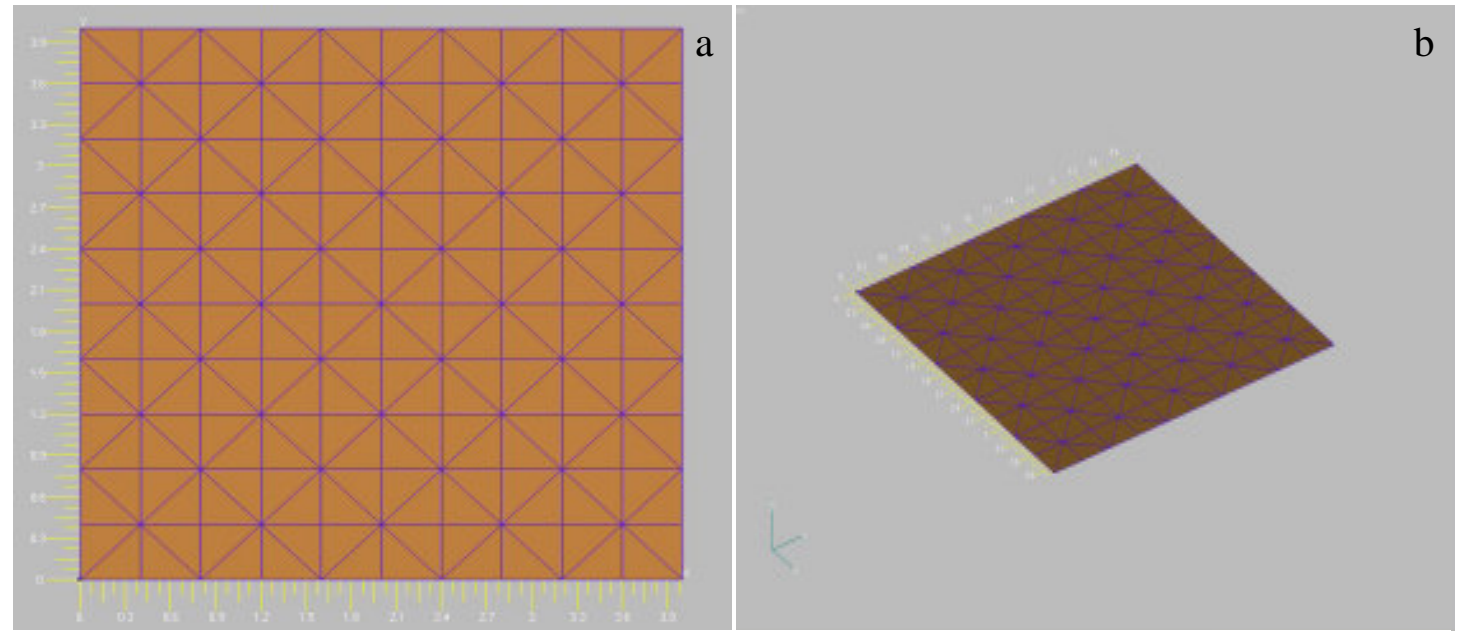

Figure 3.10 Equivalent Core FE Model (4"x4" Section) 


\section{Chapter 4}

\section{Stiffness Evaluations of Beam Samples in Bending}

Linear elastic bending evaluations of longitudinal and transverse beam samples are performed based on experimental testing and finite element analysis. In this chapter, we discuss the experimental testing and the finite element modeling of representative beam samples, and the results for displacements and strains are used to validate the two types of finite element models developed in the study.

\subsection{Experimental Testing of Beam Samples}

The beam samples described in Chapter 3 are tested in 3-point bending using several span lengths. The tests are conducted well within the linear elastic region of the material. In this section, we discuss the instrumentation of the samples, testing protocol and the reported results.

Each beam sample is instrumented with four strain gages and three LVDT's, while the load is recorded using a two-kip load cell. The strain gages used are 350-Ohm linear quarter bridge gauges. Three of the gages are bonded to the top face sheet and one to the bottom face sheet. The gages on the top face sheet are separated by a distance of one fourth the width of the beam, and are placed at a longitudinal distance of 6" away from the center line of the beam, because the load is applied at mid-span. The gage 
bonded to the bottom face sheet is located at the center of the bottom face with respect to the length and width of the sample. All the gages are oriented along the length of the beam to record the longitudinal tensile and compressive strains.

Deflections are measured using Linear Voltage Differential Transducers (LVDT's) which have a range of two inches. Three LVDT's are used along the length, L, of the beam at distances of $\mathrm{L} / 3, \mathrm{~L} / 2$ and $2 \mathrm{~L} / 3$ from one end. The LVDT's were calibrated before starting the tests to ensure accuracy of results.

The load is applied using a displacement-controlled hydraulic jack and is recorded using a two-kip load cell. A rectangular plate resting atop an elastomeric pad is used to allow for uniform distribution of the load at midspan. A sample test setup is shown in Figure 4.1 below.

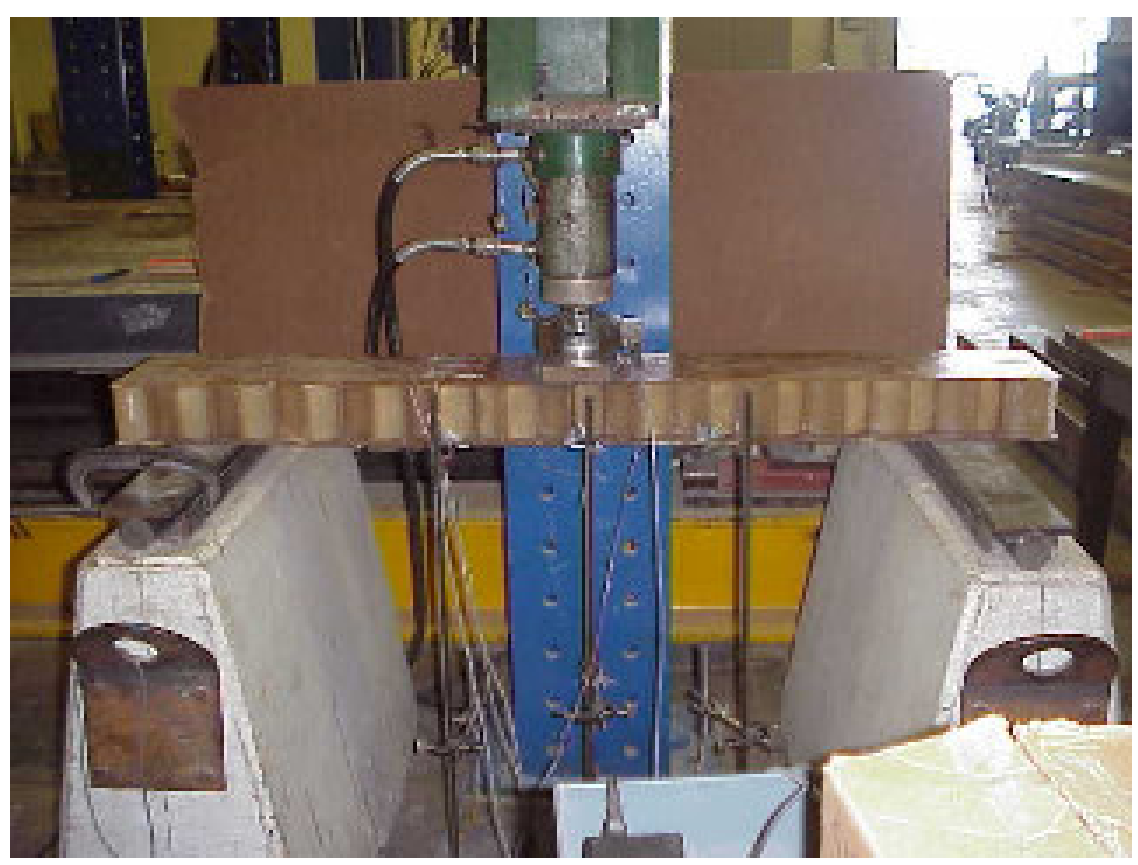

Figure 4.1 Typical Test Setup for a Beam Sample in Bending 


\subsubsection{Testing Procedure}

A steel cylinder placed over a rigid concrete block is used for each support of the beam sample. Depending on the overall length of the sample, the placement of the supports was adjusted to achieve the required span-length. The 5' long samples are tested at a span-length of 4'; then, the 6' long sample is tested with a span of 5.5', and finally the 7' long sample is tested at a 6' span-length. The Load is applied at and approximate

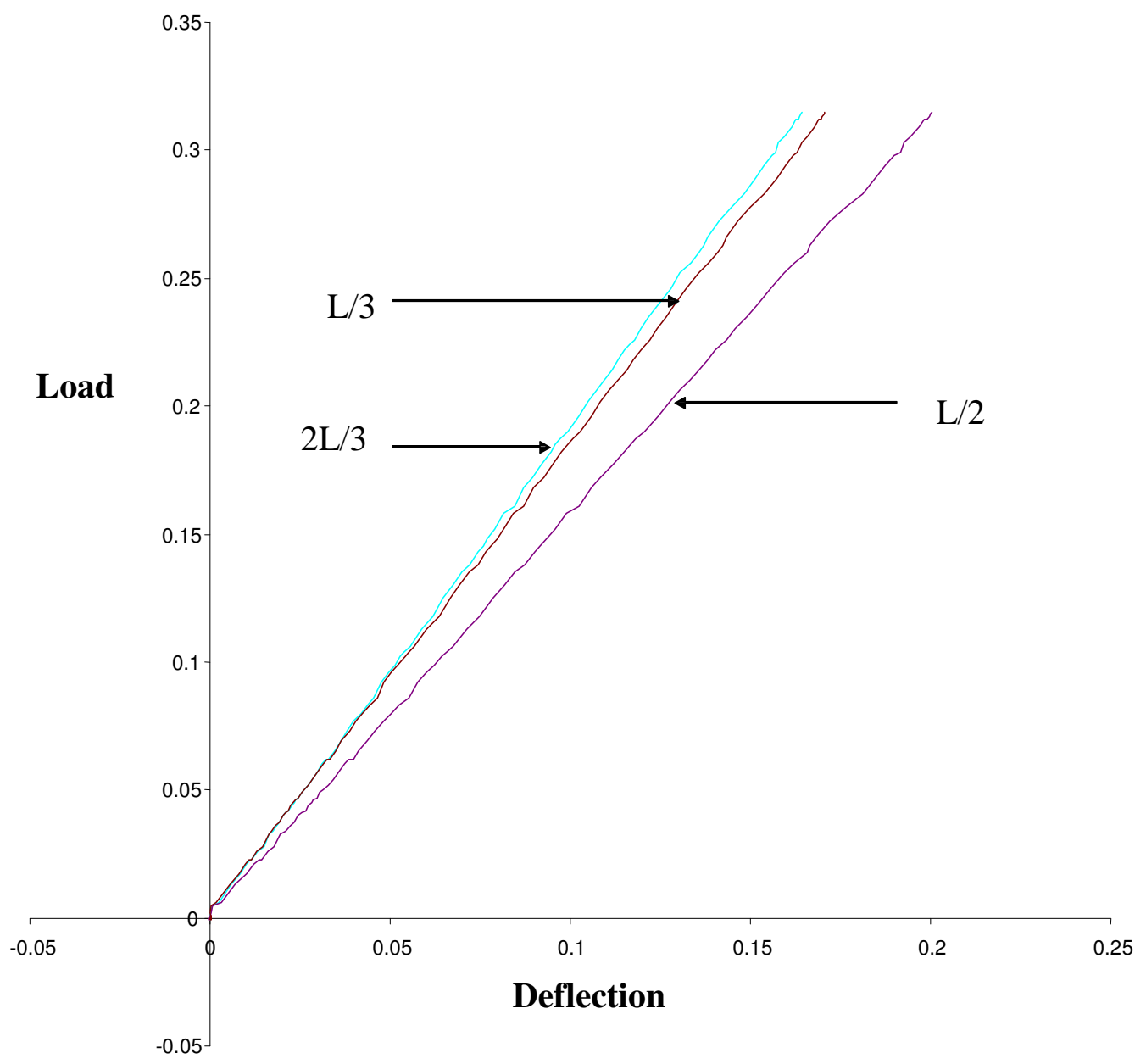

Figure 4.2 Load Versus Deflection Data for a 4' Transverse Sample of a Side-Panel 
rate of 10 pounds per second, to a maximum of 500 pounds, which is well within the elastic limit of the material. Strain and deflection data is recorded using a computerized data acquisition system, System 5000 from Vishay. The data collected is processed by the program "Strain Smart" and is then reduced using Microsoft Excel. Each test is repeated a number of times to ensure repeatability and consistency of results. Using MS Excel, the load versus deflection and load versus strain graphs are plotted. The results presented in the following tables are obtained from linear regressions of data recorded for each sensor at a load of 100 pounds. A typical graph produced from data reorded for a 4' transverse sample of a side panel is shown in Figure 4.2.

\subsubsection{Results of Experimental Testing}

Deflection results obtained at span lengths of $L / 3$ and $2 \mathrm{~L} / 3$ are averaged, and together with deflections at L/2 are reported in Table 4.1. Similarly, strains recorded across the width, w, at w/3 and $2 \mathrm{w} / 3$ are averaged and given in Table 4.2, which also provides the strains at $w / 2$ for the top and bottom facesheets. The experimental values are compared to the results obtained from finite element analyses (Section 4.3) of actual and equivalent core- geometry models, which are described in the next section.

\subsection{Finite Element Modeling of Beam Samples}

Two types of finite element models, actual core-geometry model and equivalent core-geometry model, are used to verify their accuracy based on the experimental results. 
The details of these models are discussed in Chapter 2. In this section, the modeling of the beam samples is discussed based on the unit-cell of Figure 3.3 for actual geometry and shell elements for equivalent geometry. A discussion of the reported results is also included.

\subsubsection{Actual Core Geometry}

Finite element models of beam samples in bending are generated using the 4" x 4 " "unit cell" of Figure 3.3 in Chapter 3. Using the element copy-and-paste method in FEMAP (1999), beam models can be defined for any length and core orientation. Thus this method is used to create all the beam models described in this thesis. To decrease computational effort, symmetry is exploited by defining a shear release boundary condition at mid-span. A line load is applied at the mid-span to simulate the experimentally applied load. Only one half of the applied experimental load is prescribed

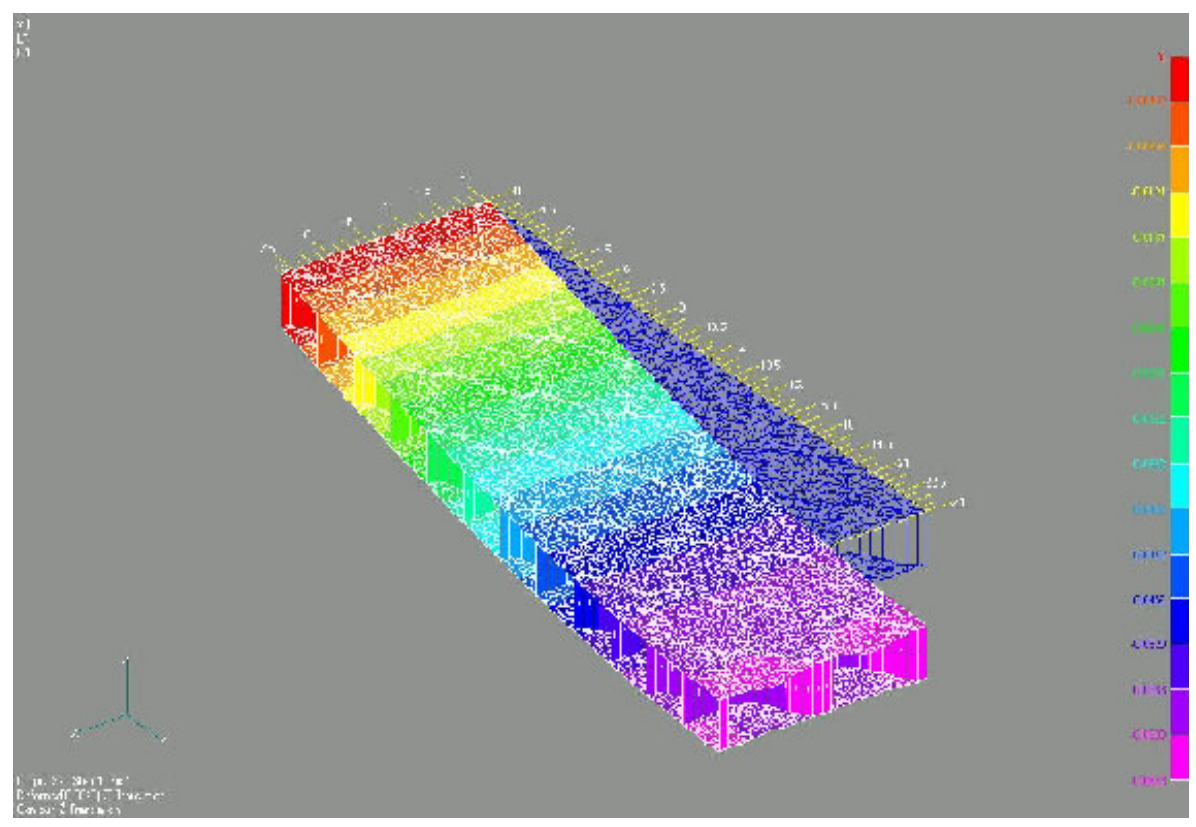

Figure 4.3 Deflection Shape for Actual Geometry Transverse Sample of a Side Panel 
because of the symmetry boundary condition. A simply-supported boundary condition is assumed at the support edge. Figure 4.3 shows the deflection diagram of the actual geometry model for a transverse sample.

\subsubsection{Equivalent Core Plate}

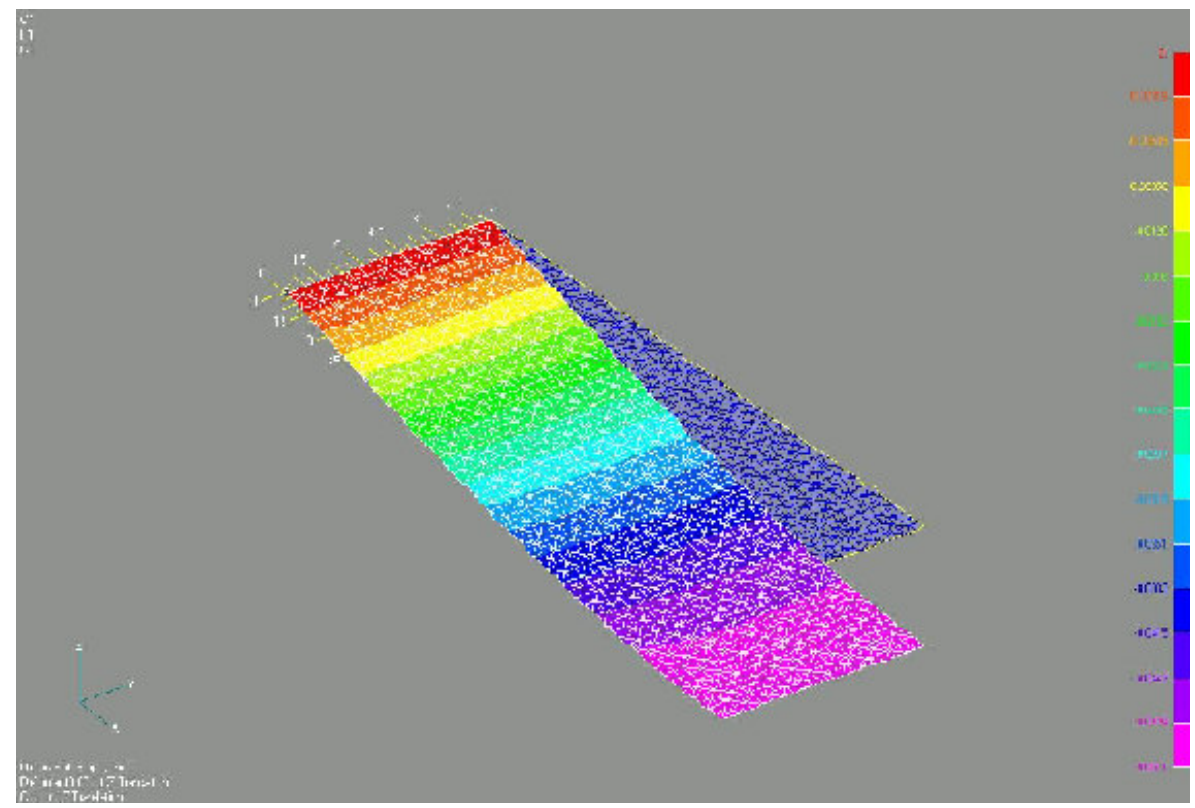

Figure 4.4 Deflection Shape for the Equivalent Side Panel Transverse Sample

For the equivalent core-geometry finite element model, the whole beam geometry is simply modeled using shell elements, because of the simple 3-layer plate configuration. Symmetry is specified by prescribing a shear release boundary condition at mid-span and the same type of loads and boundary constraints as in the actual- core geometry model are used. Figure 4.4 shows the deflection diagram of the equivalent model for a transverse sample. A brief summary of the finite element analysis results is given in the next section. 


\subsubsection{Finite Element Analysis Results}

The displacements are readily obtained from nodal data corresponding precisely to the experimental locations. However, the strain data is obtained by examining the nodal values across the entire width at the desired location with respect to the midspan. Due to mesh irregularities with the actual geometry model, strain data varies across the width, and therefore, the average values are reported. The strain results are given in microstrain, while deflections are given in inches. At the midspan, the displacements and strains are obtained at a small distance away from the symmetry boundary condition to avoid anomalous values. The results are shown in Table 4.1 for displacements and Table 4.2 for strains.

Table 4.1. Deflection Results for Beam Samples

\begin{tabular}{|c|c|c|c|c|c|c|c|c|}
\hline \multirow{3}{*}{ Span } & \multirow{3}{*}{ Width } & \multirow{3}{*}{ Orientation } & \multicolumn{6}{|c|}{ Deflections, inch } \\
\hline & & & \multicolumn{3}{|c|}{ @ L/2 } & \multicolumn{3}{|c|}{$@ \mathrm{~L} / 3$} \\
\hline & & & Experimental & Actual FE & Equivalent $\mathrm{FE}$ & Experimenta & Actual FE & Equivalent FE \\
\hline \multicolumn{9}{|c|}{ Bottom Panel (height $=4 ")$} \\
\hline 4 ' & $8 "$ & Longitudinal & 0.0138 & 0.0138 & 0.0110 & 0.0119 & 0.0115 & 0.0093 \\
\hline 4 ' & $8 "$ & Transverse & 0.0164 & 0.0170 & 0.0137 & 0.0144 & 0.0142 & 0.0115 \\
\hline 6' & $12 "$ & Longitudinal & 0.0246 & 0.0288 & 0.0240 & 0.0214 & 0.0246 & 0.0205 \\
\hline \multicolumn{9}{|c|}{ Side Panel (height $=2 ”)$} \\
\hline 4 , & $8 ”$ & Longitudinal & 0.0591 & 0.0593 & 0.0450 & 0.0513 & 0.0515 & 0.0390 \\
\hline 4 ' & $8 "$ & Transverse & 0.0645 & 0.0605 & 0.0503 & 0.0533 & 0.0522 & 0.0426 \\
\hline $5.5^{\prime}$ & $12 "$ & Transverse & 0.0866 & 0.0927 & 0.0848 & 0.0709 & 0.0787 & 0.0723 \\
\hline
\end{tabular}


Table 4.2. Strain Results for Beam Samples

\begin{tabular}{|c|c|c|c|c|c|c|c|c|c|c|}
\hline \multirow{4}{*}{ Span } & \multirow{4}{*}{ Width } & \multirow{4}{*}{ Orientation } & \multicolumn{8}{|c|}{ Strains $\left(\mathrm{X} 10^{6}\right)$} \\
\hline & & & \multicolumn{5}{|c|}{ Top Face Sheet } & \multicolumn{3}{|c|}{ Bottom Face Sheet } \\
\hline & & & \multicolumn{3}{|c|}{ Experimental } & \multirow{2}{*}{$\begin{array}{c}\text { Actual } \\
\text { FE }\end{array}$} & \multirow{2}{*}{$\begin{array}{c}\text { Equivalent } \\
\text { FE }\end{array}$} & \multirow{2}{*}{\begin{tabular}{|c|} 
Experimental \\
$@ \mathrm{w} / 2$
\end{tabular}} & \multirow{2}{*}{$\begin{array}{c}\text { Actual } \\
\text { FE }\end{array}$} & \multirow{2}{*}{\begin{tabular}{|c|} 
Equivalent \\
FE
\end{tabular}} \\
\hline & & & @w/3 & @w/2 & Average & & & & & \\
\hline \multicolumn{11}{|c|}{ Bottom Panel (height = 4”) } \\
\hline 4 ' & $8 "$ & Longitudinal & 93 & 99 & 96 & 84.975 & 84.46 & 117 & 115.83 & 108.81 \\
\hline 4 ' & $8 "$ & Transverse & 109 & 118 & 114 & 87.78 & 100.32 & 125 & 107.5 & 130 \\
\hline 6' & $12 ”$ & Longitudinal & 91 & 98 & 94 & 81.9 & 93.6 & 106 & 108.12 & 110.24 \\
\hline \multicolumn{11}{|c|}{ Side Panel (height = 2”) } \\
\hline 4 , & $8 "$ & Longitudinal & 220 & 244 & 232 & 191.97 & 182.49 & 255 & 216.75 & 239.7 \\
\hline 4 ' & $8 "$ & Transverse & 230 & 238 & 234 & 231.57 & 204.18 & 268 & 222.44 & 262.64 \\
\hline 5.5 & $12 "$ & Transverse & 230 & 270 & 250 & 232.5 & 202.5 & 311 & 289.23 & 239.47 \\
\hline
\end{tabular}

\subsection{Comparison of Results}

A comparison of experimental results and FE predictions shows a good correlation for strain and displacement values. Predictions with the actual-geometry models show better correlations with the experimental results than those obtained with equivalent property models, which under-predict the displacements and most of the strains as well, although the actual-geometry models also under-predict the strains in most cases. The discrepancies observed with the equivalent geometry model are probably due to the approximations and assumptions in developing the equivalent property formulae, such as plane-strain assumption. In general, however, the results indicate that both deflections and strains can be predicted by both of the finite element models with reasonable confidence, although the discrepancies with the experimental results are significant in some cases. It must be noted, however, that there were manufacturing imperfections in the samples, leading to non-uniform dimensions and resin content of 
face- sheet and core components. Based on the relatively favorable results obtained for the elastic behavior of the panels, the side-to-bottom panel connection is evaluated, both experimentally and numerically, in the next chapter. 


\section{Chapter 5}

\section{Testing and Analysis of Connections}

Two different designs for the connection of the side-panel to the bottom-panel were proposed, and samples for each connection type were produced and tested. The goal of the experimental testing is to evaluate the two connections and suggest the best design for production of the tank. A description of the two connection designs is given in Chapter 3. In this chapter, we discuss the experimental testing and finite element modeling and results obtained for both types of connection samples, and recommendations are made for their application in the assembly of the fish tank panels.

\subsection{Experimental Testing of Connection Samples}

Experimental testing of the connection is performed by fixing the bottom panel of the sample to a rigid steel vertical column, as shown in Figure 5.1. A tip load is applied to the side panel at a distance of 36-inches from the interior face of the bottom panel. Vertical deflections are recorded at distances of 24- and 36-inches. Strains are measured at 11 locations on each of the samples (see Figure 5.2), with 5 gages bonded to the bottom panel (\#1, \#2, \#3, \#6 and \#7), which is fixed to the steel column, and 6 gages bonded to the cantilever side-panel (\#4, \#5, \#8, \#9, \#10 and \#11) as shown in Figure 5.2. The gages on the side-panel are located for the purpose of obtaining the distribution of strains from the intersection of the panels to the free end, while the gages bonded to the 
bottom-panel are located to determine how rigidly the panel is fixed to the steel column. The gages are bonded at similar locations in each of the two samples to allow for easy comparisons, the exception being gages \#6 and \#7 for the stiffened sample, which are bonded on the stiffener. The data is reduced using the same method as for the beam samples, and the strains and deflections for 100 pounds of loading are shown in Table 5.1

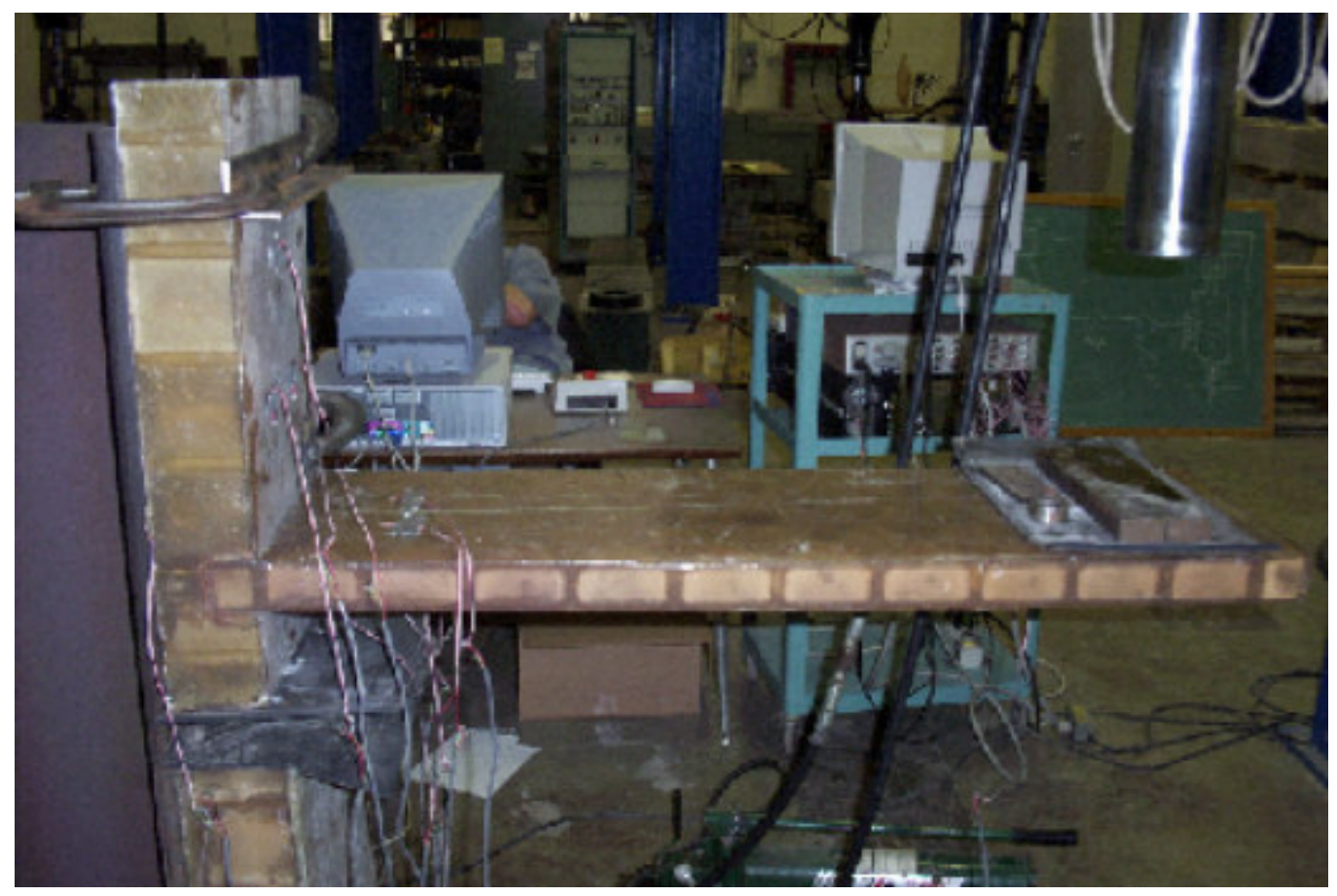

Figure 5.1 Experimental Setup for the Connection 


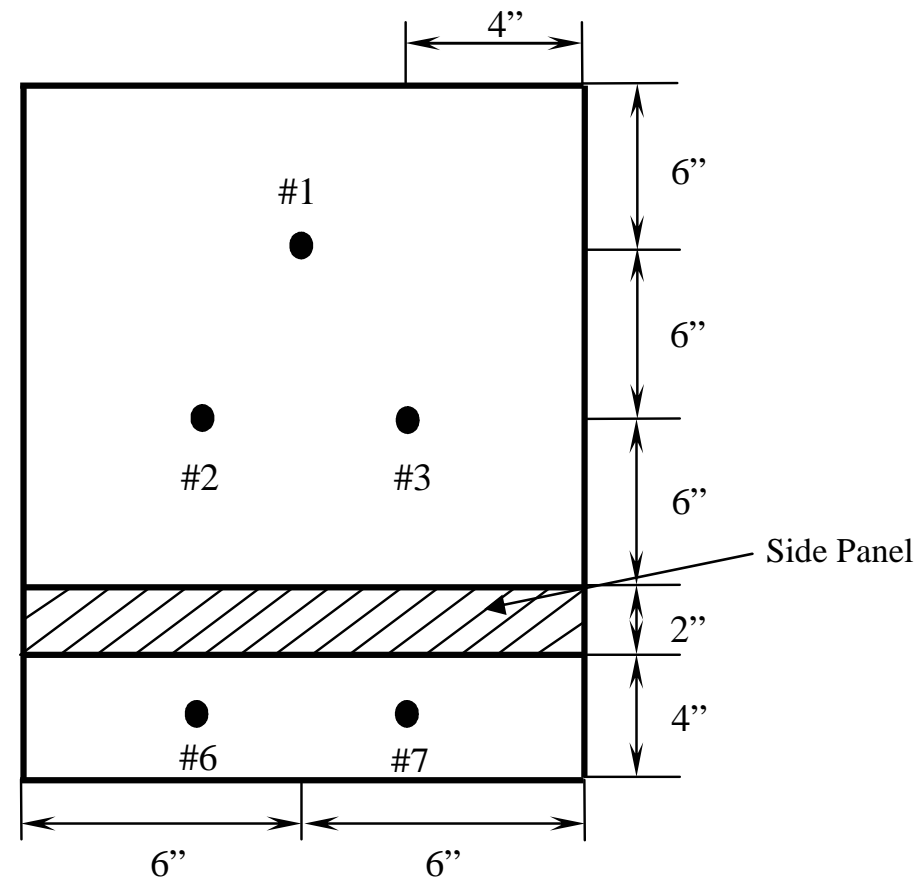

Unstiffened connector: All gages are bonded on the upper face sheet

Stiffened connector : $\# 1, \# 2$ and \#3 are bonded on the upper face sheet $\# 6$ and \#7 are bonded on the stiffener

\section{(a) Bottom Panel}

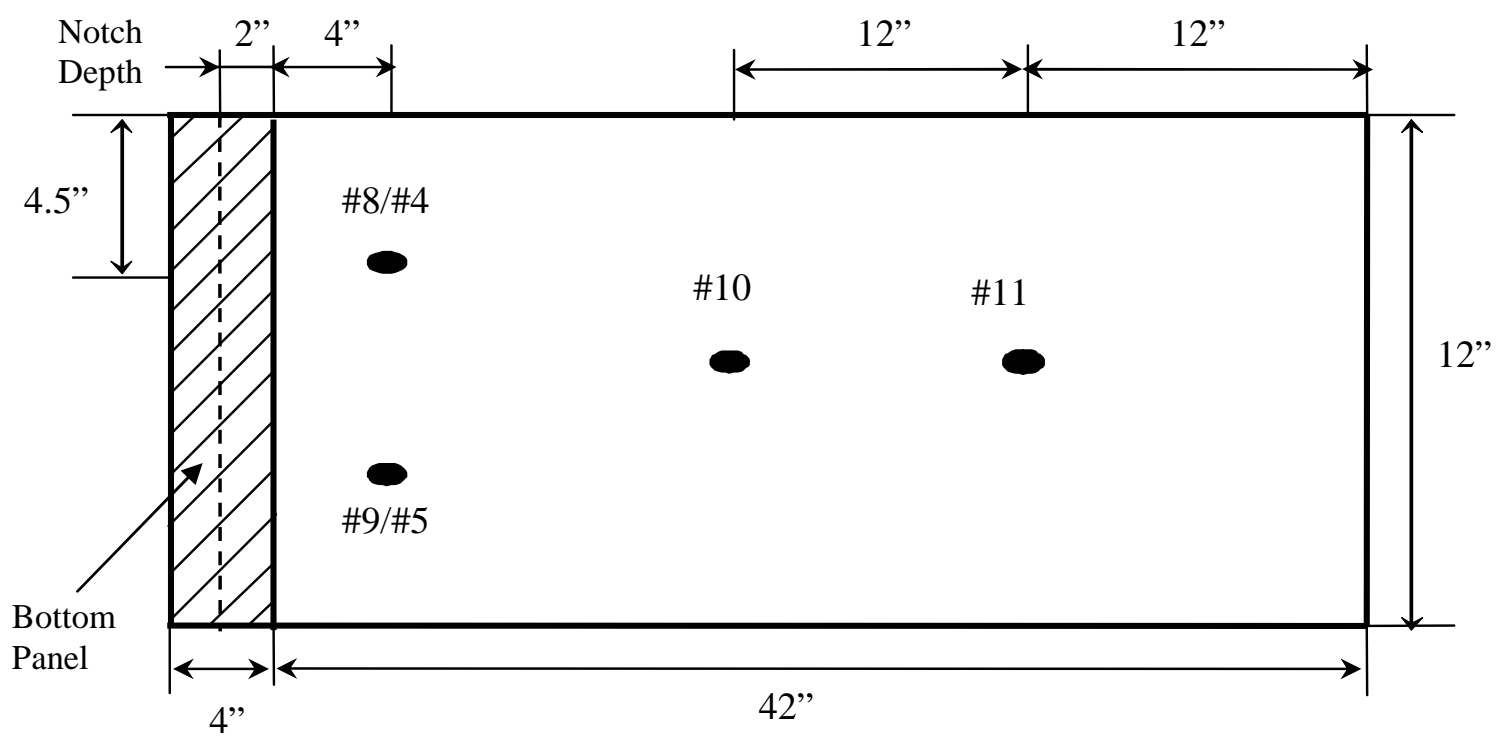

$\# 4$ and \#5 on the top facesheet of the panel

$\# 8$, \#9, \#10 and \#11 on the bottom facesheet of the panel

(b) Side panel

Figure 5.2 Location of Strain Gages 


\subsection{Finite Element Modeling of Connection Samples}

\subsubsection{Actual Core Geometry}

4"x4" unit cells (Figure 3.9) of the side panel and the bottom panel are used to generate the actual core geometry models of the connected panels. Only half the width of the sample is modeled and symmetric boundary conditions are applied to minimize computational effort. Using the element copy-and-paste feature in FEMAP (1999) for the corresponding unit cells, the side-panel and bottom-panel are modeled, with dimensions as shown in Figures 5.1 and 5.2. A void, 2 inch wide and 2 inch deep, is created along the width of the bottom-panel by deleting elements at the location of the connection joint. The side panel is then inserted into the void and, the common nodes are merged at the joint. This creates a model of the unstiffened connection as shown in Figure 5.3. A line load equivalent to $100 \mathrm{lb}$ is applied at the edge of the side panel, 36" away from the inner

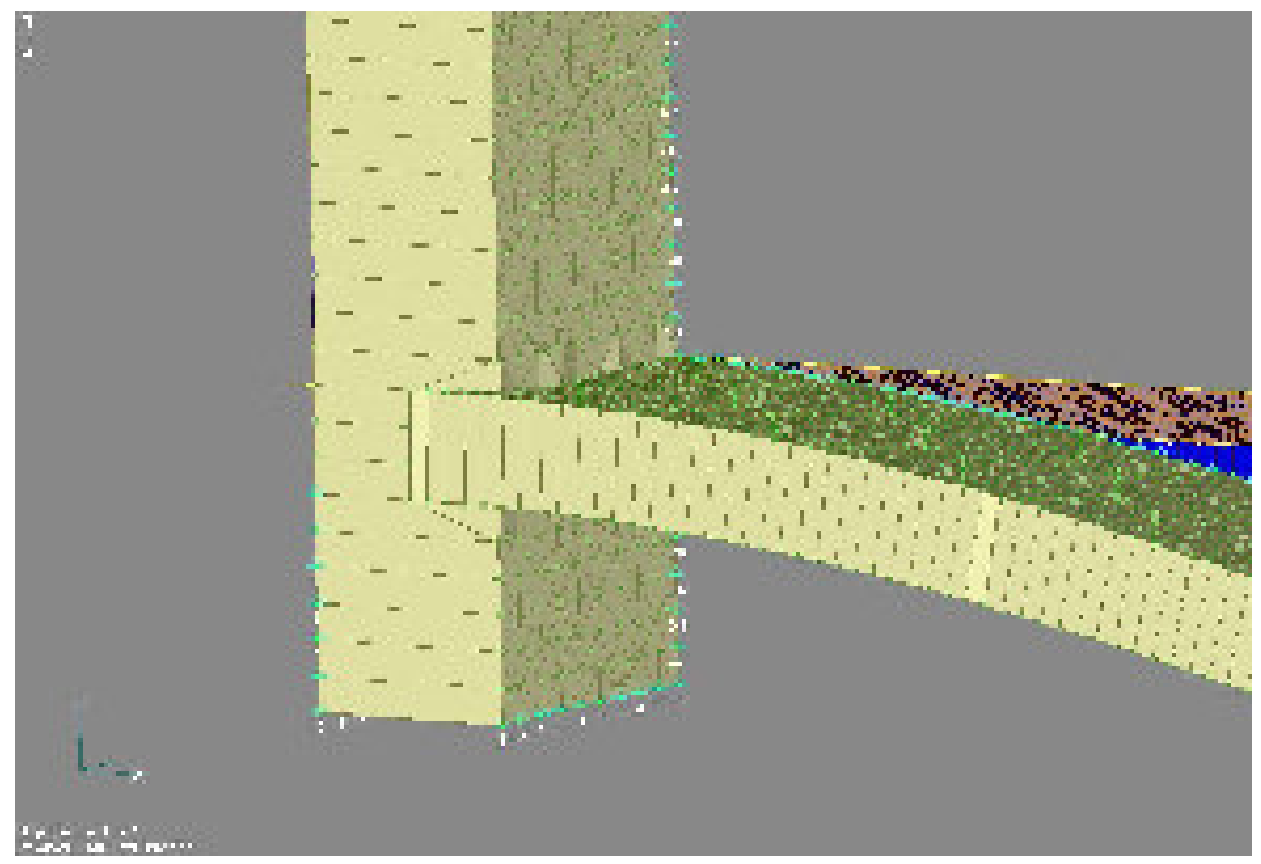

Figure 5.3 Actual Geometry Model of the Unstiffened Connection 
face of the intersection. The bottom nodes of the bottom panel are restrained from moving in the vertical direction, to simulate the support of the bottom panel over a rigid surface in the experiment. Also specific nodes on the bottom panel above the connection are constrained in all directions to simulate the boundary conditions in the experimental setup, where the bottom panel is fixed to the rigid column using clamps as shown in Figure 5.1.

For the stiffened connection design, a stiffener is added to the unstiffened model as follows. Elements of the unit cell of the bottom panel are copied to create a 6" wide beam. The beam is sliced through the cross-section at a 45 angle, and a face sheet is added to the cut-surface; this triangular wedge (Figure 5.4) is then joined to the bottompanel and side-panel at the connection, thus creating the stiffener. Nodes on adjacent faces of the wedge and the raceway panels are merged for strain and deflection continuity. This creates the stiffened connection as shown in Figure 5.4. Similar loads

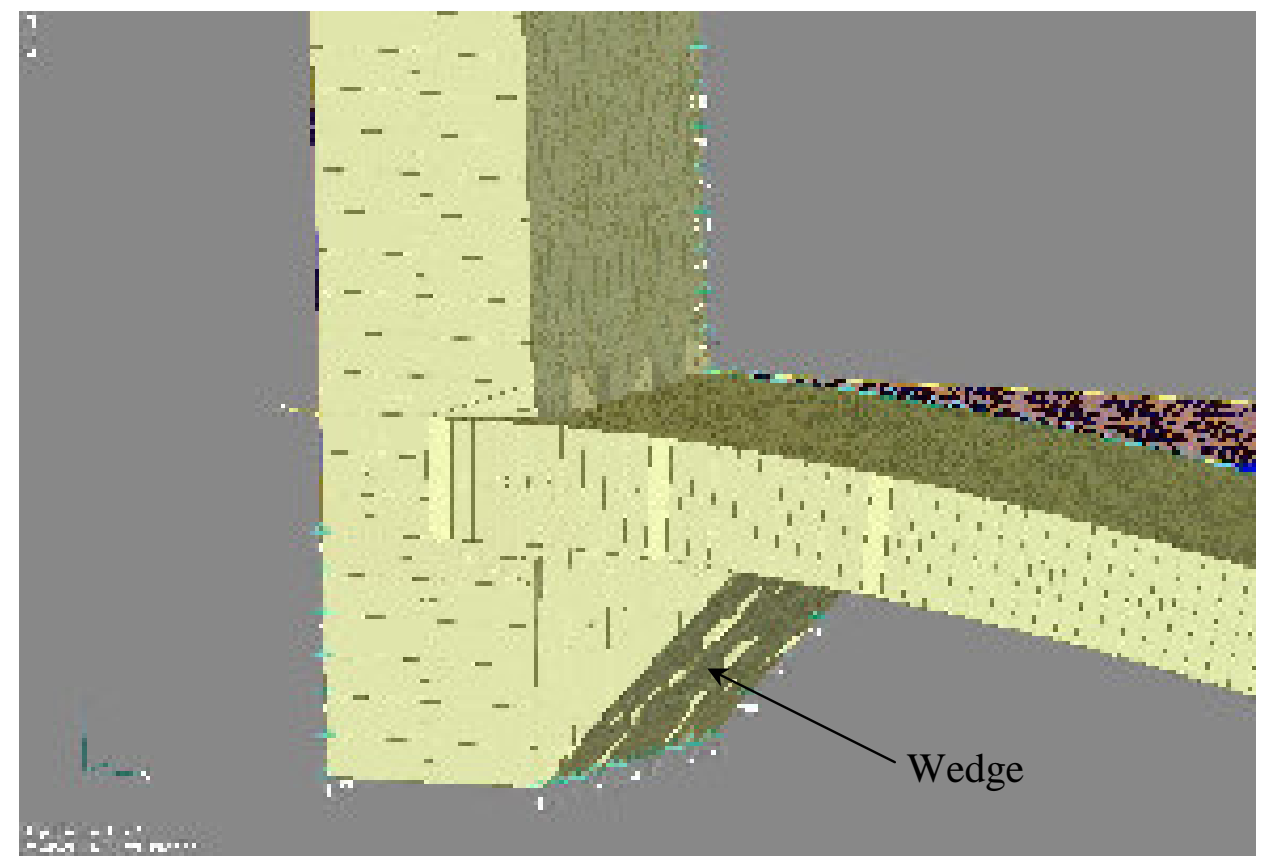

Figure 5.4 Actual Geometry Model of the Stiffened Connection 
and constrains are applied to this model as in the unstiffened model. The response of the connections is analyzed using ABAQUS (1998), and nodal deflections and strains are obtained and compared to experimental results.

\subsubsection{Equivalent Core Plate}

For the equivalent core-geometry model, the side and bottom panels are generated using 4-node shell elements, and the two panels are joined along coincident nodes, at the intersection located at 4" from the lower-end of the bottom-panel. This forms the unstiffened connection design as shown in Figure 5.5. For the stiffened connection design, approximations are made regarding the stiffener, by placing vertical triangular shell elements representative of the core elements, placed equidistantly at 4-inch apart

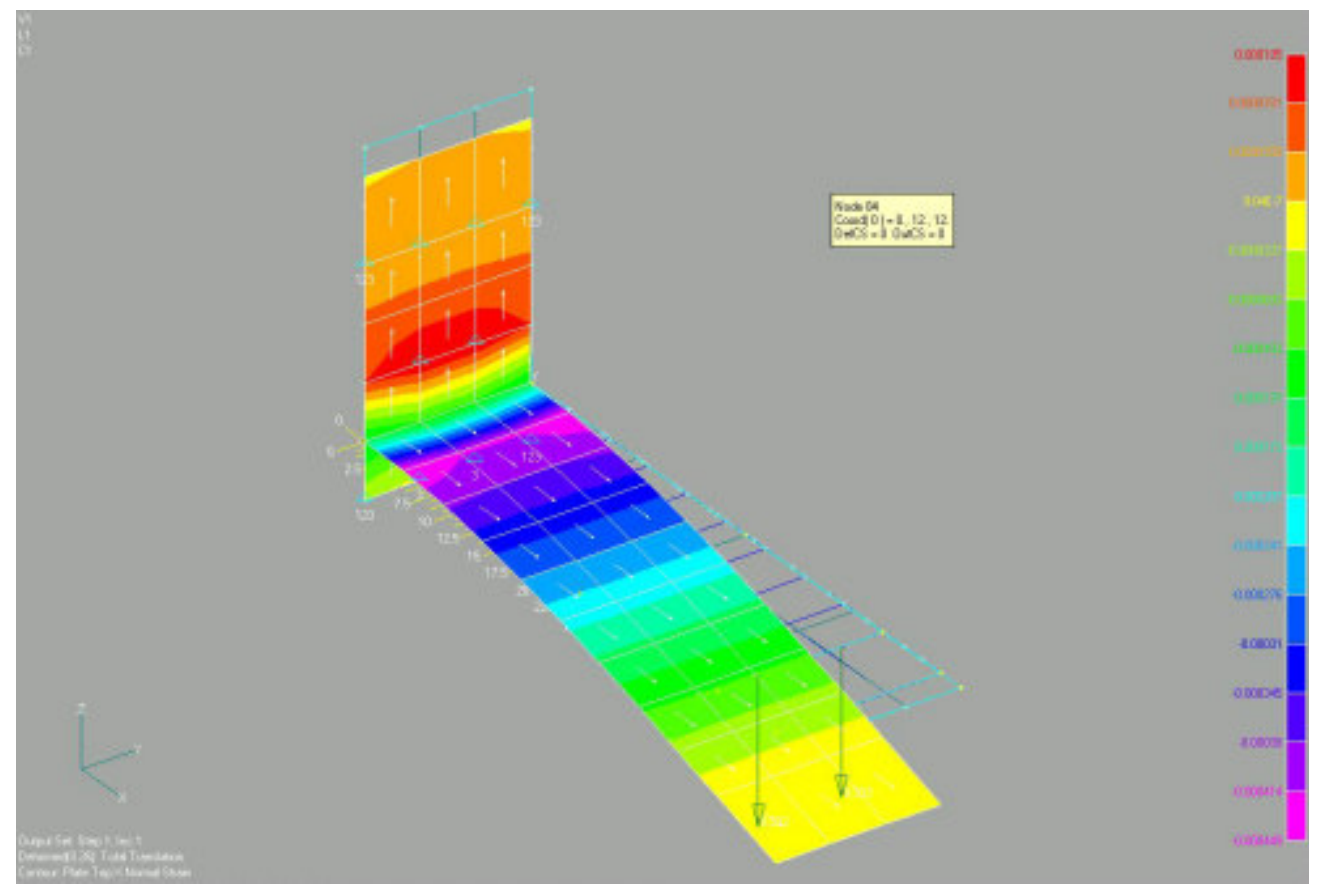

Figure 5.5 Equivalent Core Geometry Model of the Unstiffened Connection 
across the panel-width. A facesheet of shell elements is attached over the inclined edges of the discrete stiffners. The stiffened equivalent core model is shown in Figure 5.6. As in the case of the actual-core geometry model, a line-load equivalent to $100 \mathrm{lb}$ is applied at a distance of 36 " from the inside of the panel intersection, as in the experiment. The model is analyzed using ABAQUS (1998), and the results are compared with the experimental values.

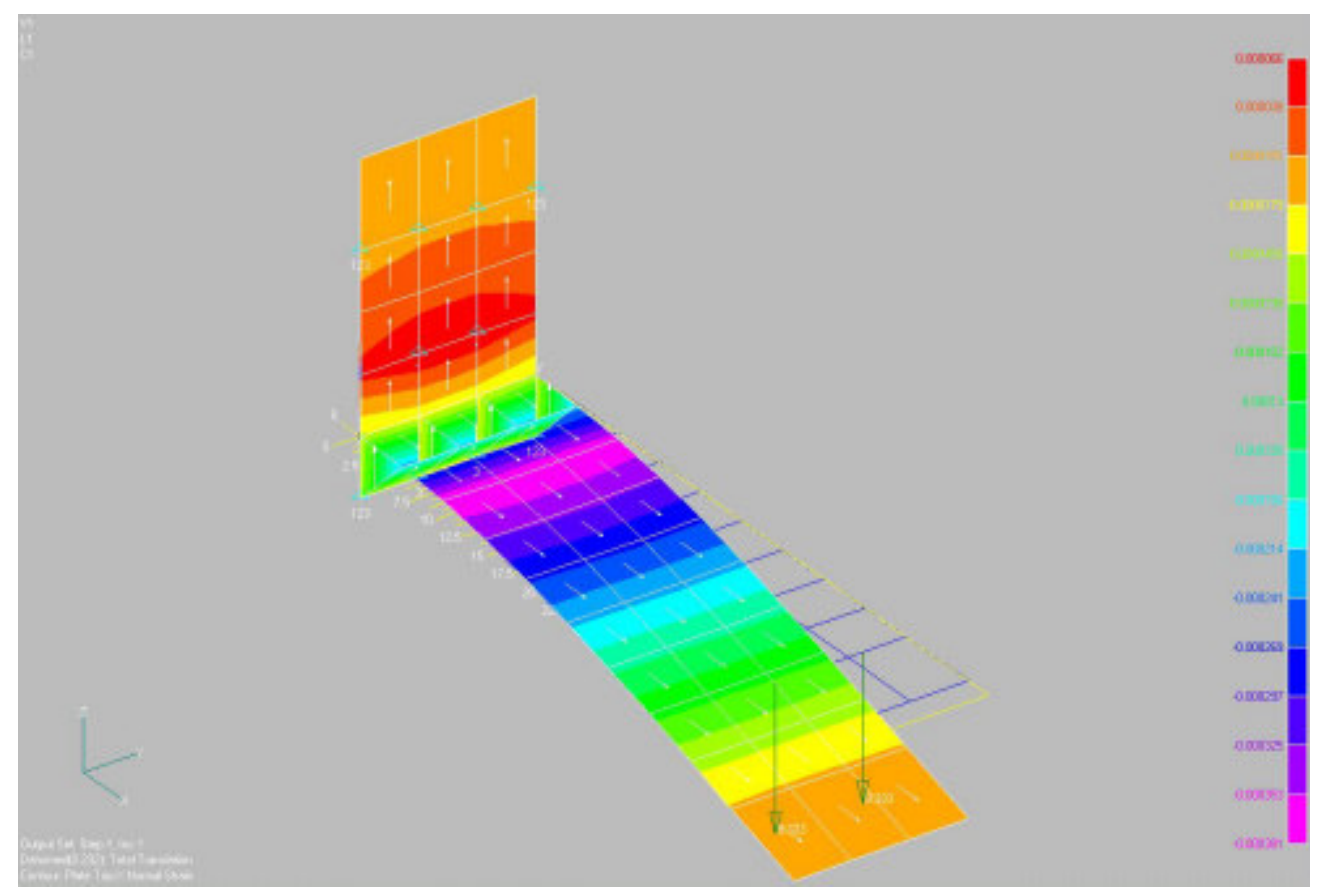

Figure 5.6 Equivalent Core Geometry Model of the Stiffened Connection

\subsubsection{Cantilever Beam FE Modeling}

A 36" long side panel beam is generated using both actual core-geometry and equivalent core properties. One end of the beam is constrained by specifying fixed-end boundary conditions, and a tip line-load is applied on the other end to simulate a 
cantilever beam in bending. The cantilever beam is assumed to be the ideal connection as it does not allow for any rotations at the joint. Strains and deflections for this model are obtained at the same locations as for the stiffened and unstiffened connection models. The results are used to compare the responses of the other two connection models to an idealized fixed-end connection.

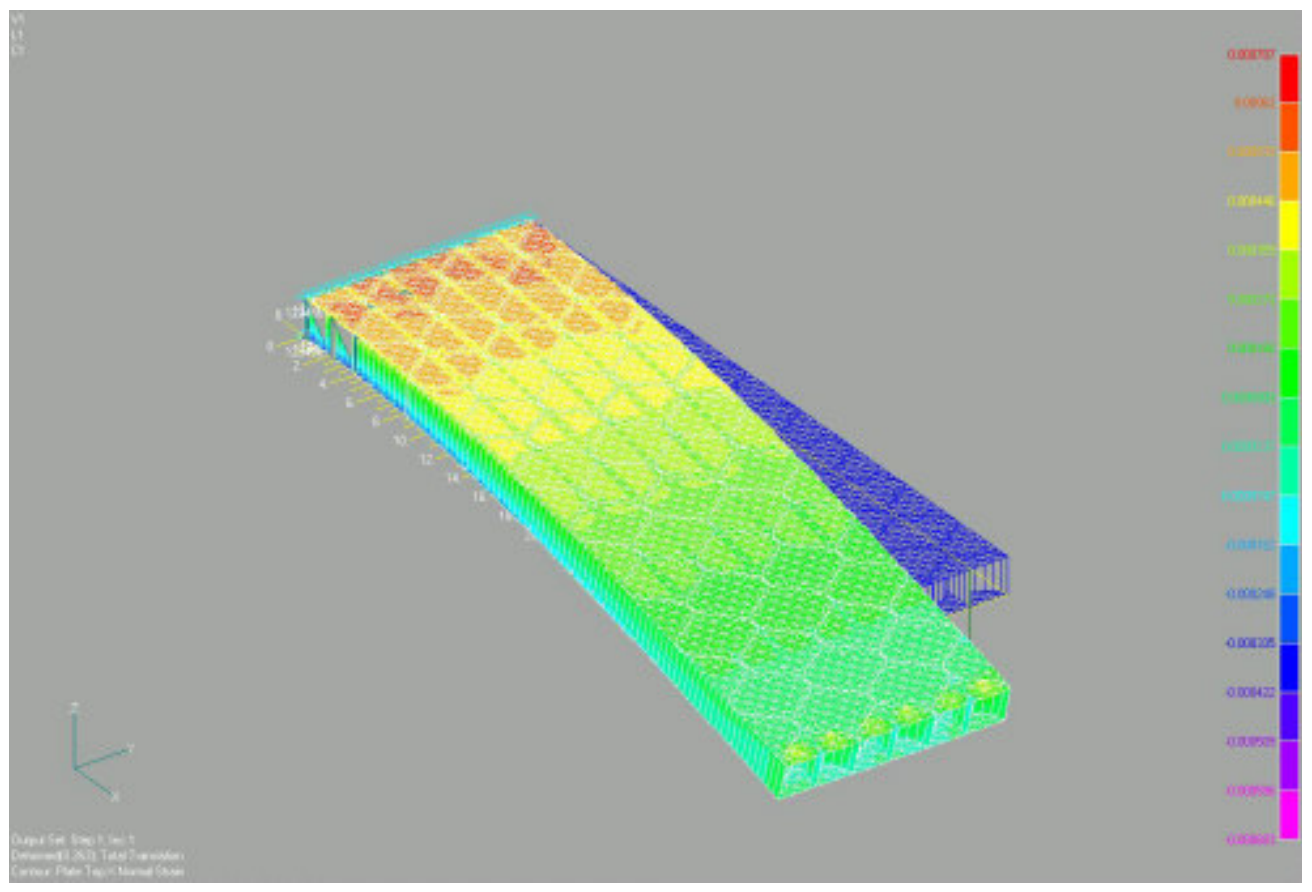

Figure 5.7 Cantilever Beam FE Model

\subsection{Comparison of Experimental and FE results}

Table 5.1 shows the experimental and finite element modeling results. It can be seen that there is a significant difference in the strain results of the FE models and the experimental samples for the bottom panel. One reason for this is the proximity of the boundary condition to the position of the strain gages, which may lead to error in the 
collection of data, both in the experimental setup and finite element analysis. It was also learnt in the failure testing of the beam samples, which is discussed in the next section, that the bottom panels have a very high factor of safety. Thus it is concluded that the strains of the bottom panel are not as critical as the strains of the side panel and hence they will not be discussed further in this section.

For the side panel, the actual geometry FE models are more flexible compared to the experimental results, while the equivalent models are stiffer. Further, the actual geometry FE results are much closer to the experimental results than the equivalent model results. This is partly because of the assumptions in calculating the equivalent properties of the sinusoidal core. There were also considerable manufacturing defects in the experimental samples, leading to the discrepancies in the results. The equivalent models predict the actual behavior of the samples to within $20 \%$ for the stiffened models and $30 \%$ for the unstiffened models for deflections; similarly for strains, the discrepancies are within $20 \%$ for the stiffened models and $10 \%$ for the unstiffened models. Although these differences are significant, it was decided that for ease of computation and economy, the complete raceway can still be modeled using equivalent properties.

From Table 5.1, it can be seen that the stiffened connection yields the least deflection of all the models tested and approaches the cantilever beam condition, which assumes perfect fixity at the connection. The unstiffened connection is more flexible, showing a relative rotation at the joint. Examining the maximum displacement values in 
Table 5.1, we can see significant differences between the two designs. The deflections of the unstiffened sample are about $42 \%$ greater than those of the stiffened sample. Since the strains of the side panel (the panel on which the load is applied) for both connection types are approximately the same, we can infer that the joint rotation of the unstiffened sample is significantly greater than that of the stiffened sample.

Table 5.1 Comparison of Results for the Stiffened and Unstiffened Connection Samples

\begin{tabular}{|c|c|c|c|c|c|c|c|c|}
\hline \multirow{3}{*}{ Location } & \multicolumn{3}{|c|}{ Unstiffened } & \multicolumn{3}{|c|}{ Stiffened } & \multirow{2}{*}{\multicolumn{2}{|c|}{$\begin{array}{c}\text { Cantilever Beam } \\
\text { FE Model }\end{array}$}} \\
\hline & \multirow[b]{2}{*}{ Experimental } & \multicolumn{2}{|c|}{ FE Model } & \multirow[b]{2}{*}{ Experimental } & \multicolumn{2}{|c|}{ FE Model } & & \\
\hline & & $\begin{array}{l}\text { Actual } \\
\text { Core }\end{array}$ & \begin{tabular}{|c|}
$\begin{array}{c}\text { Equivalent } \\
\text { Core }\end{array}$ \\
\end{tabular} & & $\begin{array}{c}\text { Actual } \\
\text { Core }\end{array}$ & \begin{tabular}{|c|}
$\begin{array}{c}\text { Equivalent } \\
\text { Core }\end{array}$ \\
\end{tabular} & $\begin{array}{l}\text { Actual } \\
\text { Core }\end{array}$ & $\begin{array}{c}\text { Equivalent } \\
\text { Core }\end{array}$ \\
\hline \multicolumn{9}{|c|}{ Deflection (inch) } \\
\hline $24 ”$ & 0.177 & 0.179 & 0.108 & 0.122 & 0.125 & 0.096 & 0.134 & 0.101 \\
\hline $36 "$ & 0.303 & 0.326 & 0.205 & 0.213 & 0.246 & 0.188 & 0.257 & 0.195 \\
\hline \multicolumn{9}{|c|}{ Strain $\left(X 10^{-6}\right)$} \\
\hline$\# 1$ & 82 & 5 & 10 & 40 & 10 & 48 & No Data & No Data \\
\hline \#2/\#3 & 174 & 59 & 39 & 89 & 60 & 83 & No Data & No Data \\
\hline \#4/ \#5 & 402 & 390 & 435 & 431 & 298 & 211 & 516 & 435 \\
\hline \#6/ \#7 & 2 & -75 & -54 & -186 & -105 & -153 & No Data & No Data \\
\hline \#8/ \#9 & -412 & -368 & -431 & -379 & -362 & -309 & -475 & -435 \\
\hline$\# 10$ & No Data & -223 & -248 & -222 & -238 & -248 & -241 & -248 \\
\hline$\# 11$ & -51 & -71 & -84 & -61 & -80 & -84 & -122 & -84 \\
\hline
\end{tabular}

While larger displacements are observed for the unstiffened connection design, both connection types are adequate for use in the production of the tank. The stiffened connection was used for the exterior panels, and the unstiffened connection was used for the interior partition panel as shown in Figure 5.8. To further increase the rotational stiffness of the connections, a 6" unidirectional fabric was placed at the connection as shown in Figure 5.9. 


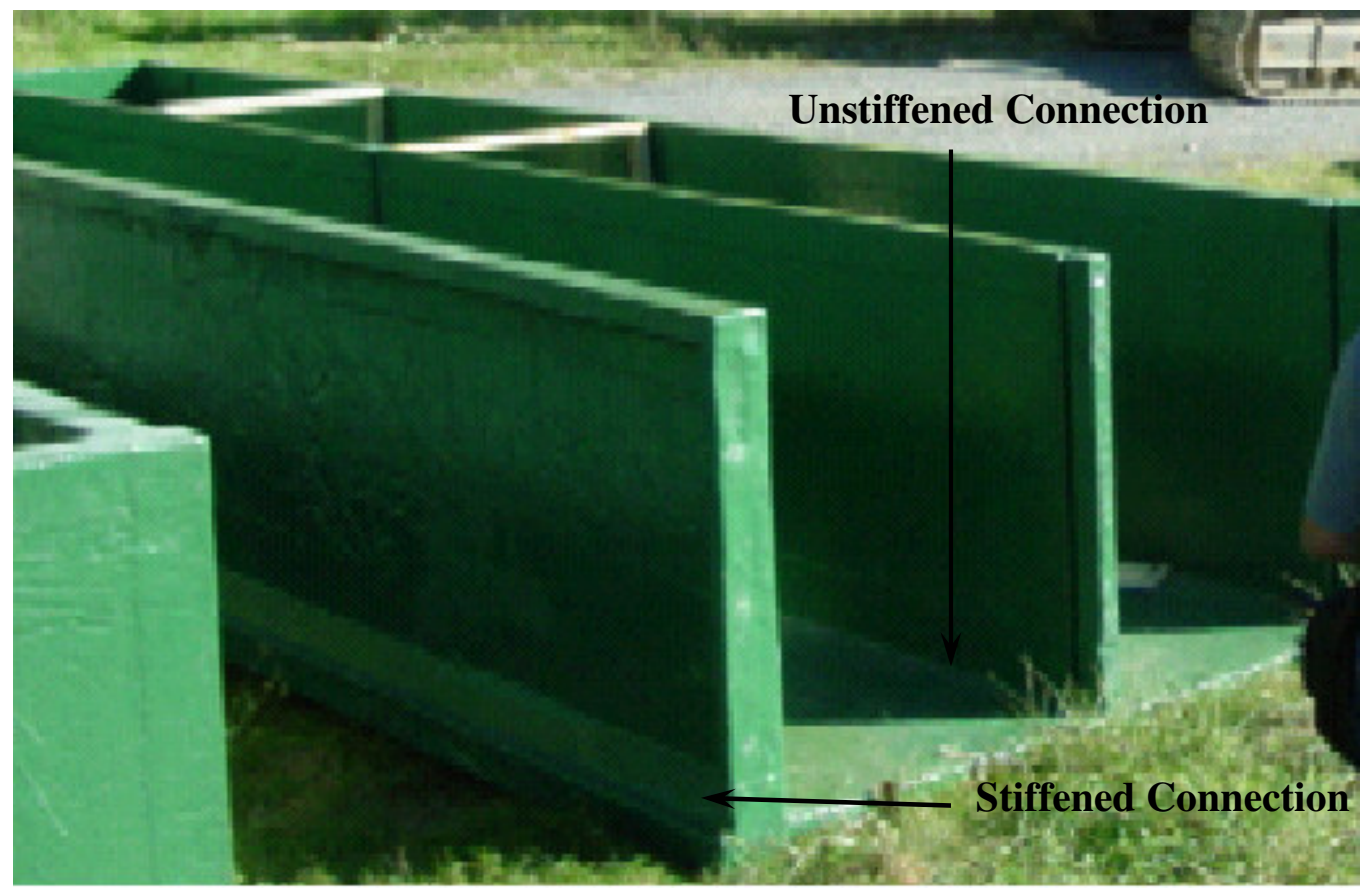

Figure 5.8 Connector Selection for the Raceway

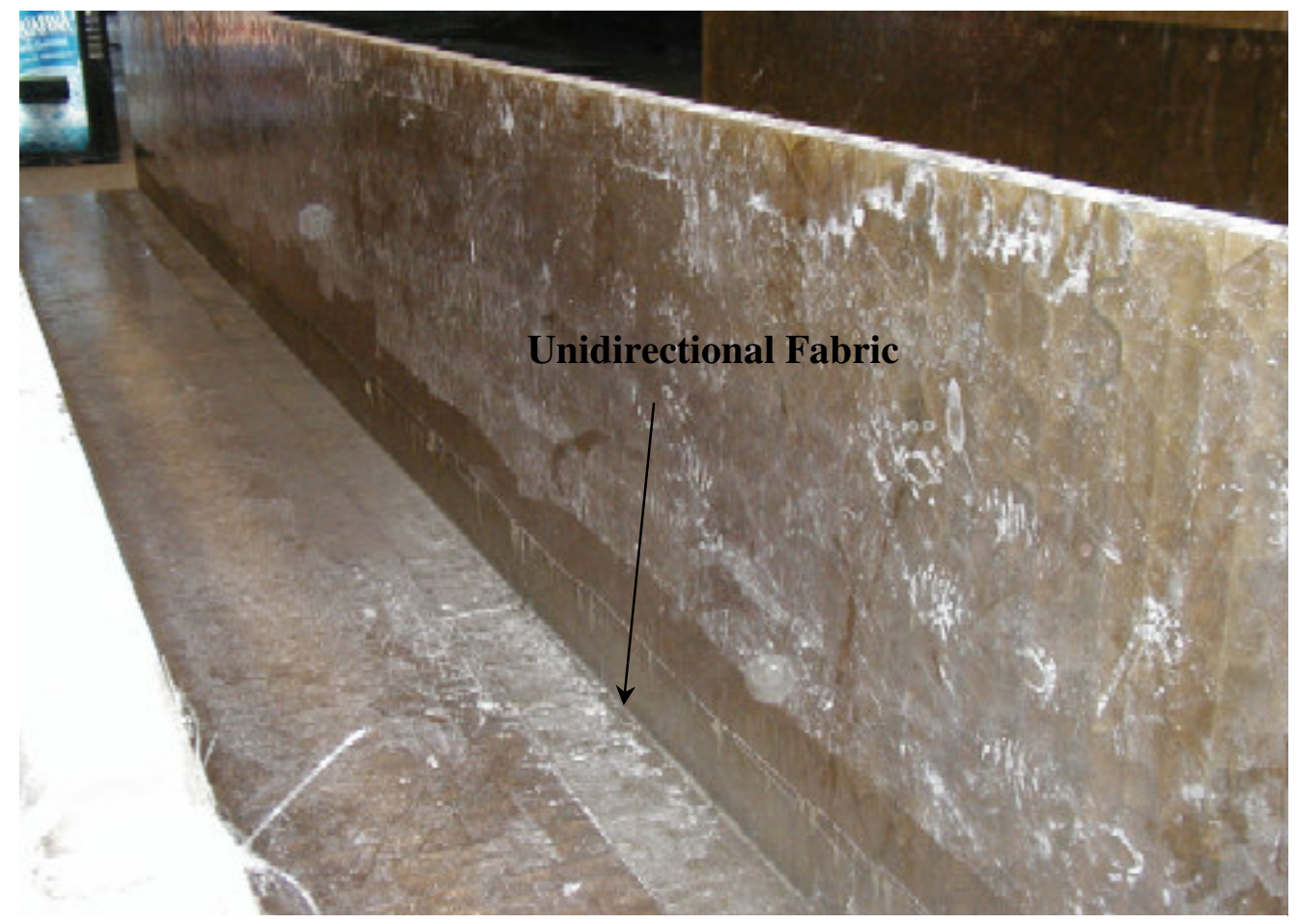

Figure 5.9 Placement of a Unidirectional Fabric at the Connection 


\section{Chapter 6}

\section{Failure Testing of Beam Samples}

The beam samples which were tested in the linear range in Chapter 4 were again tested in bending, this time to failure. This was done to determine the ultimate loads and corresponding failure modes of the material, which can provide failure limit loads for the raceway. This study is also directed to observe the behavior of the panels at various levels of loading.

\subsection{Experimental Setup}

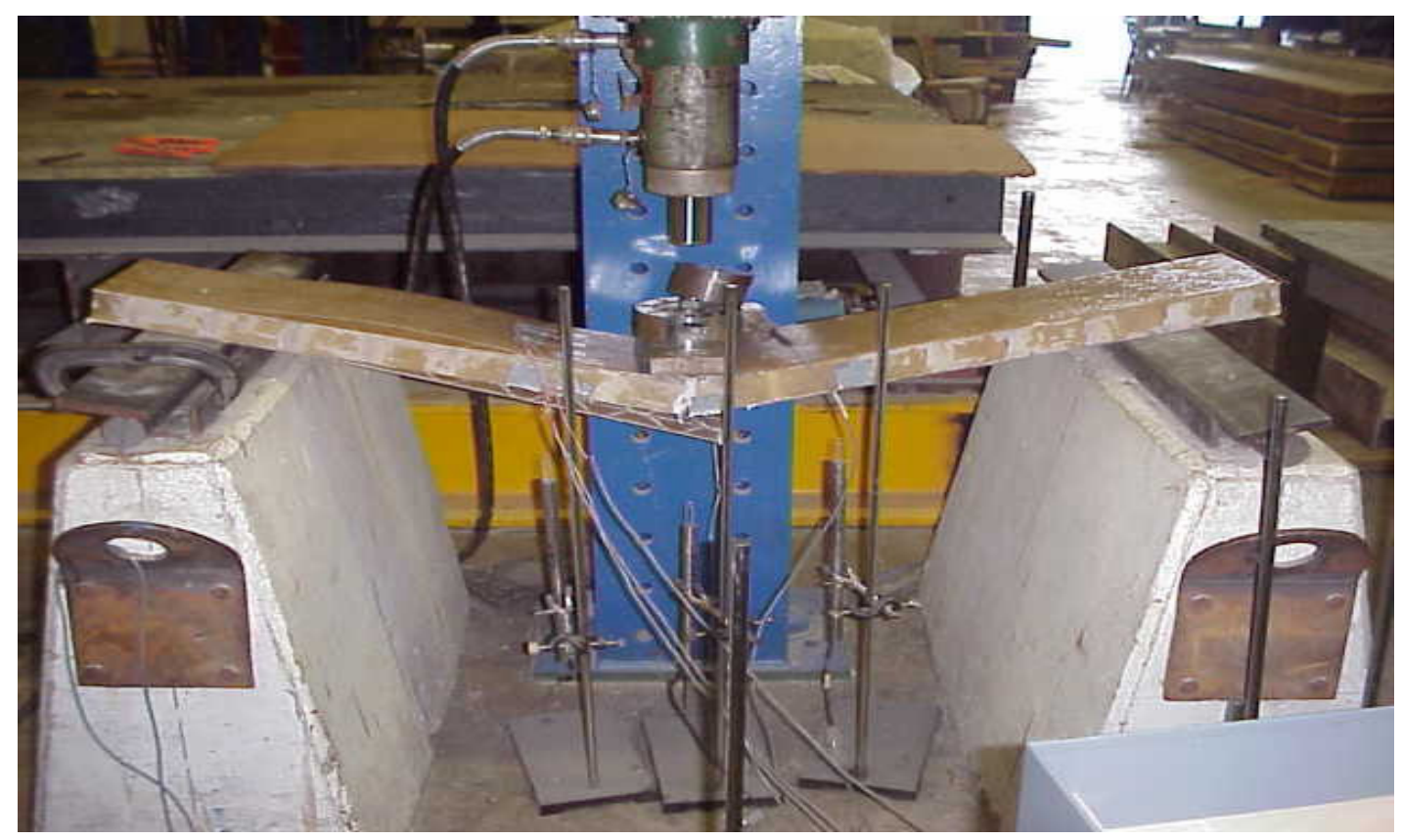

Figure 6.1 Testing to Failure Load 
The experimental setup for the failure tests was the same as for the linear tests. The beams were tested in three point bending as shown in Figure 6.1. The load was gradually applied first in the linear range to verify the values with the previous tests in the linear range. On obtaining satisfactory results, the load was gradually increased to failure, and the mode of failure was noted and the failure load was recorded.

\subsection{Failure Testing of Beam Samples}

The beams previously tested in the linear range were subsequently tested to failure to determine the behavior of the panels at various levels of loading. The results provide valuable information about failure modes and ultimate loads (Table 6.1). The load-deflection and load-strain data are plotted as shown in Figures 6.2 and 6.3, respectively, and the linear limits for all the samples are estimated graphically. Maximum in-service deflection and strain values for the side and bottom panel are predicted by the finite element modeling of the entire raceway, as discussed in the next chapter, and are summarized in Table 6.2. These values are used to calculate the factors of safety for deflection and strain (Table 6.3), from the linear and failure limits obtained experimentally. 
Table 6.1 Failure Information for Beam Samples

\begin{tabular}{|c|c|c|c|}
\hline Span & Orientation & Mode of failure & Load (lb) \\
\hline Bottom Panel & \\
\hline $4^{\prime}$ & Longitudinal & Delamination of top face sheet & 7500 \\
\hline $4^{\prime}$ & Transverse & Shear of the core & 1575 \\
\hline $6^{\prime}$ & Longitudinal & Material failure in compression & 9000 \\
\hline Side Panel & \\
\hline $4^{\prime}$ & Longitudinal & Delamination and material failure of bottom face sheet & 3800 \\
\hline $4^{\prime}$ & Transverse & Shear of the core & 1682 \\
\hline $5.5^{\prime}$ & Transverse & Material failure in compression & 1630 \\
\hline
\end{tabular}

Table 6.2 In-Service Maximum Deflection and Strain from the FE Model of Tank

\begin{tabular}{|c|c|c|}
\hline Variable & Bottom Panel & Side Panel \\
\hline Maximum Deflection (in) & 0.0041 & 0.281 \\
\hline Maximum Strain $\left(\times 10^{-6}\right)$ & 77 & 615 \\
\hline
\end{tabular}

Table 6.3 Factors of Safety for Experimental Samples

\begin{tabular}{|c|c|c|c|c|c|c|c|c|c|c|}
\hline \multirow{2}{*}{ Sample } & \multicolumn{2}{|c|}{\begin{tabular}{|c|} 
Maximum Load \\
$(\mathrm{lb})$
\end{tabular}} & \multicolumn{2}{|c|}{$\begin{array}{c}\text { Maximum } \\
\text { Deflection (in) }\end{array}$} & \multicolumn{2}{|c|}{$\begin{array}{l}\text { Maximum Strain } \\
\left(10^{6} \mathrm{in} / \mathrm{in}\right)\end{array}$} & \multicolumn{2}{|c|}{$\begin{array}{l}\text { Deflection } \\
\text { Ratio }\end{array}$} & \multicolumn{2}{|c|}{ Strain Ratio } \\
\hline & Linear & Ultimate & Linear & Ultimate & Linear & Ultimate & $\frac{\Delta^{\text {linear }}}{\Delta} \Delta^{\text {design }}$ & $\frac{\Delta \Delta^{\text {ultimate }}}{\Delta^{\text {design }}}$ & $\frac{\varepsilon^{\text {linear }}}{\varepsilon^{\text {design }}}$ & $\frac{E^{\text {ultimatc }}}{\varepsilon^{\text {design }}}$ \\
\hline \begin{tabular}{|c|}
4 ' Bottom Panel \\
Longitudinal
\end{tabular} & 2152 & 7525 & 0.312 & 1.627 & 2858 & 10940 & 76.1 & 153.0 & 37.1 & 142.3 \\
\hline $\begin{array}{c}4 \text { ' Bottom Panel } \\
\text { Transverse }\end{array}$ & 963 & 1620 & 0.176 & 0.341 & 1452 & 2507 & 42.9 & 83.2 & 18.9 & 32.6 \\
\hline \begin{tabular}{|c} 
6' Bottom Panel \\
Longitudinal
\end{tabular} & 2270 & 9003 & 0.552 & 2.56 & 2640 & 13580 & 134.6 & 624.4 & 34.3 & 176.6 \\
\hline \begin{tabular}{|l|} 
4' Side Panel \\
Longitudinal \\
\end{tabular} & 723 & 3828 & 0.466 & 2.76 & 2439 & 14930 & 1.7 & 9.8 & 4.0 & 24.3 \\
\hline $\begin{array}{l}\text { 4' Side Panel } \\
\text { Transverse }\end{array}$ & 896 & 1713 & 0.608 & 1.59 & 3089 & 6528 & 2.2 & 5.7 & 5.0 & 10.2 \\
\hline $\begin{array}{l}\text { 5.5' Side Panel } \\
\text { Transverse }\end{array}$ & 853 & 1630 & 0.753 & 1.55 & 2458 & 5107 & 2.7 & 5.5 & 4.0 & 8.3 \\
\hline
\end{tabular}

Note: Design values are obtained from finite element analysis of the tank 
4' Transverse B ottom Panel

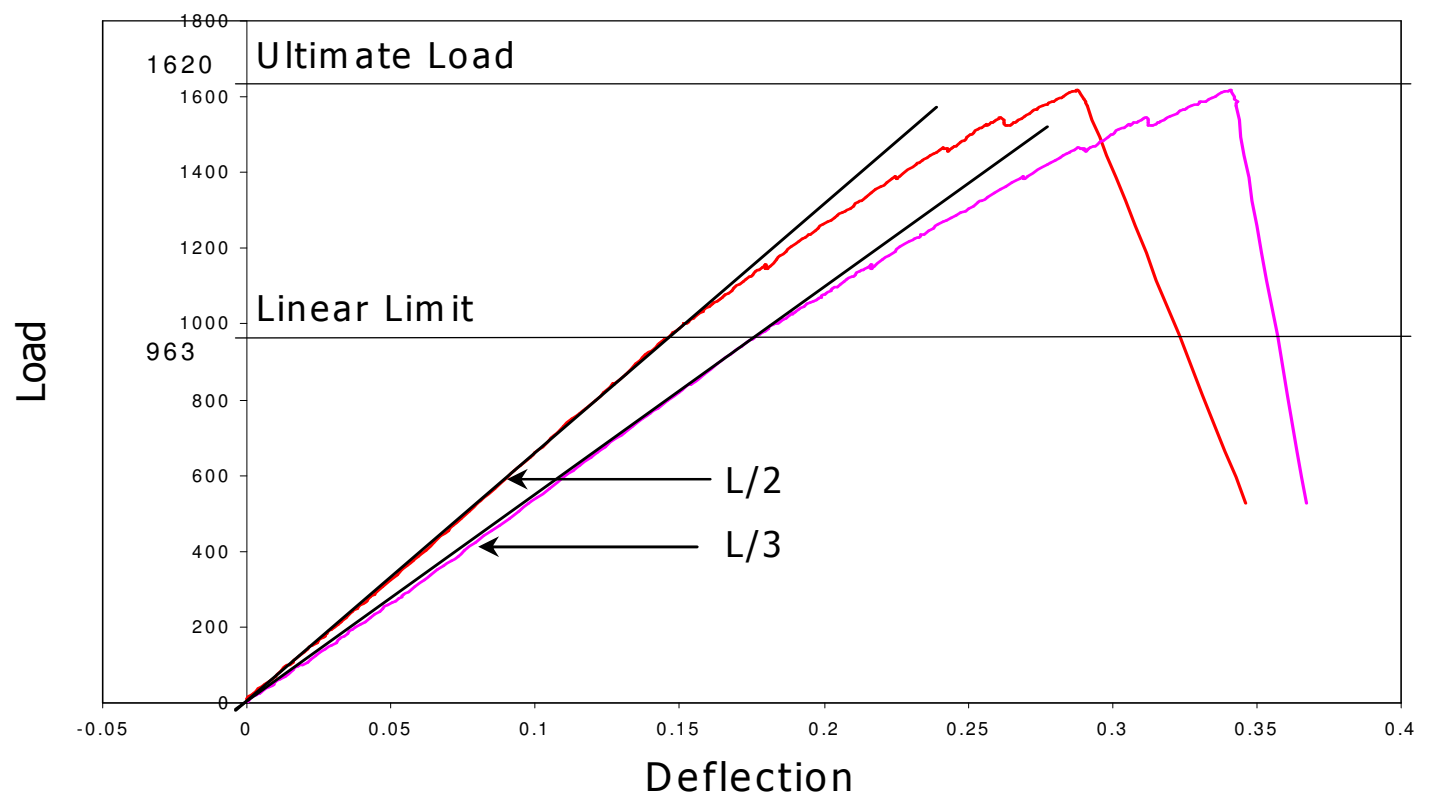

Figure 6.2 Typical Load-Strain Curve

\section{4' Transverse Bottom Panel}

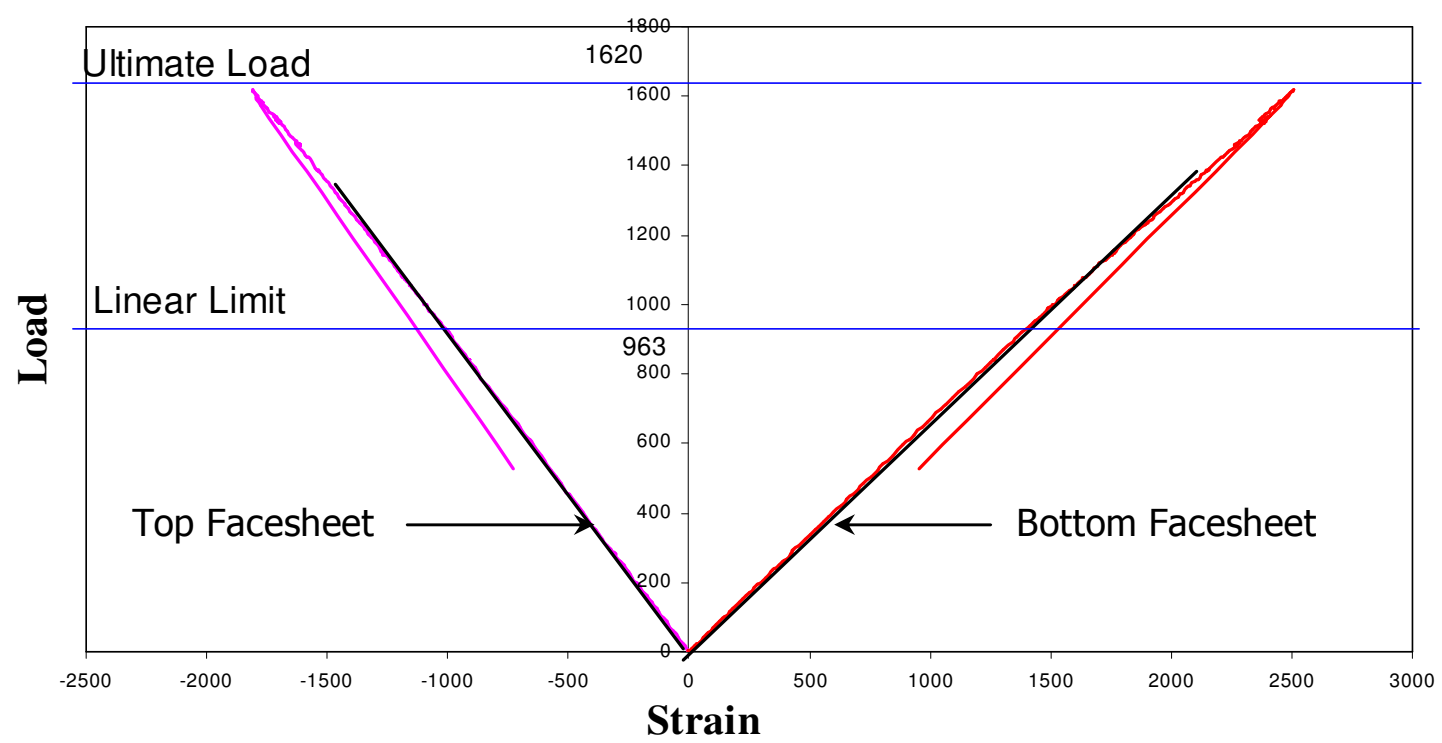

Figure 6.3 Typical Load-Deflection Curve 


\subsection{Failure Modes}

As reported in Table 6.1, the typical failure mode for the longitudinal samples was delamination of the face sheet from the core (see Figure 6.4). The transverse samples failed by shearing of the core, as shown in Figure 6.5. However, for the samples tested at a longer span, a compression failure occurred in the top face sheet (see Figure 6.6), which can be attributed to dominant bending stresses for longer spans. These results indicate that the raceway could fail in either one of these modes depending on the loading and boundary conditions. Testing to failure of plate-type samples of the same material under static and dynamic loads would further provide better knowledge about different failure modes that can be expected in service.

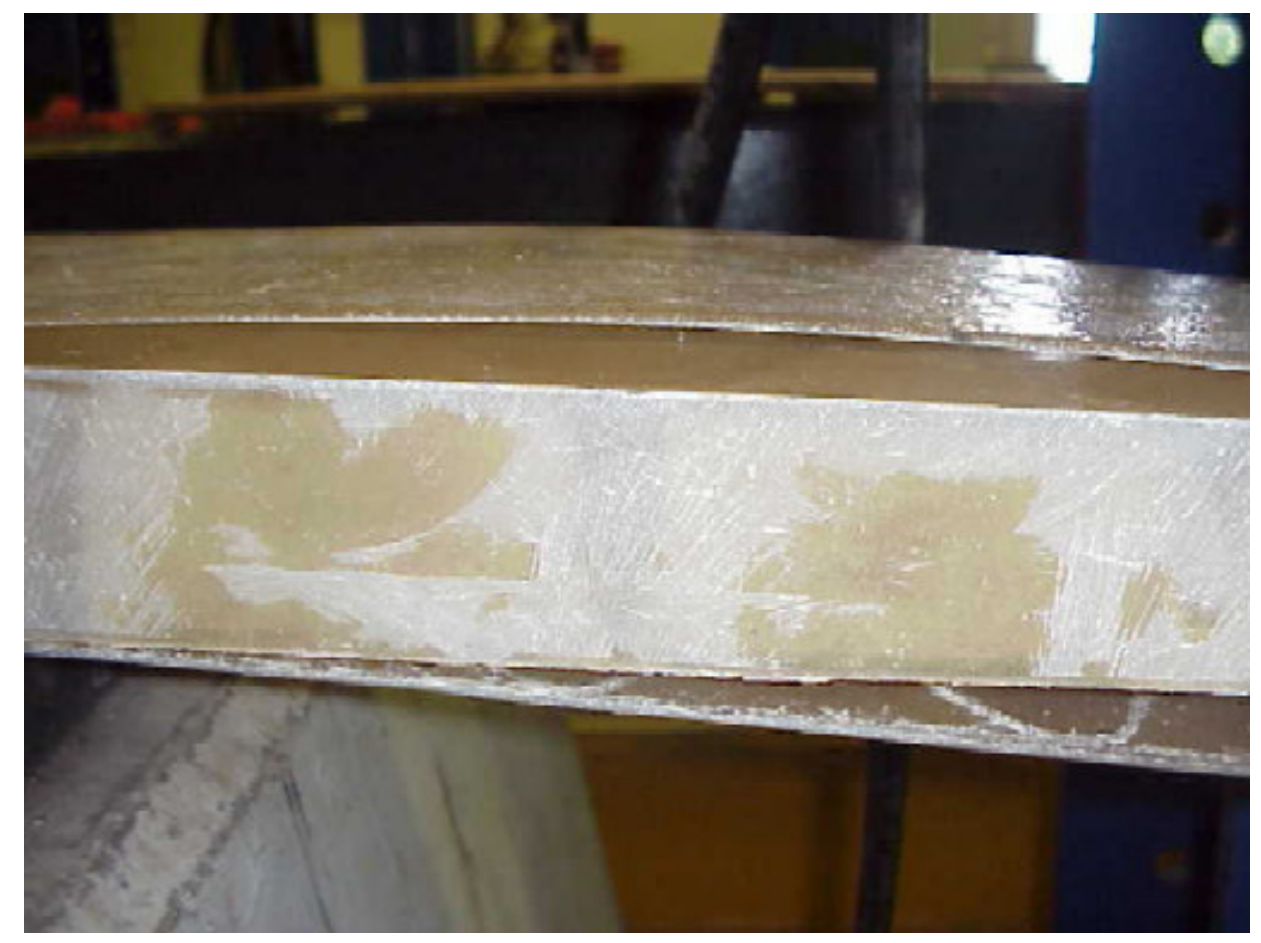

Figure 6.4 Delamination of Face Sheet from Core 


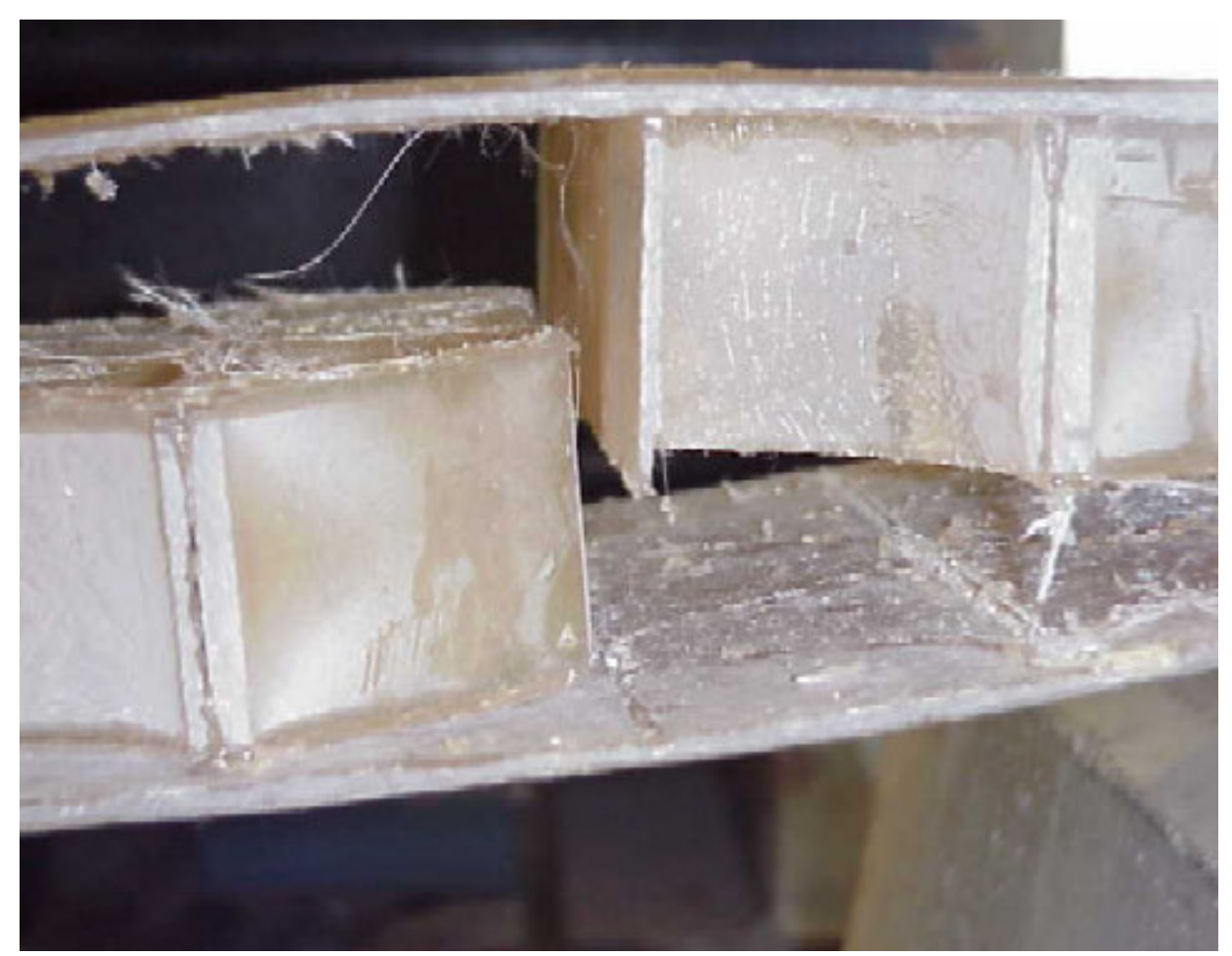

Figure 6.5 Shear Failure of Core

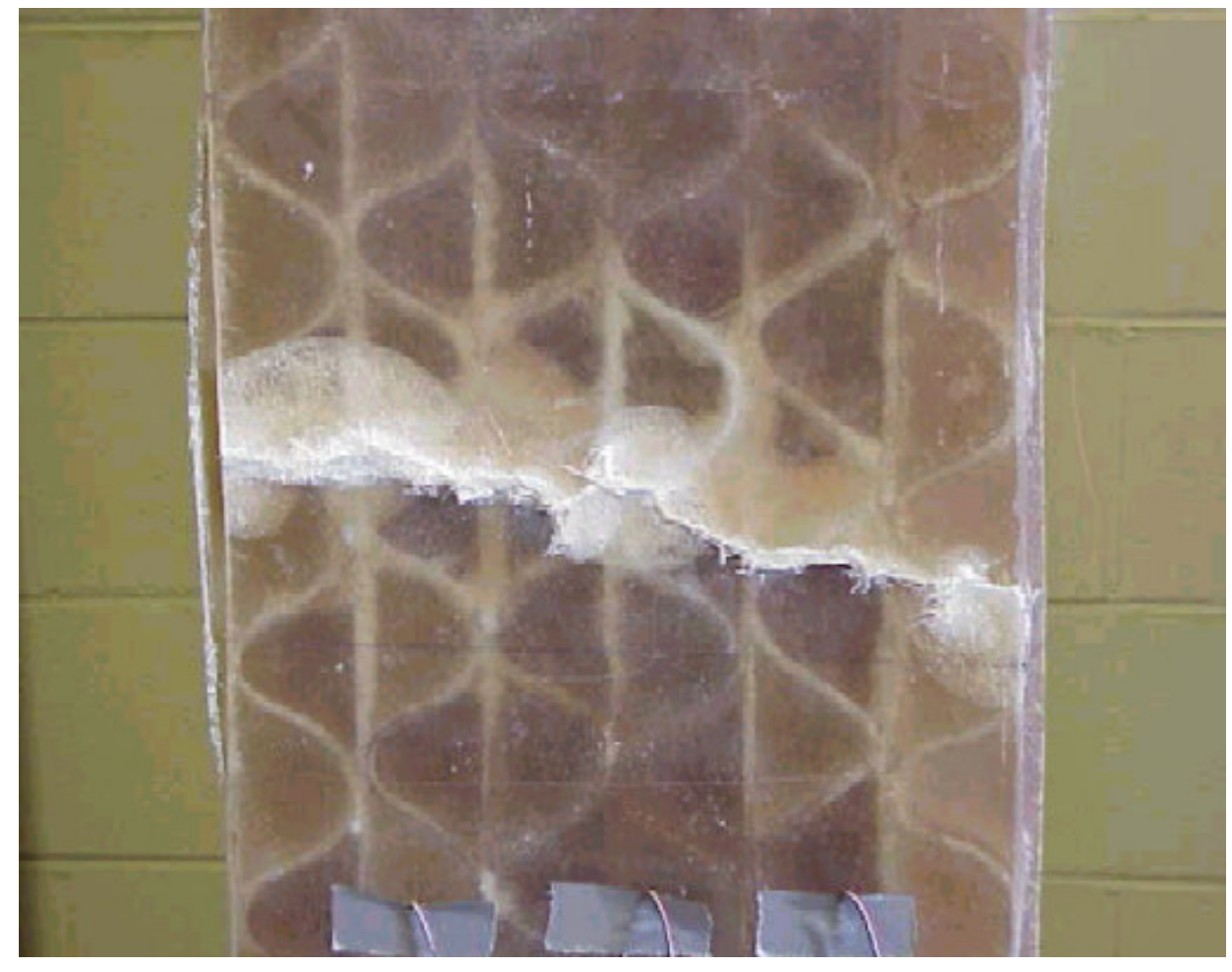

Figure 6.6 Material Failure 


\subsection{Conclusions}

From Table 6.3, it can be seen that the factors of safety for the bottom panel are very high for deflections, because the raceway rests over closely spaced transverse supports placed on the ground, thus limiting bottom panel deflections. For the side panel, the factors of safety in the linear region due to deflection range from 1.7 to 2.7 and due to strain range from 4.0 to 5.0, while the factors of safety for failure due to deflection range from 5.5 to 9.8 and due to strain range from 8.3 to 24.3 . These results indicate that the panels and connections can withstand failure with reasonable factors of safety. 


\section{Chapter 7}

\section{Modeling of Complete Raceway}

\subsection{Introduction}

It is not feasible to experimentally test the raceway unit behavior in laboratory conditions due to cost and complexity of the work. For this reason, a finite element model of the complete raceway unit was developed, which can be subjected to any loading and boundary conditions suggested by the user. From the results of the experimental testing and comparisons with the finite element models discussed in the preceding chapters, it was decided that the complete raceway can be confidently modeled using equivalent properties. Also various degrees of rigidity for the connection of the main tank to the

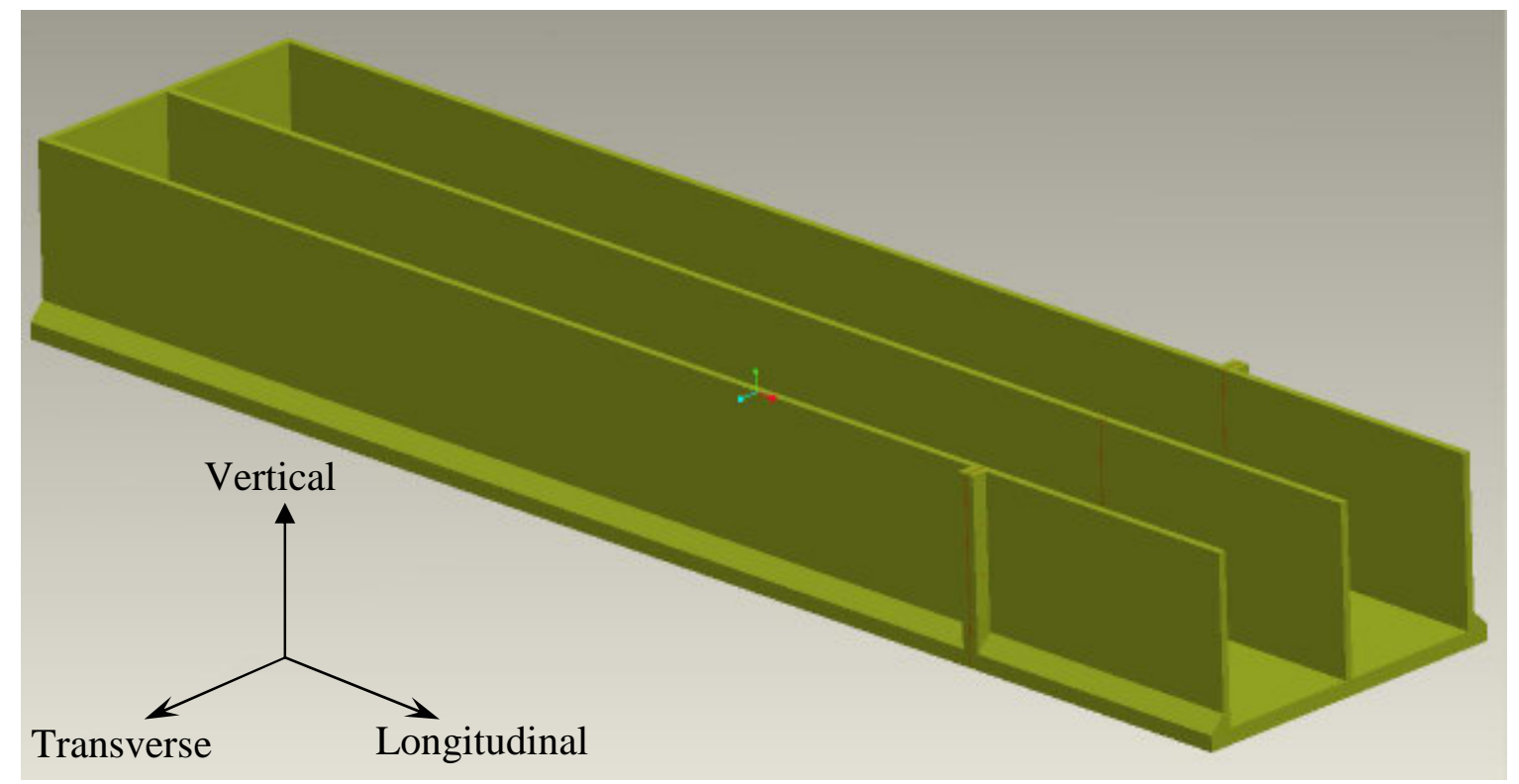

Figure 7.1 Complete Raceway Unit 
quiescent zone were analyzed to evaluate its performance. This chapter deals with the finite element modeling details of the raceway unit, various analyses performed on the model and their results, and possible applications of the model. 3D- view of a complete raceway is shown in Figure 7.1. The figure also shows the terminology for directions of the tank, according to which, the longitudinal direction is along the length of the tank, transverse direction along the width of the tank and the vertical direction is along the height of the raceway.

\subsection{Finite Element Modeling of the Raceway}

\subsubsection{Model Dimensions}

The complete raceway is modeled using the dimensions of the actual raceway shown in Figure 1.10, but with the addition of stiffeners for the outer side-to-bottom

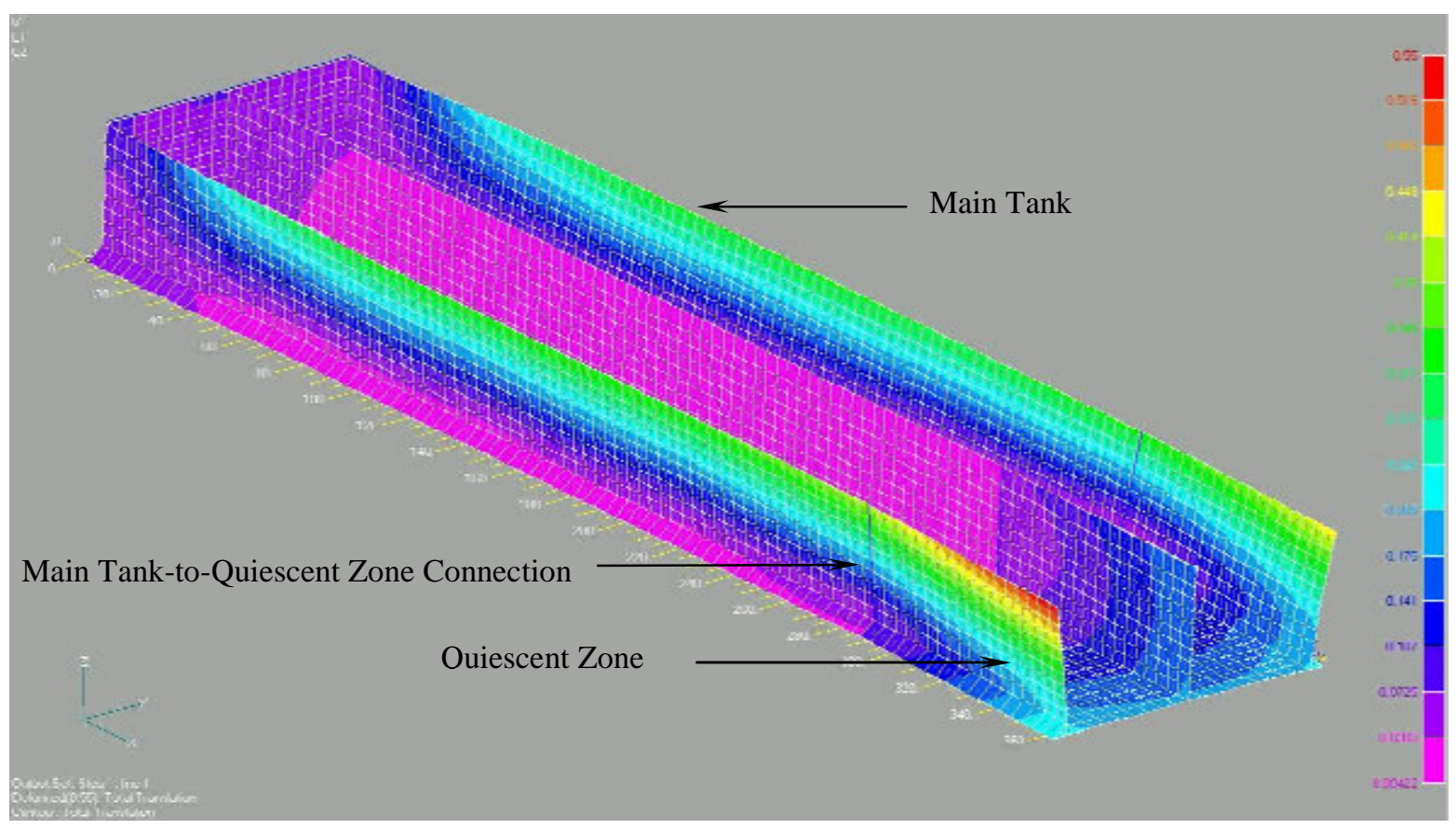

Figure 7.2 Finite Element Model of the Raceway 
panel connection. It is developed as two sections, the 24-foot long main tank and the 6foot long quiescent zone. Each section is divided longitudinally into two 3-foot wide parallel channels separated by an interior panel. The stiffened side-to-bottom panel connection detail was used for the exterior side panels, while the interior panel was formulated using the unstiffened connection type. The side panel rises 42 " from the interior of the bottom panel. An FE model of the complete raceway model is shown in Figure 7.2.

\subsubsection{Connection Design}

Four types of connections of the main tank to the quiescent zone are considered. The first model simulates the actual raceway installed at Dogwood Lakes, where the two sections are joined using three bolts on each outer panel. The second connection design assumes the failure of the top bolt joining the outer panels. The third model assumes complete connectivity of the joint, while the fourth design assumes the connectivity of the joint till mid height of the side panels. These conditions are analyzed to evaluate the connection design and to verify the strength of the connection in practice.

\subsubsection{Mesh Selection}

To simplify the model, equivalent core properties are used to simulate the complete raceway. The mesh size used in the beam and connection models in the previous chapters was 0.2 "x0.2". The complete fish tank could not be modeled using 
such a fine mesh because of computational difficulties resulting from the large number of elements and nodes. Hence a coarser mesh had to be utilized, consisting of 4"x4"mesh size to model selected experimental beam and connection samples, and the convergence of results is studied and the deflection results are provided in Table 7.1. The study shows that the results did not vary much with the increase in mesh size. Also, the differences in results for a three-node and four-node elements was also studied, which indicated that the shape of the elements did not influence the results to any considerable extent. This study indicated that the whole tank could be modeled using the coarser mesh size and quadrilateral elements instead of triangular elements, which would decrease computational effort.

Table7.1 Comparison of Results for a Side Panel Transverse Section for Central Deflections

\begin{tabular}{|c|c|c|}
\hline & $\begin{array}{c}\text { Triangular Element } \\
\text { (inch) }\end{array}$ & $\begin{array}{c}\text { Quadrilateral Element } \\
\text { (inch) }\end{array}$ \\
\hline Fine Mesh & 0.0505 & 0.0505 \\
\hline Coarse Mesh & 0.05046 & 0.05 \\
\hline
\end{tabular}

\subsubsection{Loads}

For the analysis, hydraulic loads along with other miscellaneous loads, like people leaning on the raceway walls, are considered. Water is assumed to be static in the tanks for the calculation of the loads. This is justified because of the low flow rate of water. The Hydraulic pressure is given by 
Pressure $=\gamma \mathbf{x} \mathbf{h}_{\mathrm{c}}$

Where $\gamma=$ specific weight for water $\left(62.4 \mathrm{lb} / \mathrm{ft}^{3}\right) ; \mathrm{h}_{\mathrm{c}}=$ Depth of water at centroid

The Hydraulic force is given by

Force $=$ Hydraulic pressure $x$ Area

If the depth is divided into $n$ sections, pressure at a section $\mathrm{i}(\mathrm{i}<\mathrm{n})$ is given by

$\mathbf{P}_{i}=\mathbf{P}_{i-1}+\left(\gamma \mathbf{x} \mathbf{h}_{c}\right)$

Using the above concepts, the hydraulic pressure acting on various nodes of the side panel vary from $0 \mathrm{lb} / \mathrm{in}^{2}$ at the free water surface ( 36 " from the base) to $6.67 \mathrm{lb} / \mathrm{in}^{2}$ at the bottom of the tank. The effective area of application of this pressure is found and the effective nodal loads are calculated and applied on the panels. The pressure on the bottom panel due to water standing to a height of 36" is calculated and applied. Also, forces assumed to be from people of average weight of $180 \mathrm{lb}$ standing inside the tank and leaning on the walls is applied.

\subsubsection{Boundary Conditions}

Two types of boundary conditions are considered. The first assumes that the tank completely rests on the ground. The second assumes that the bottom of the tank rests intermittently on the ground, with supports placed at a distance of 6 feet from each other and the quiescent zone completely overhanging. These two conditions represent the optimal and the most extreme conditions in which the tank can be installed. 


\subsubsection{Reported Results}

For all types of main tank to connection joints studied, the results for maximum deflection and strains are reported. Maximum strains are reported for the vertical direction at the side-to-bottom panel connection and for the longitudinal direction at the main-tank-to-quiescent zone joint. The vertical strain indicates the bending strains on the side panel due to the loads, while the longitudinal strain indicates the deformations induced due to the effect of the connectors (bolts) at the joint. Also, maximum transverse deflections are reported for the side panel for all models and maximum vertical deflection for the bottom panel is reported for intermittently supported models. Maximum opening of the two sections of the tank at the joint for all the joint designs is evaluated. The behavior for combinations of various boundary and loading conditions is also predicted and reported.

\subsection{Dogwood Lakes Simulation}

\subsubsection{Modeling}

The following provides a model for the existing case at Dogwood Lakes. The main raceway is connected to the quiescent zone using three bolts on the outer surfaces of the exterior panels (Figure 7.3). The tank rests completely on the ground. A person of average height of $5^{\prime} 10^{\prime \prime}$ and weighing $180 \mathrm{lb}$ is considered to be standing at the center of the quiescent zone and leaning against the center panel. The tank holds water up to a height of 3 '. 


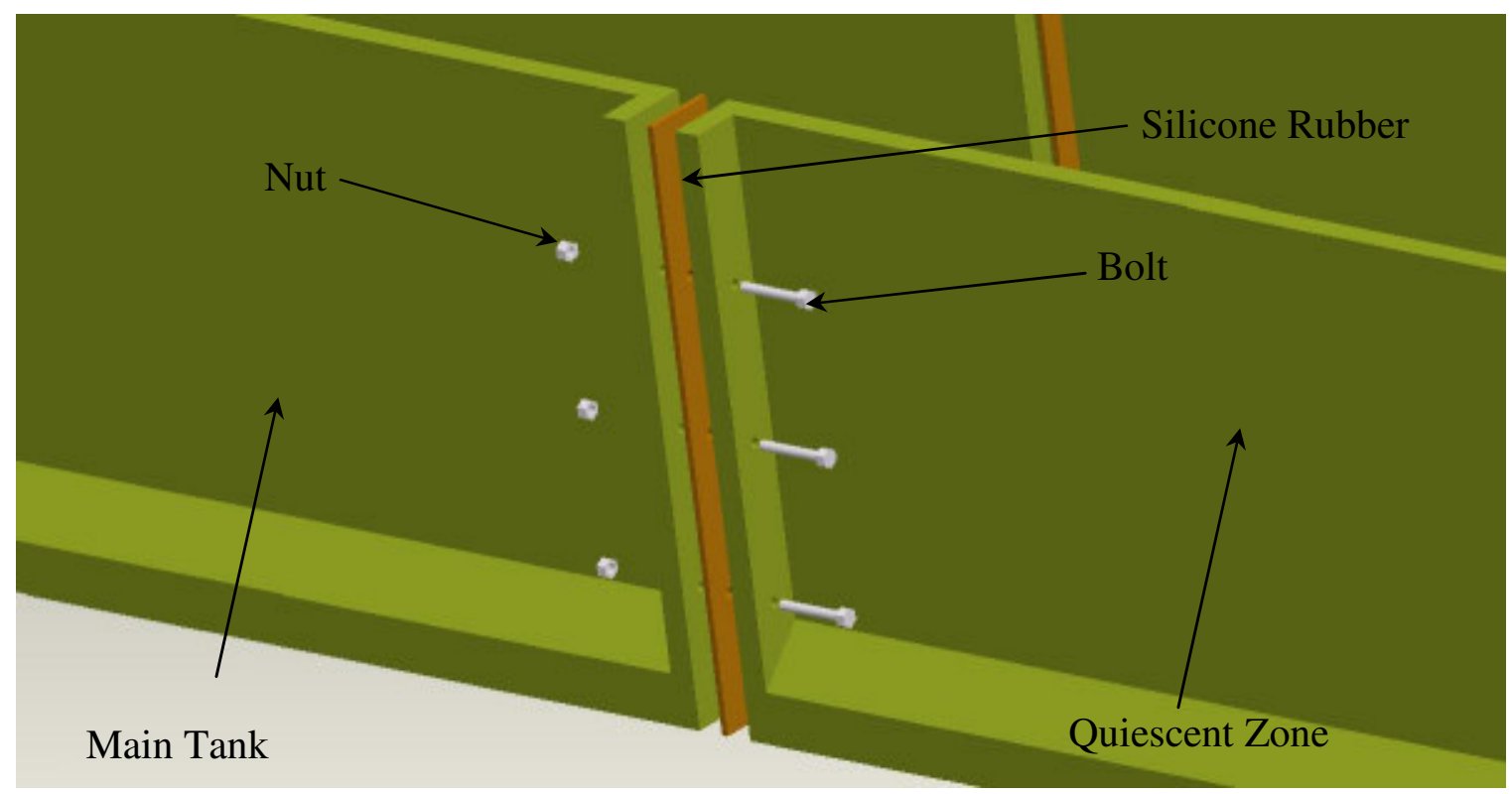

Figure 7.3 Main Tank-to-Quiescent Zone Connection at Dogwood Lakes

The results reported in Table 7.2 are the maximum overall openings at the main tank-to-quiescent zone connection for the outer panels and for the inner panel, maximum transverse deflection at the main tank-to-quiescent zone connection, maximum transverse deflection of the outer panel at the end of the raceway and maximum longitudinal and vertical strains in the tank.

Table 7.2. Results of FE Model Simulation of Dogwood Lakes Raceway Units

\begin{tabular}{|c|c|c|c|c|c|c|c|}
\hline \multicolumn{2}{|c|}{ Maximum Opening at Connection, in } & $\begin{array}{c}\text { Maximum Transverse } \\
\text { Deflection at } \\
\text { Connection, in }\end{array}$ & $\begin{array}{c}\text { Maximum } \\
\text { Transverse } \\
\text { Deflection } \\
\text { at End of } \\
\text { Raceway, } \\
\text { in. }\end{array}$ & \multicolumn{2}{|c|}{$\begin{array}{c}\text { Maximum Strain, } \\
\text { microstrain }\end{array}$} \\
\cline { 5 - 8 } Outer Panel & Inner Panel & Bottom Panel & Outer Panel & Inner Panel & $\begin{array}{c}\text { At Bolted Joint } \\
\text { (Longitudinal) }\end{array}$ \\
\hline 0.005 & 0.02 & 0 & 0.26 & 0.028 & 0.281 & 615 & 446 \\
\hline
\end{tabular}




\subsubsection{Discussion of Results}

The maximum opening at the main tank to quiescent zone joint is found to be 0.005 " for the outer panel and 0.02 " for the inner panel. The maximum opening for the outer panel is observed between the two bolts at the top. It can be inferred from these results that the opening is not big enough for water to leak out of the raceway, since a half inch thick elastomeric pad is used at the joint as shown in Figure 7.3. The maximum opening for the center panel, against which a person is assumed to be leaning, was estimated as 0.02 ". For all the boundary conditions and connections tested, the maximum opening for the center panel was found out to be 0.05 ", which is insignificant.

The strains for the tank were also evaluated, and the maximum value is the vertical strain of the side panel near the panel-to-panel joint, which is 615 micro strains. This is well within the elastic limit of the material and hence would not cause any failure. Assuming an error of $20 \%$ in the results for deflections and strains for the equivalent property models, as reported in Chapter 5, the maximum strain would be about 770 micro strains, which is still below the elastic limit of the material.

\subsection{Comprehensive Raceway Simulations}

From the above discussion, we can see that for the actual case in Dogwood Lakes, the model indicates no concern with failure of the tank or water leaking out of the connection joint. The maximum deflection is also within the elastic limit. A summary of 
results for other conditions is reported in Table 7.3, which includes both fully supported boundary condition and intermittent boundary condition, for which the raceway rests over narrow strips at discrete locations along the bottom of the tank.

Table 7.3 Behavior of the Tank Under Various Loading and Boundary Conditions

\begin{tabular}{|c|c|c|c|c|c|c|c|c|c|c|c|}
\hline \multirow{3}{*}{$\begin{array}{l}\text { Main tank to } \\
\text { Quiescent } \\
\text { Zone } \\
\text { Connection }\end{array}$} & \multicolumn{4}{|c|}{$\begin{array}{l}\text { Maximum deflection at } \\
\text { connection }\end{array}$} & \multicolumn{3}{|c|}{$\begin{array}{c}\text { Maximum Transverse } \\
\text { Deflection }\end{array}$} & \multicolumn{4}{|c|}{ Maximum Strain } \\
\hline & \multicolumn{2}{|c|}{ outer panel } & \multicolumn{2}{|c|}{ inner panel } & \multirow{2}{*}{ FS } & \multicolumn{2}{|c|}{ IS } & \multicolumn{2}{|c|}{ Vertical } & \multicolumn{2}{|c|}{ At Bolted Joint } \\
\hline & FS & IS & FS & IS & & side & bottom & FS & IS & FS & IS \\
\hline \multicolumn{12}{|c|}{ Water in both channels } \\
\hline 3 Bolts & 0.26 & 0.34 & 0.028 & 0.076 & 0.281 & 0.383 & 0.135 & 615 & 1150 & 446 & 1277 \\
\hline 2 Bolts & 0.22 & 0.29 & 0.03 & 0.03 & 0.29 & 0.44 & 0.28 & 874 & 1140 & 170 & $2028 *$ \\
\hline $\begin{array}{l}\text { Completely } \\
\text { fixed }\end{array}$ & 0.26 & 0.345 & 0.016 & 0.27 & 0.28 & 0.44 & 0.078 & 578 & 978 & - & - \\
\hline $\begin{array}{l}\text { Fixed till } \\
\text { mid height }\end{array}$ & 0.23 & 0.29 & 0.023 & 0.024 & 0.29 & 0.46 & 0.17 & 540 & 615 & - & - \\
\hline \multicolumn{12}{|c|}{ Water in one channel } \\
\hline 3 Bolts & 0.23 & 0.312 & 0.33 & 0.36 & 0.436 & 0.47 & 0.094 & 890 & 1260 & 293 & 852 \\
\hline 2 Bolts & 0.31 & 0.35 & 0.21 & 0.38 & 0.27 & 0.38 & 0.22 & 917 & 1500 & 153 & 1208 \\
\hline $\begin{array}{l}\text { Completely } \\
\text { fixed }\end{array}$ & 0.215 & 0.28 & 0.293 & 0.32 & 0.375 & 0.45 & 0.073 & 951 & 912 & - & - \\
\hline $\begin{array}{l}\text { Fixed till } \\
\text { mid height }\end{array}$ & 0.185 & 0.26 & 0.328 & 0.348 & 0.43 & 0.46 & 0.146 & 884 & 948 & 100 & 871 \\
\hline
\end{tabular}

Note: FS is Fully Supported boundary condition

IS is Intermittently Supported boundary condition

* Maximum Strain Observed

It can be seen that if the main tank is connected to the quiescent zone using only two bolts on either side and if the tank rests intermittently on the ground, the maximum strain at the joint is more than 2000 micro strains (Figure 7.4), which is the highest in all the cases studied. Assuming a $20 \%$ error in reporting the results due to the use of equivalent properties (as mentioned in Chapter 5), the maximum strain at the joint is about 2550 micro strains. This value exceeds the linear limit of strain for the material. 
This condition simulates the possibility of either improper connection or failure of the top bolt. Thus it can be observed that the three bolt system is better suited for the joint and if the top bolt fails, the connection itself can exhibit localized failure.

Figure 7.5 shows maximum opening at water level and maximum deflection of side panel. Also, when water flows through a single channel, Figure 7.6, it is observed that the maximum strain developed on the interior panel-to-panel connection is 1500 micro-strains, which is well within the elastic limit of the material.

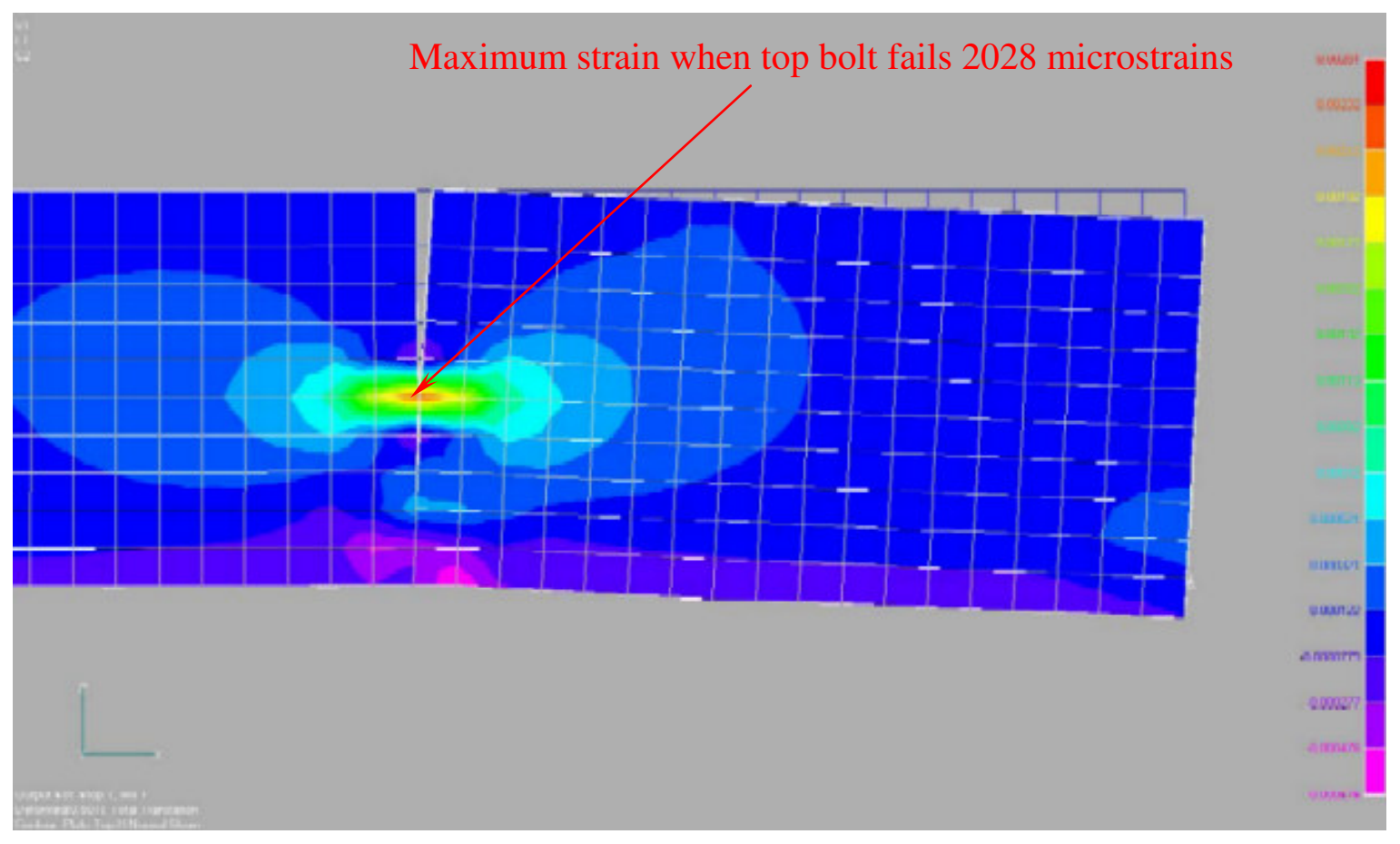

Figure 7.4 Transverse Stress at the Top Bolt when Only Two Bolts are Used at the Connection 


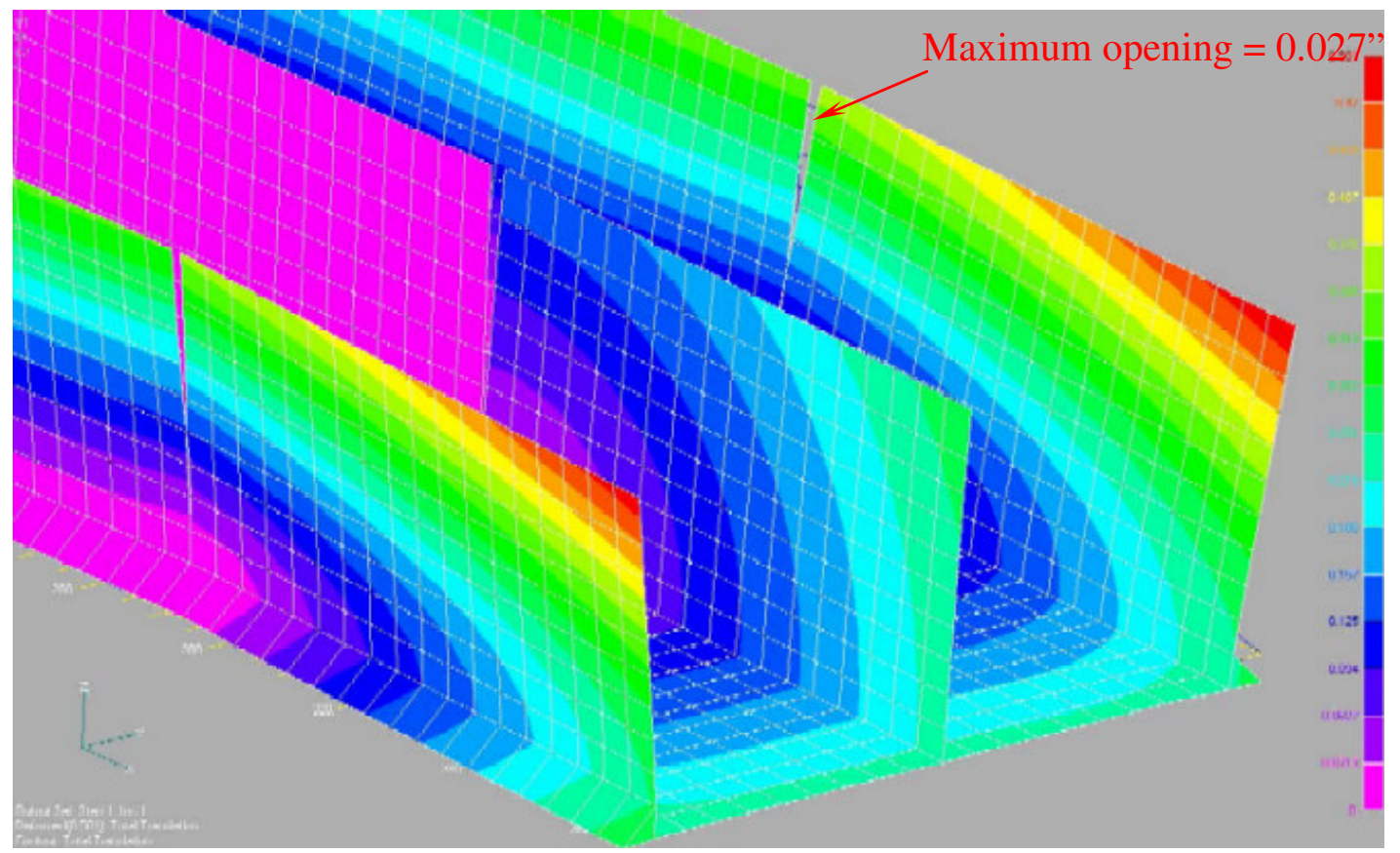

Figure 7.5 Maximum Deflection at the Joint

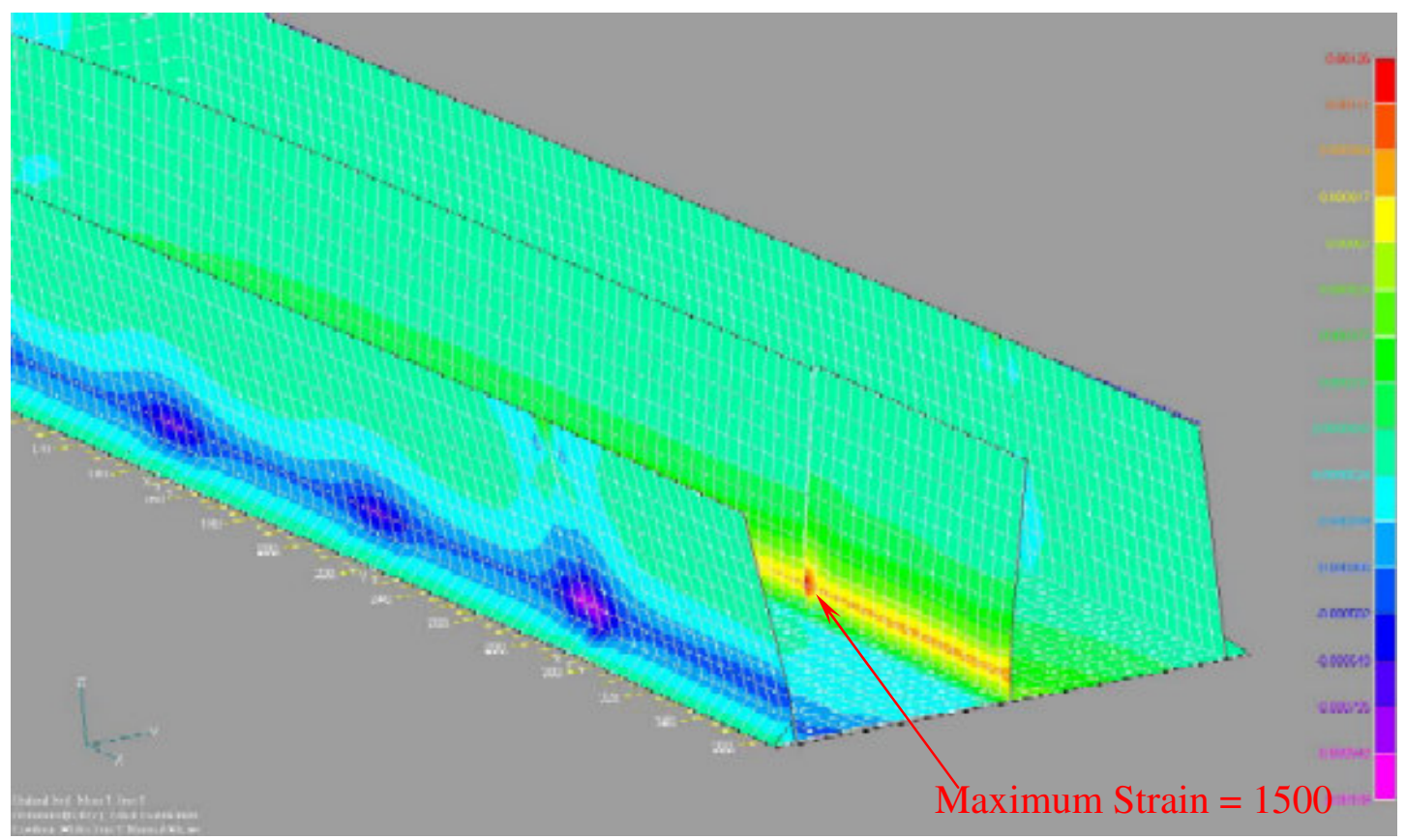

Figure 7.6 Strains and Deflections when Water Flows Through a Single Channel 


\subsection{Conclusions}

From the finite element modeling of the complete raceway, it can be seen that the design is satisfactory to withstand all the expected loads during and after installation of the raceways. It is also observed that the three bolt connection is sufficiently strong for the studied boundary conditions, but if the top bolt fails, there is a possibility that the whole joint may fail, when the tank is intermittently supported with the quiescent zone completely overhanging. The best way to avoid such a situation is to place the raceway in such a way that the whole bottom panel rests completely on the ground. Studies of water flowing through only one channel show that the strains are well within the elastic limit of the material under all expected loading conditions. 


\section{Chapter 8}

\section{Field Implementation of HFRP Raceway Systems}

After the testing of the beam and connection samples, design modifications to the raceways were suggested. Three sets of raceways were installed in West Virginia and Pennsylvania. This chapter provides a brief overview on the three field projects currently underway. It should be noted that this chapter deals with the applications of HFRP raceway systems and the raceways were set up with the help of various contractors.

\subsection{Transportability}

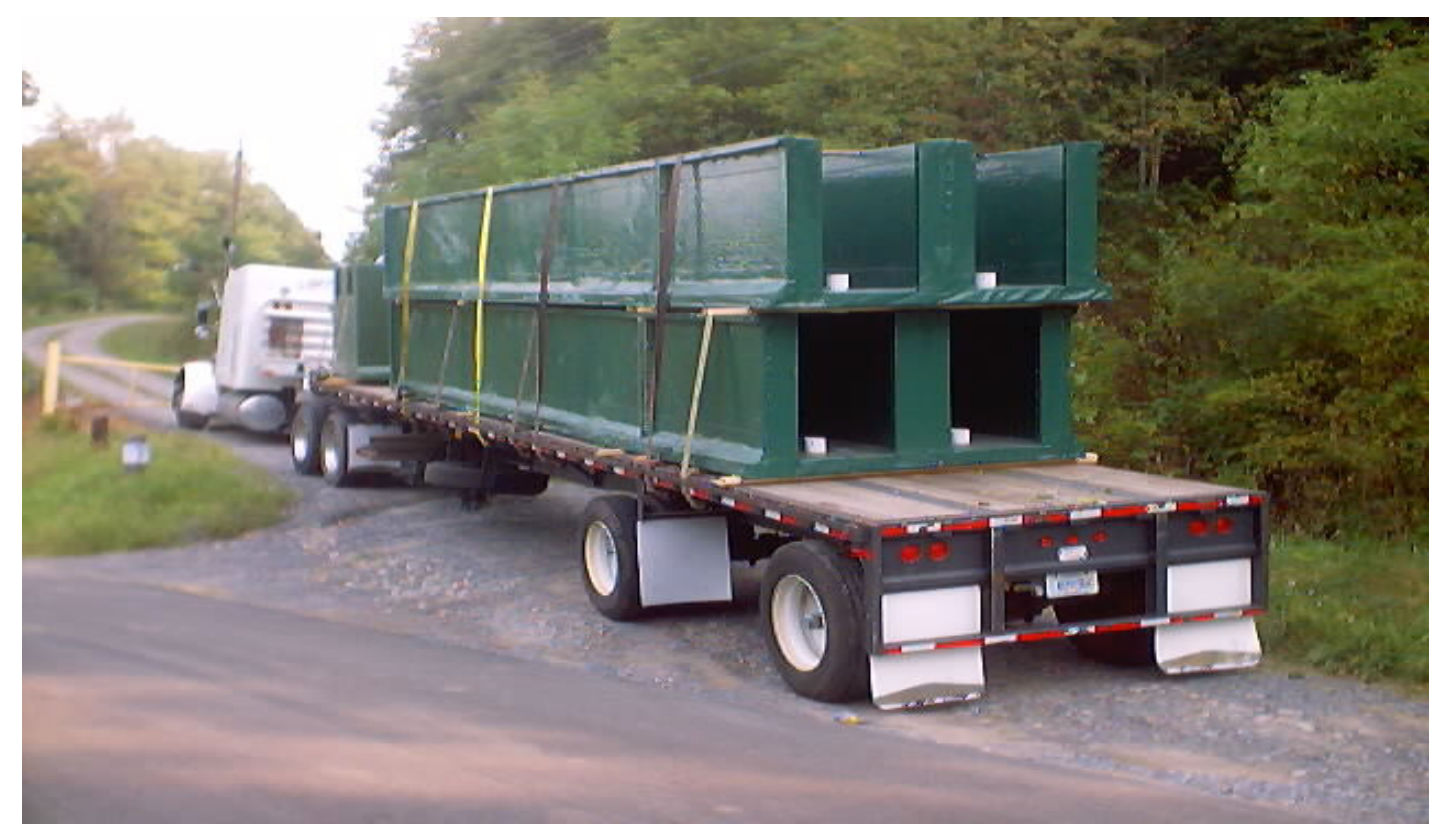

Figure 8.1 Transportation of Fish Racewavs 
One of the prime purposes of using HFRP raceways is that they are light weight and can be easily transported from one location to another. Figure 8.1 shows that the tanks can be stacked on top of each other while they are transported from the manufacturing plant in Russell, KS to other locations. In Figure 8.2, we can see that the tanks are lightweight and rugged and can be easily moved using light equipment during installation.

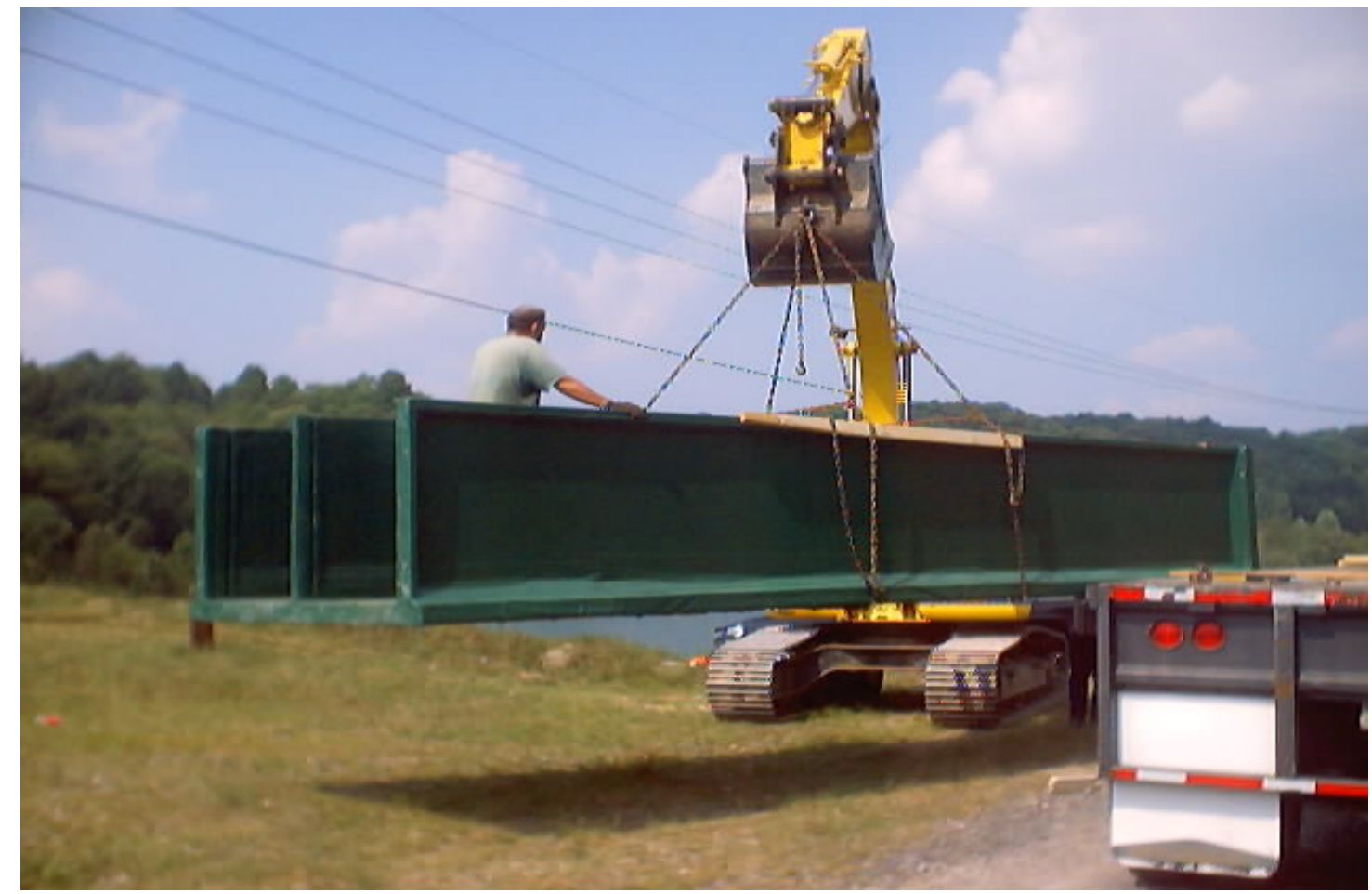

Figure 8.2 Unloading of Tanks from the Trailers

\subsection{Accomplished Projects}

Modular Honeycomb FRP raceways have been installed at three locations in and around West Virginia and Pennsylvania. The first site to implement HFRP raceway units is located at the Dogwood Lakes water treatment facility near Morgantown, West 
Virginia, which is owned by Consolidated Coal Company. The second site is Reymann Memorial Farm in Wardensville, West Virginia, a research facility managed by WVU. While the terrains and water sources at these two sites are different, they both share the need for a modular and transportable raceway system. A third set of tanks are installed as floating raceways at Warwick mine water treatment facility in Greene County, Pennsylvania. The floating raceways can float inside a pond and have a different design compared to the above designs installed over ground.

\subsubsection{Dogwood Lakes}

Dogwood Lakes is an acid mine water treatment facility near Morgantown, WV. Acid mine water treated with various chemicals is collected in afinishing pond where the solids precipitate. The purified water is then discharged into a stream. The terrain at Dogwood Lakes is very rugged, making it nearly impossible to use conventional concrete tanks. Moreover, the coal company will not allow permanent structures to be built at this site, thus the decision to use transportable HFRP raceways. Following is a brief description of the facility, raceway installation details, problems encountered and prescribed solutions to the problems.

The site chosen for the raceway placement was a small plot of wooded hillside, loaned to West Virginia University by Consolidated Coal Company. Figure 8.3 shows the terrain at the designated location after initial clearing, but before any ground work was started. It can be clearly seen that the terrain is steep and rugged, making it necessary to 


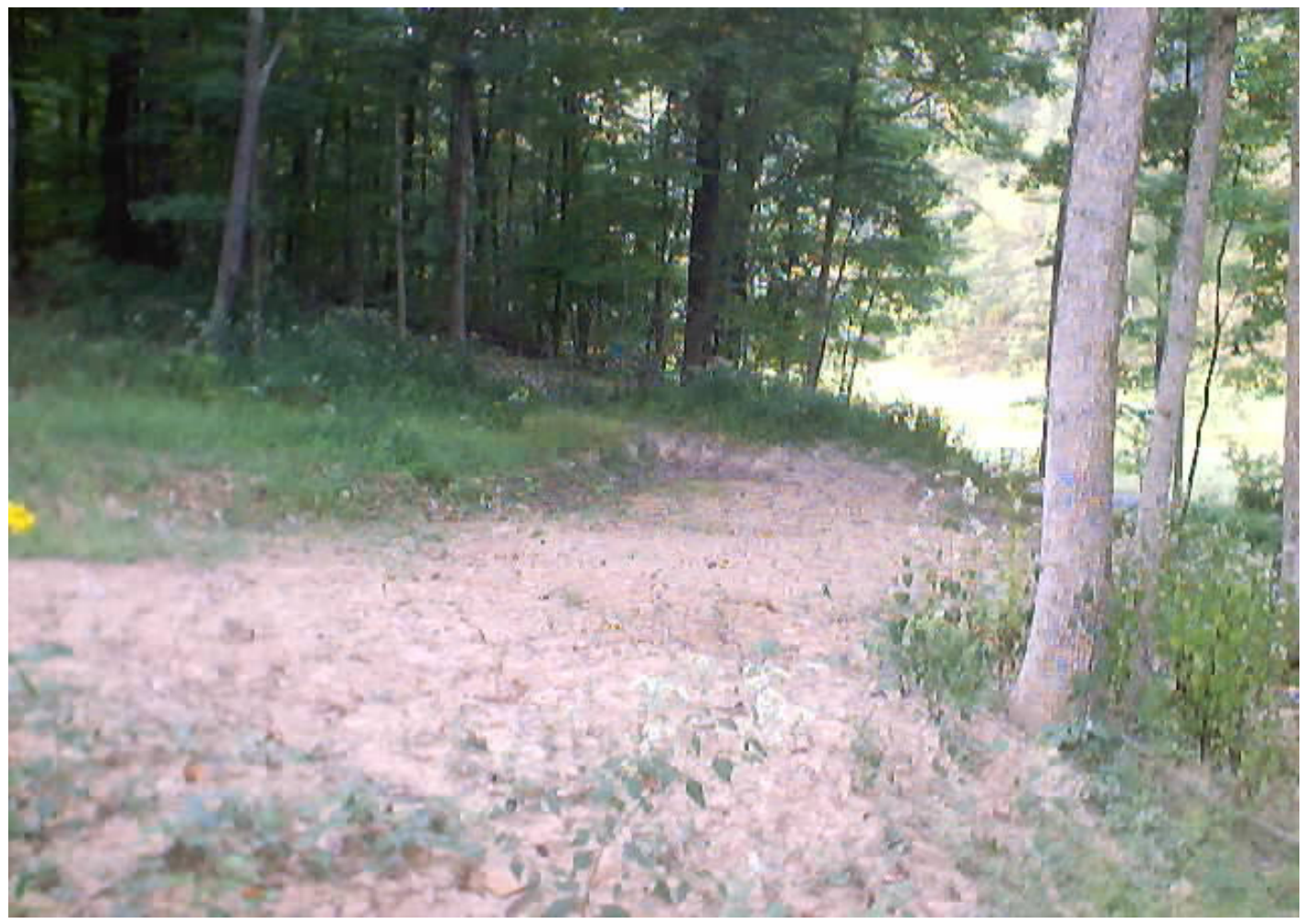

Figure 8.3 Terrain at Dogwood Lakes

install HFRP tanks. The Dogwood Lakes location was selected because of the results from previous studies performed at the site, which indicated acceptable water quality for healthy fish growth and a high water flow rate. It was decided that a set of four staggered tanks would be placed in series, the end of one tank resting on the top of the next tank. Water is first allowed to collect in a distribution box, which diverts it into the two parallel channels of the first raceway. After water flows through the first raceway, it falls into the next set of tanks thus making it a continuous cascading flow system. 


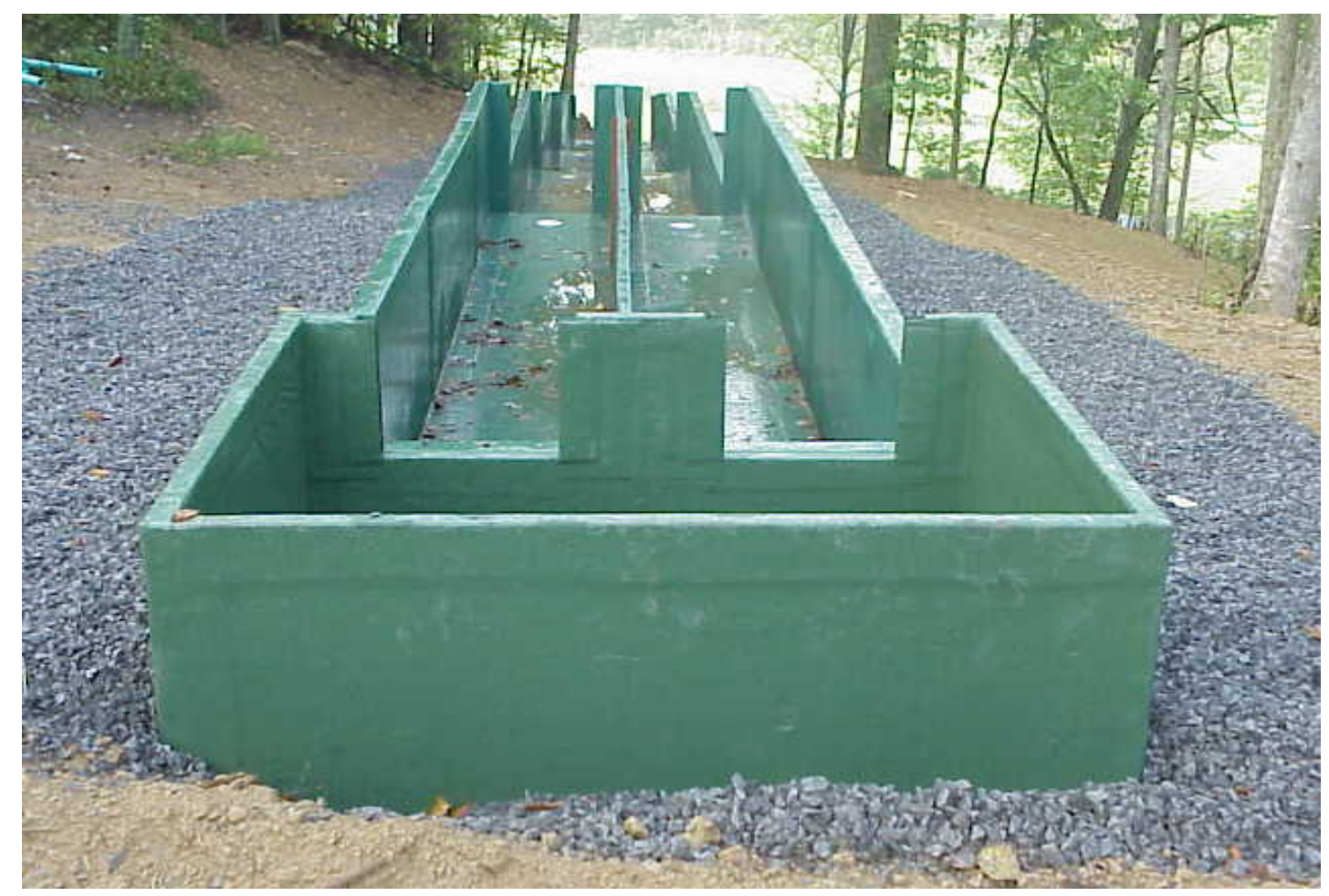

Figure 8.4 Tanks after Installation

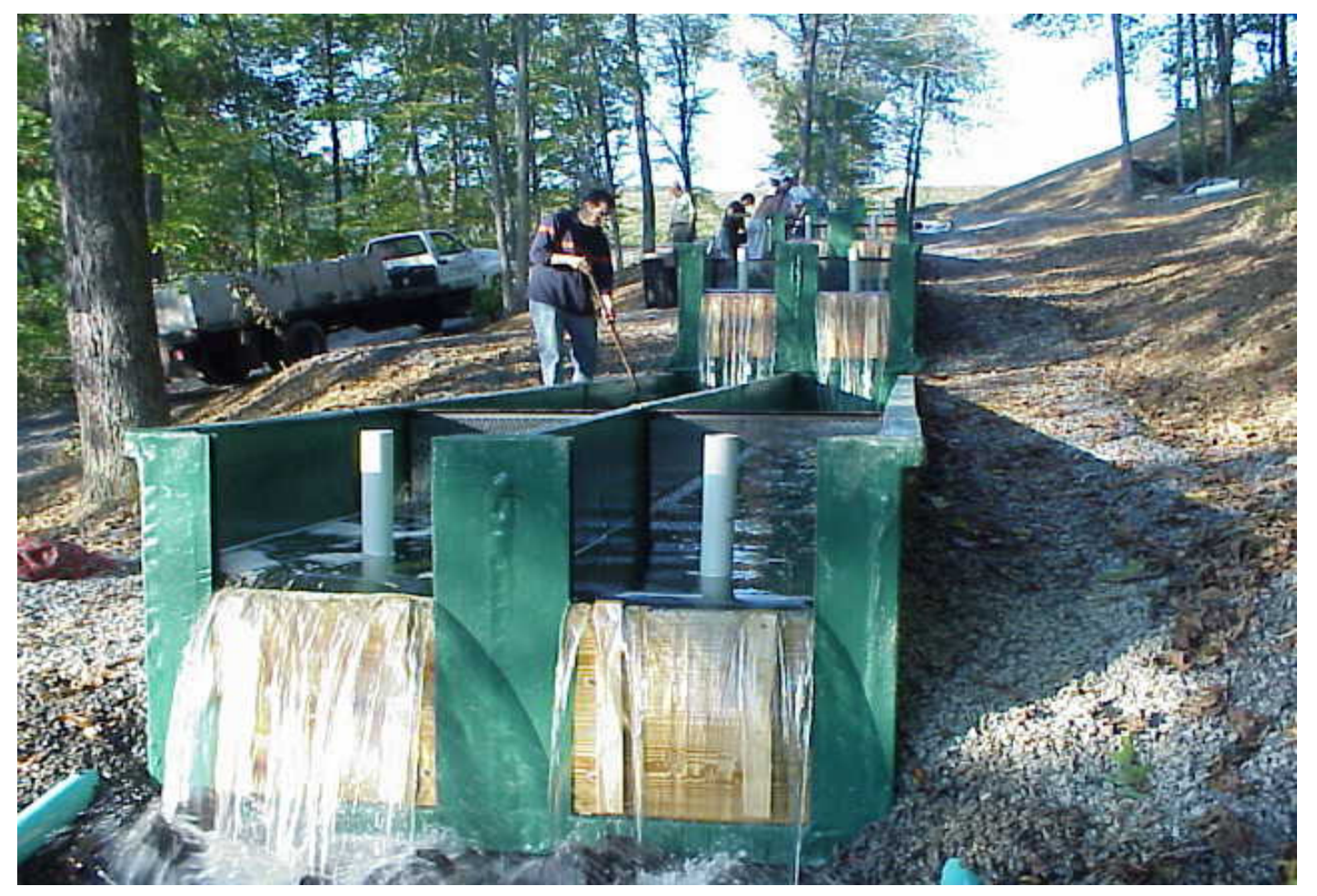

Figure 8.5 Completed Project 
The terrain had to be cut into four flat step-wise sections, one for each raceway. A slight drop to allow the flow of water was maintained throughout. Each tank rested perfectly on the ground over a gravel bed, minimizing excessive stresses and deflections. Figure 8.4 shows the final installation of the tanks, without the water flowing. After all the necessary piping was installed, the water was allowed to flow through the tanks, which were inspected for defects. Minor problems like leakage of water into the honeycomb core and at the joints were taken care using a polymer adhesive. After all the field problems were addressed, the fish were transferred into the tanks, enabling aquaculture studies. Figure 8.5 shows the functional tanks at Dogwood Lakes.

\subsubsection{Reymann Memorial Farm}

The location of the second HFRP raceway system is at Reymann Memorial Farms in Wardensville, WV. This is an agricultural research facility maintained and operated by WVU. This raceway system is being used as a research and demonstration facility, in which fish growers have the opportunity to examine and consider using the HFRP raceway units and system. There are several fresh-water springs on the farm, one of which provides the source of water for the system.

There are marked differences between the Dogwood Lakes and Reymann Memorial Farms sites. At Dogwood Lakes, there is a significant elevation drop and abundant water resource. The Wardensville site has very little elevation drop, and a water flow rate of about $1 / 3$ of the Dogwood Lakes site. Thus, the construction of the 
raceway system at Reymann Memorial Farms posed several new and interesting challenges.

Because of the gentle slope of the terrain, the drop between two adjacent tanks is much less compared to the tanks at Dogwood Lakes as shown in Figure 8.6. Part of the spring water is diverted into a collection box from where it is allowed to evenly flow through the 4-tank raceway system. After the water flows through all the four raceways, it is emptied into a pond. The raceway design is similar to that at Dogwood Lakes., but the quality and workmanship of this system is much better. Also, the coonection of the quiescent zone was simplified using external steel angles. A close-up view during unloading of the tanks is shown in Figure 8.7.

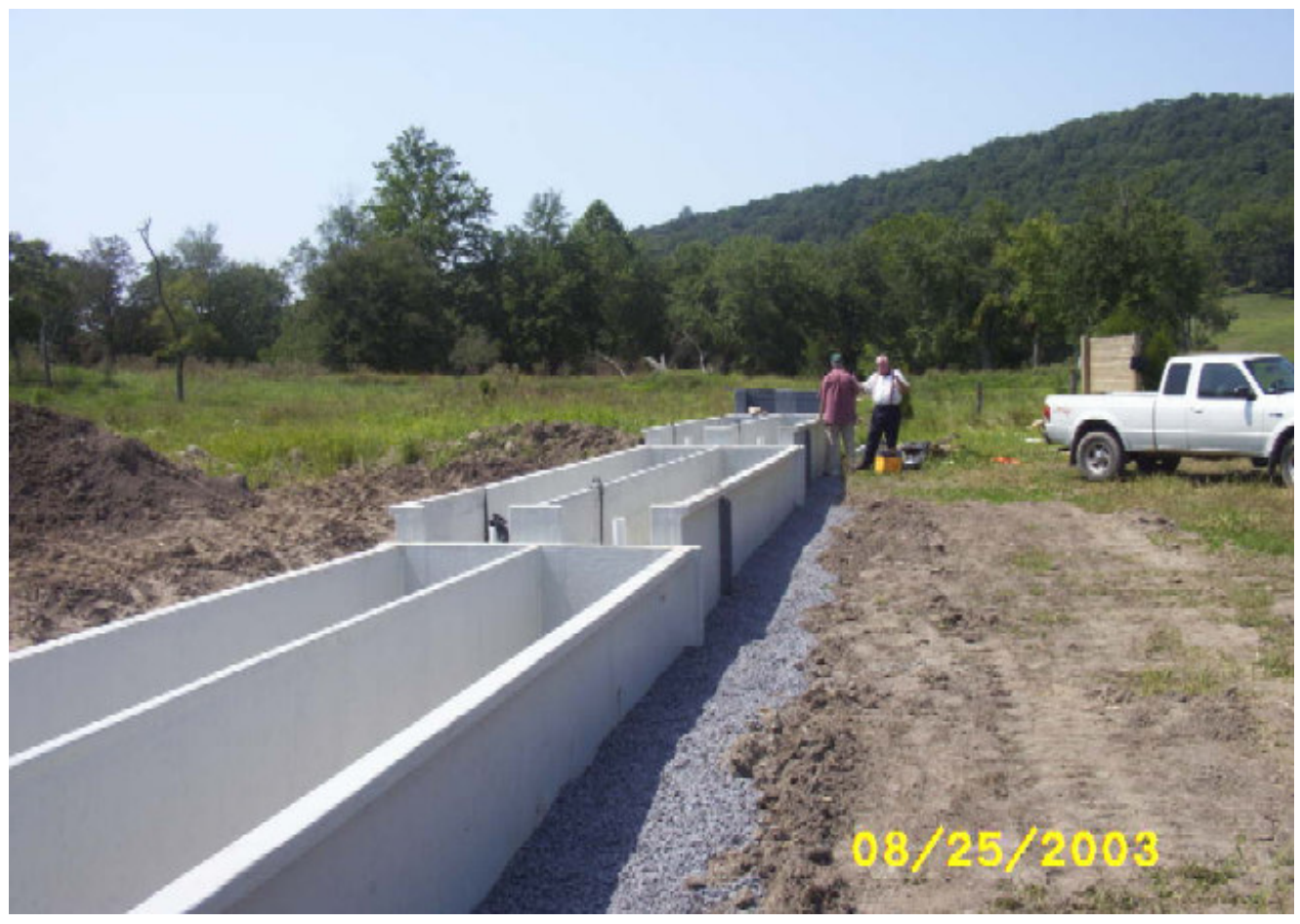

Figure 8.6 Installation of Raceways at Wardensville 


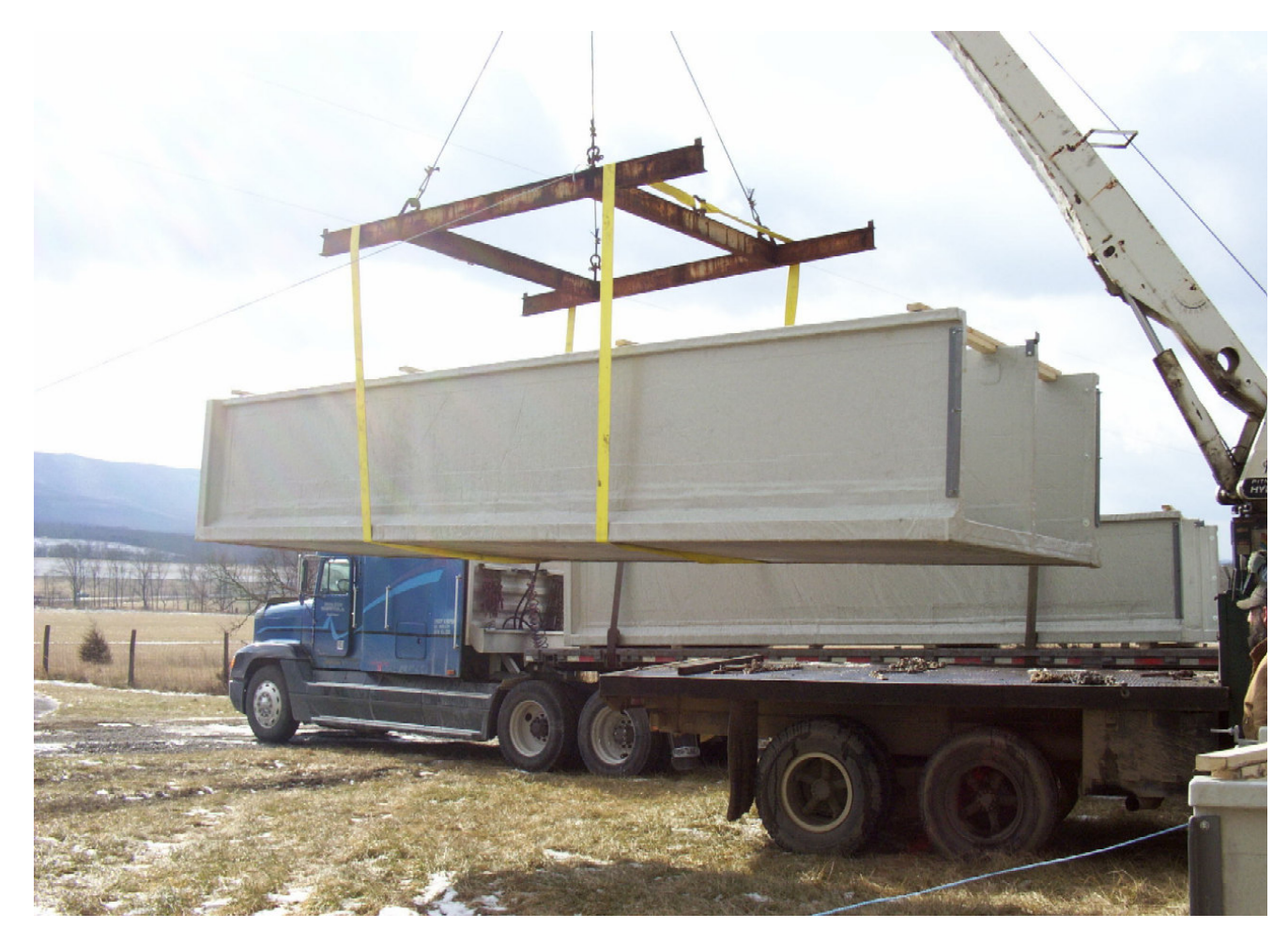

Figure 8.7 Unloading of Raceways at the Facility

\subsubsection{Floating Raceways}

Water discharged from coal mines is an underutilized resource for production of trout in Appalachia. At numerous sites throughout West Virginia, Pennsylvania and Maryland, mine drainage (whether acidic or alkaline) is collected and routed through treatment plants where the acidity or alkalinity are neutralized and metals are removed

The suitability of a given pond for trout production is a function of flow rate, water quality and temperature (among other factors). In many mine water treatment systems, polishing ponds are too large to maintain water temperatures within acceptable 
ranges and sufficient flow rate to keep trout supplied with oxygenated water. Through the use of HFRP floating raceways, it should be possible to effectively use ponds while concentrating the water flow through raceway systems, which would deliver colder, oxygenated water directly to the trout, regardless of the size of the pond. It would also allow the trout producer to collect the solid wastes at the end of each raceway before it is dispersed throughout the pond. These advantages should help to promote trout production at these water treatment facilities.

As part of this effort, a floating raceway unit was installed at the Warwick Mine Water Treatment Plant in Greene County, Pennsylvania (Figure 8.8). Before the installation of the floating raceways, the treatment plant used net-pens as shown in Figure 8.8. But waste removal from these pens is not possible and many fish fatalities were reported because of the waste settling in the bottom of the pool and polluting the water.

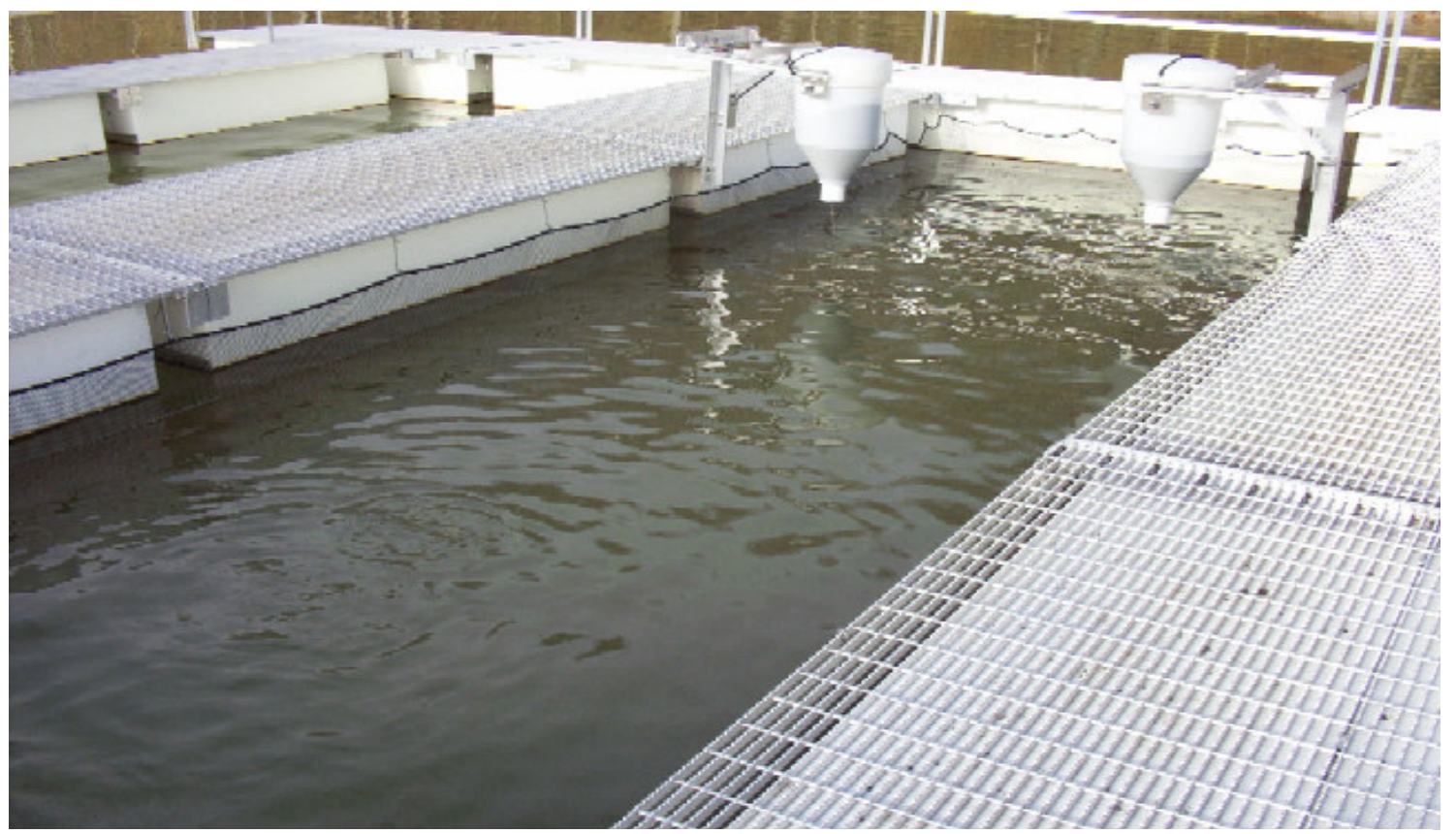

Figure 8.8 Net-Pens Used at Warwick Mine Water Treatment Plant 
Hence it was decided that HFRP sandwich composites can be used with a modified quiescent zone, which will allow the wastes to be directed out of the raceway, thus reducing the level of fish wastes in the pond.

The WVU researcher team came up with a modification to the existing system and developed the floating HFRP raceways (Figure 8.9). The tanks are submerged in a pond and are fitted with all adjustable ballast to permit the tank to float above the water level, which is needed to safely keep the fish inside the tank and to dispose of the fish waste without contaminating the pond. Modifications to the quiescent zone were also made and tests on the new design will be carried out. Figure 8.10 shows the floating raceways in service at the Warwick treatment facility.

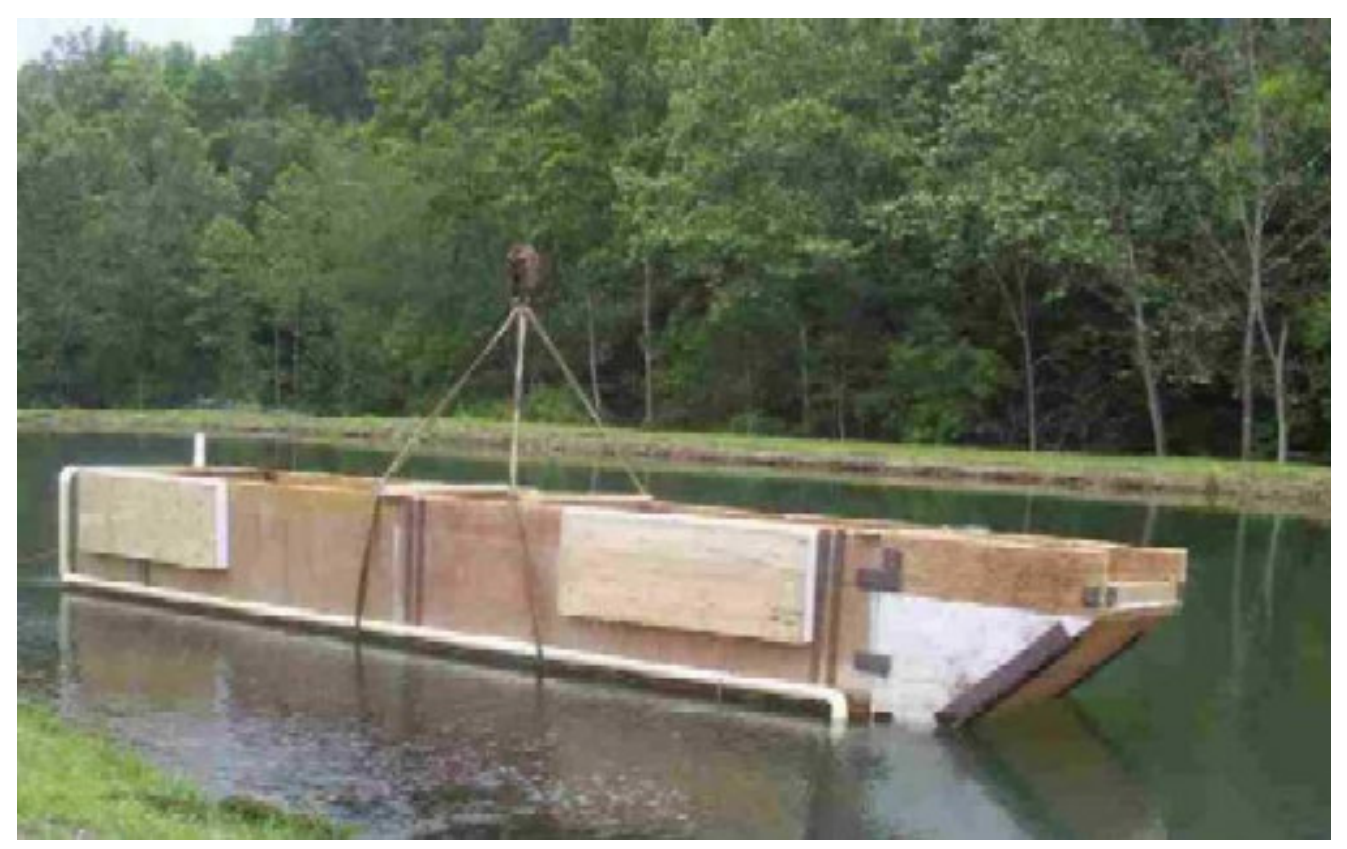

Figure 8.9 Installation of Floating Raceways at the Warwick Mine Water Treatment Plant 


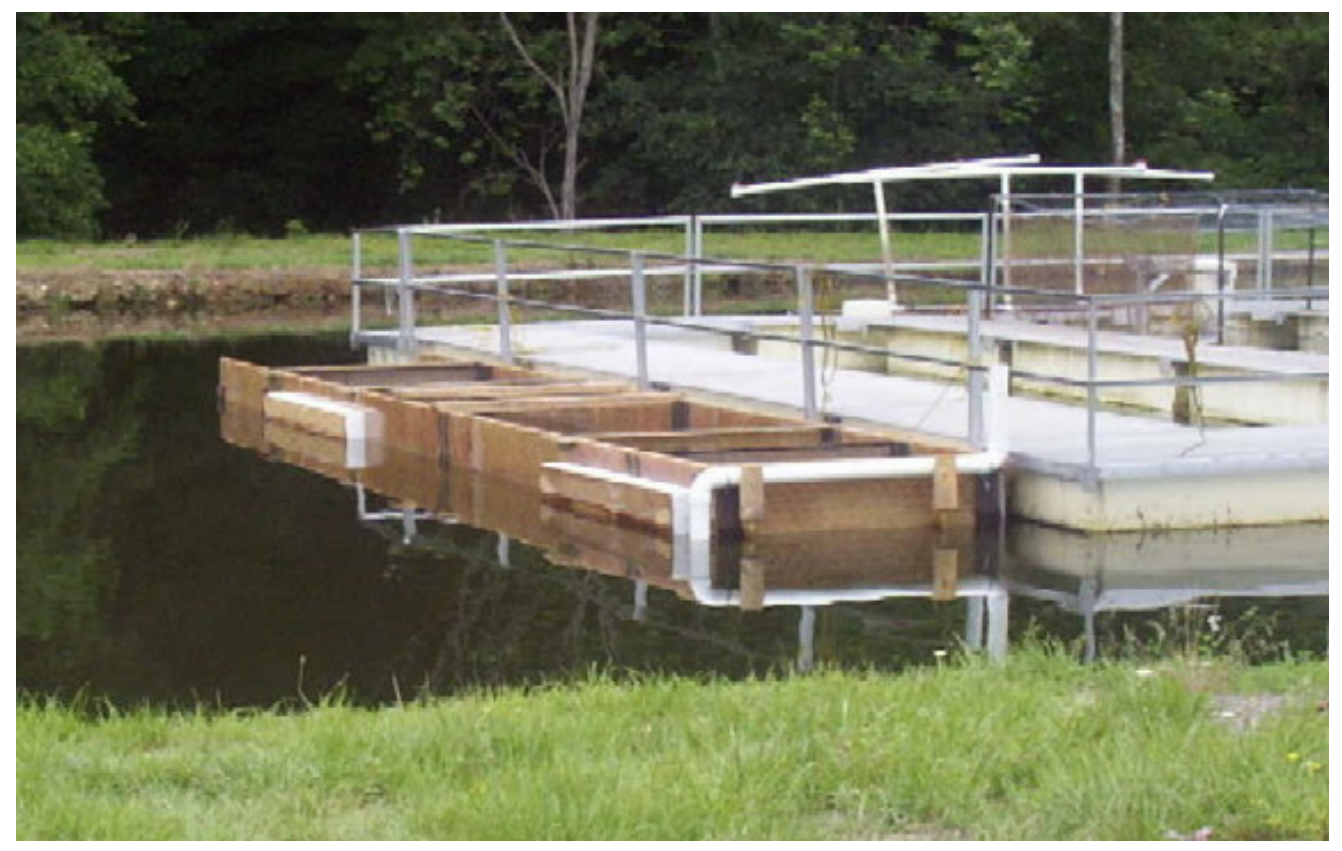

Figure 8.10 Floating Raceways 


\section{Chapter 9}

\section{Recommendations}

\subsection{Overview of the Project}

In this study, an overview of design of fish raceway systems using Honeycomb Fiber-Reinforced Polymer sandwich composites was presented. Experimental testing of beam and connection samples was performed both in the linear range and to failure. Finite element modeling of the samples was done and the results were correlated with the experimental results. Equivalent properties of HFRP were determined and equivalent core geometry FE models were created. Modifications to the initial design were suggested based on the experimental testing and finite element modeling results. The complete tank was modeled using the equivalent properties and the behavior of the tank under various loading and boundary conditions was analyzed. Factors of safety of the tank during field implementation under various loading and boundary conditions are predicted. Current applications of HFRP raceways in West Virginia and Pennsylvania were discussed.

\subsection{Recommendations}

Experimental testing and finite element modeling of the beam and connection samples provided useful insight into the behavior of HFRP material and the raceways. 
Based on these test and modeling results, design modifications were suggested. Field implementation of the raceways provided valuable experience based on which functional modifications to the raceway were suggested. This section deals with some of the design and functionality modifications proposed and implemented.

\subsubsection{Based on Experimental Testing}

Upon evaluating the two connection designs, it was recommended that the stiffened connection should be used for the outer panels and the unstiffened connection should be used for the inner panels as shown in Figure 5.8. It was also decided that a Chopped Strand Mat fabric should be placed at the connection to increase its rotational stiffness (Figure 5.9).

\subsubsection{Based on Experience from Field Implementation}

\section{Main Tank-to-Quiescent Zone Joint:}

In the first set of raceways installed at Dogwood Lakes, the main tank and quiescent zone were connected using 3 sets of bolts on the side panels (Figure 9.1 (a)). The uneven nature of surface posed difficulties during assembly of the raceways at the site. Hence, in the second set of raceways at Wardensville, the main tank-to-quiescent

zone joint was modified to include steel angles at the end, as shown in Figure 9.1 (b). This design greatly increased assembly efficiency. 


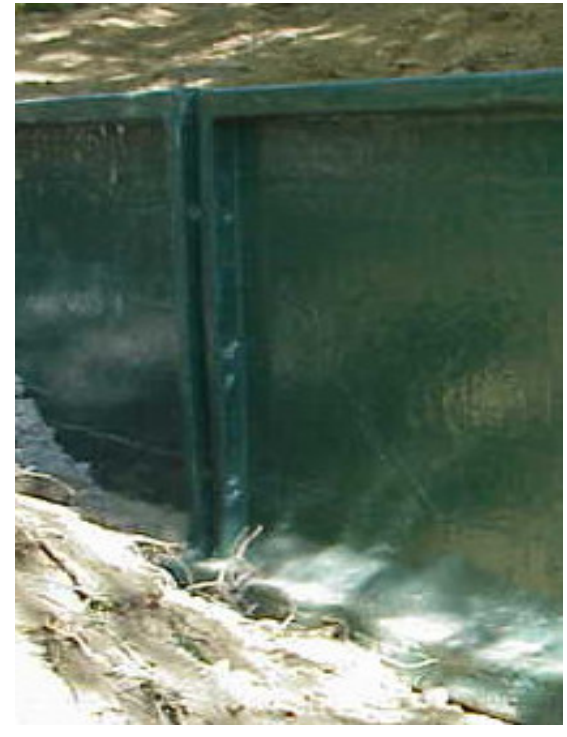

(a) Dogwood Lakes

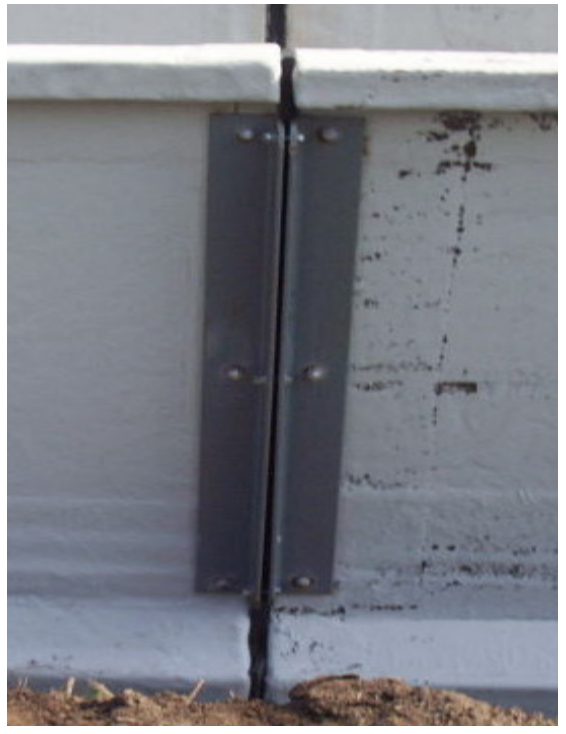

(b) Reymann Memorial Farms

Figure 9.1 Main Tank-to-Quiescent Zone Joint

\section{Mechanical Connector Joining the Central Panels of Main Tank and Quiescent Zone:}

In the current sets of tanks, the central dividing panels of the main tank and the quiescent zone are not joined using any mechanical connectors. In the second set of tanks installed at Wardensville, a new connector was designed to join the two central panels as shown in Figure 9.2, which increased the joint strength.

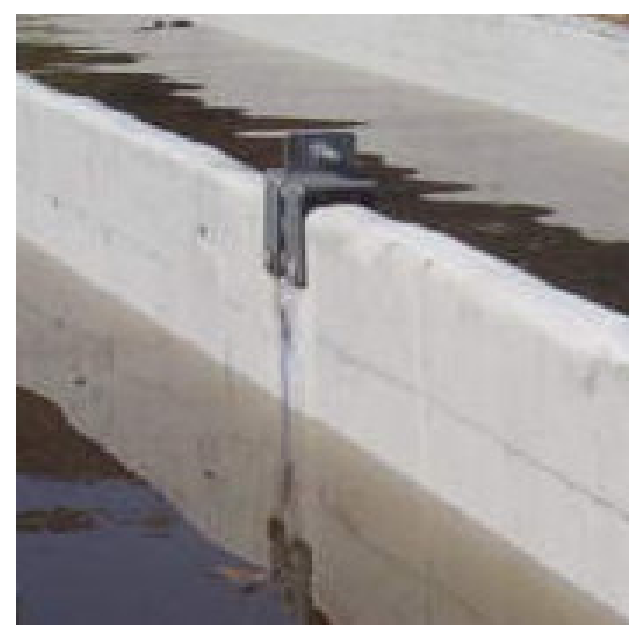

Figure 9.2 Mechanical Connector Joining the Two Central Panels 


\subsubsection{To Decrease Manufacturing and Assembly Costs}

As the tanks are not cast as a single unit, one of the major costs associated with the manufacture of the current HFRP raceways is the machining required to join the side panel to the bottom panel. In the present set of tanks, the two panels are manufactured separately. Grooves are cut in the bottom panel. The side panel is then inserted into the grooves and is bonded to the bottom panel using resin. To decrease machining of the panels, and thus the overall cost of the raceway, a new connection design is being proposed, which allows the user to assemble a fully functional raceway unit from flat panels. A brief description of the proposed design is provided in the next section.

\subsection{Future Work}

To decrease the cost of manufacture, assembly and transportation of the HFRP raceways, modifications to the current side-to-bottom panel connection design were proposed, which allows the user to completely assemble a raceway using flat HFRP panels at the desired location using easy-to-use connectors. Work is being done in this regard at WVU and an initial design was suggested (shown in Figure 9.3). Based on formulations proposed by Davalos and Chen (2004) [13], the coefficient of elastic restraint was calculated and finite element models were created. FE models created using the elastic coefficient of restraint and the equivalent properties discussed in Chapter 2 showed favorable results. On assembly of the first set of samples, certain flaws in the design were identified and design modifications were suggested. Experimental testing for 
stiffness and strength of the connection will be carried out shortly. It is also proposed that a complete tank should be manufactured with the new connection design and implemented in the field.

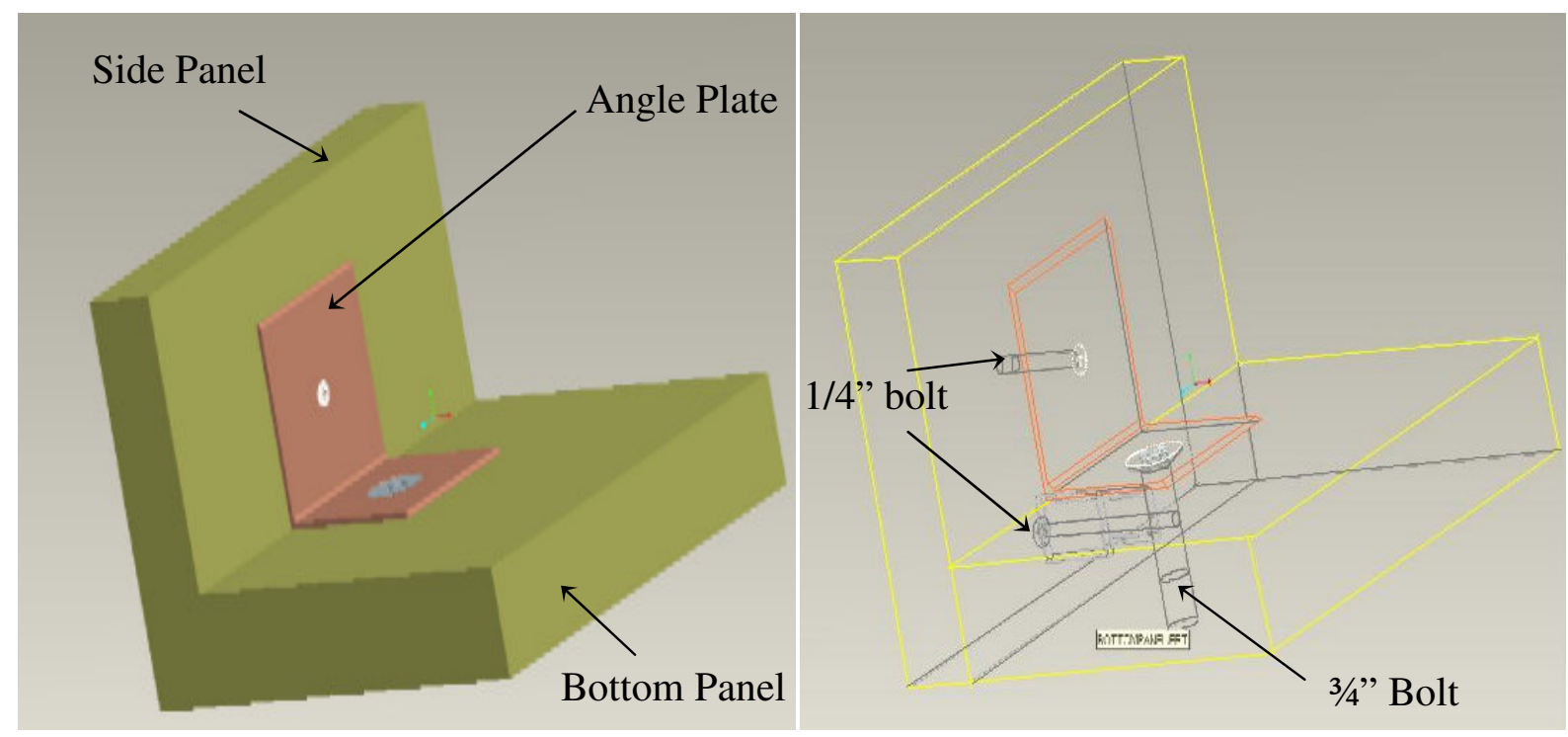

(a) Solid Model of the Proposed Connection

(b) Wire Frame Model of the Proposed Connection
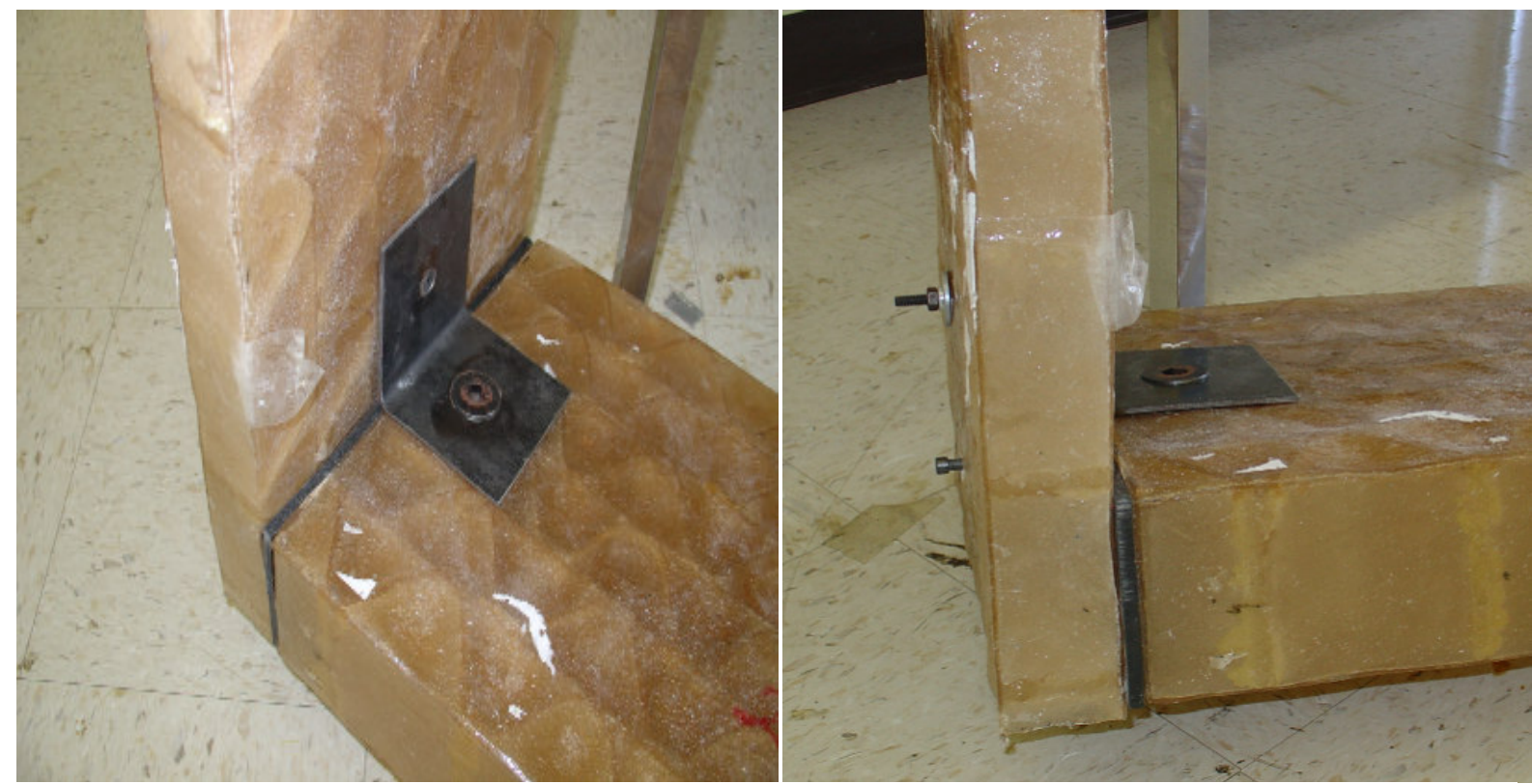

(c) Assembled Connection Sample

(d) Test Sample

Figure 9.3 Initial Design of the New Connector Joining the Side and Bottom Panels 


\subsection{Conclusions}

Design modifications based on the experimental testing and finite element modeling of the HFRP beam samples and connection samples increased the stiffness of the raceways. Failure testing of the samples gave us an indication of the various types of failure possible during field implementation. Factors of safety predicted from the complete raceway model gave useful insight on the performance of the raceways in the field. It also indicated that the raceway functions without any expected failure under all boundary conditions, even when it is intermittently supported. It was also concluded that the material may reach its linear limit when the top bolt of the main tank to quiescent zone fails.

Experience gained from the field installation of the raceways provided valuable knowledge based on which certain functional changes have been proposed and implemented in the design of the tank, as discussed in section 9.2. Though it may be too early to predict the future of HFRP raceways, current field studies show promise and indicate a wide rage of applications in the aquaculture industry.

\subsection{Author's Contribution}

The project has been completed in several stages with the involvement of many people and organizations. Hence it is important to specifically note the contribution of the author to this study. He is responsible for the evaluation of actual material properties, 
calculation of equivalent core properties based on existing formulations, experimental evaluation of HFRP beam samples in bending, evaluation of connection samples for rotational stiffness, finite element modeling of beam and connection samples, failure analysis of beam samples, finite element modeling of complete raceway and predicting the behavior of the raceway under various installation conditions, assisting in field installation of HFRP raceways at Dogwood Lakes, aiding in proposing design modifications based on experimental testing and field implementation of raceways, and finite element modeling and experimental evaluation of the new connection design proposed to decrease manufacturing and assembly costs of the raceway. 


\section{REFERENCES}

1. http://www.fishbase.org/Glossary/Glossary.cfm

2. ABAQUS, Standard Users Manual, 1998, Version 5.8. Hibbitt, Karlsson and Sorensen, Inc., USA.

3. Barbero, E. J., "Introduction to Composite Materials Design", Taylor \& Francis, Inc., Philadelphia, PA, USA, 1998.

4. Davalos, J.F., Qiao, P.Z., Xu, X.F., Robinson, J. and Barth, K.E. (2001). "Modeling and Characterization of Fiber-Reinforced Plastic Honeycomb Sandwich Panels for Highway Bridge Applications," Journal of Composite Structures 52: 441-452.

5. Qiao, P.Z. and Wang, J.L. (2005). "On the Mechanics of Composite Sinusoidal Honeycomb Cores," Journal of Aerospace Engineering, ASCE, in press (to appear in February 2005 issue).

6. Chen, A. (2004). "Strength Evaluation of Honeycomb FRP Sandwich Panels with Sinusoidal Core Geometry", Ph.D. Dissertation, Department of Civil and Environmental Engineering, West Virginia University, Morgantown, WV, USA.

7. FEMAP Users Manual, (1999), Version 8.0. Enterprise Software Products, Inc., Exton, PA.

8. Robinson, J., Davalos, J.F., Xu, X.F., Qiao, P.Z., and Barth, K.E. (2001). “FRP Honeycomb Composite Sandwich Beams Under Bending," Proceedings of the ASC $16^{\text {th }}$ Annual Technical Conference, American Society of Composites (ASC), Blacksburg, VA, Sept. 9-12 (in CD-ROM, Paper\#111, 12 pages).

9. Robinson, J., Davalos, J.F. and Qiao, P.Z., (2002). "Modeling and Characterization of FRP Honeycomb Composite Sandwich Beams," Proceedings of the 3rd International Conference on Composites in Infrastructure (ICCI'02), San Francisco, CA, June 10-12 (CD-ROM, Paper \#015, 12 pages).

10. Robinson. J. (2001). "Analytical and Experimental Study of FRP Honeycomb Sandwich Panels with Sinusoidal Core", M.S. Thesis, Department of Civil and Environmental Engineering, West Virginia University, Morgantown, WV, USA.

11. Chandraputla, T.R. and Ashok D. Belegundu, "Introduction to Finite Elements in Engineering", Second Edition, Prentice- Hall of India, Inc., New Delhi, India, 2001. 
12. Bathe, K.J., "Finite Element Procedures in Engineering Analysis", Prentice- Hall, Inc., Englewood Cliffs, NJ, USA, 1997.

13. Davalos, J.F. and Chen, A. (2004). "Bucking Behavior of Honeycomb FRP Core with Partially Restrained Loaded Edges under Out-of-Plane compression", submitted to Journal of Composite Materials, in review. 


\section{LIST OF PUBLICATIONS ON THE PROJECT}

- Davalos, J.F., Robinson, J., Vantaram, A., Viadero, R.C, Semmens, K., Plunkett, J.D. 2002. "Honeycomb Fiber-Reinforced Polymer Sandwich Panels for Fish Culture Tanks", proceedings of the 3rd International Conference on Composites in Infrastructure (ICCI'02), San Francisco, CA, June 10-12 ( Paper \#014, 12 pages)

- Vantaram, A., Davalos, J.F., Robinson, J., Viadero, R.C, Semmens, K., Plunkett, J.D. 2002 "Honeycomb Fiber-Reinforced Polymer Sandwich Construction for Development and Implementation of Fish Raceway Systems", American Society of Composites 17th Technical Conference, Purdue University, IN, October 21-23, 2002 (Paper \#081, 9 pages)

- Vantaram, A., Davalos, J.F., Robinson, J., Viadero, R.C, Semmens, K., Plunkett, J.D. 2003 "Component Failure and System Modeling of Honeycomb FRP Aquaculture Tanks", American Society of Composites 18th Technical Conference, University of Florida, FL, October 19-22, 2003 (Paper \#159, 9 pages)

- Vantaram, A., Davalos, J.F., Robinson, J., Viadero, R.C, Semmens, K., Plunkett, J.D., "Honeycomb Fiber-Reinforced Polymer Composites: Evaluation of Components and Systems for Aquaculture”, Journal of Composites for Construction (Work in Progress)

- Vantaram, A., Davalos, J.F., Robinson, J., Viadero, R.C, Semmens, K., Plunkett, J.D., "Applications of Honeycomb Fiber-Reinforced Polymer Composites in Aquaculture", Journal of Composites for Construction (Work in Progress) 


\section{APPENDICES}




\section{APPENDIX A}

Output from CADEC to calculate the elastic properties of the unidirectional composite consisting of $\mathrm{E}$ - glass fiber and polyester resin

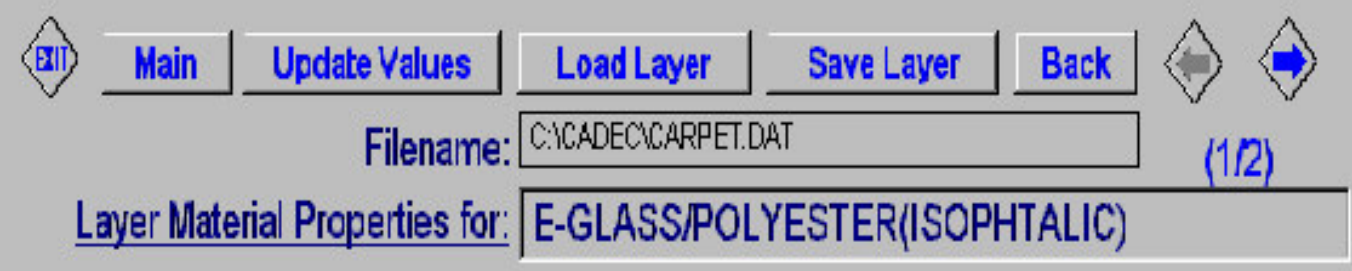

Fiber Properties:

$$
\begin{aligned}
E_{f} & =10.5 \mathrm{e} 6 \\
V_{f} & =0.255 \\
G_{f} & =4.18327 \mathrm{E}+06 \\
\alpha_{f} & =5.4 \mathrm{e}-6 \\
\mathrm{~K}_{f} & =1.05 \\
V_{f} & =.47177 \\
a b & =1 \\
\rho_{1} & =2.5 \\
\sigma_{\text {fa }} & =1.725 \\
\rho_{\mathrm{c}} & =1.81330 \mathrm{E}+00 \\
\Omega[\text { deg }] & =3.53
\end{aligned}
$$

Matrix Properties:

$$
\begin{aligned}
& E_{m}=.734 \mathrm{e} 6 \\
& V_{m}=0.3 \\
& G_{m}=2.82308 \mathrm{E}+05 \\
& \alpha_{m}=30 . e-6 \\
& k_{m}=.2 \\
& \beta_{m}=0.6 \\
& \rho_{m}=1.2
\end{aligned}
$$$$
\sigma_{\mathrm{mu}}=75.9 \mathrm{e}-3
$$$$
\sigma_{\text {muc }}=117.2 \mathrm{e}-3
$$$$
\tau_{\mathrm{mu}}=75.9 \mathrm{e}-3
$$$$
V_{y}=.01
$$

Elastic Properties:

$$
\begin{aligned}
& E_{1}=5.34131 E+06 \\
& E_{2}=2.11231 E+06 \\
& \mathrm{G}_{12}=6.78120 \mathrm{E}+05 \\
& \mathrm{G}_{23}=6.05614 \mathrm{E}+05 \\
& v_{12}=0.27877 \\
& v_{23}=0.50718 \\
& \begin{array}{l}
k_{1}=6.01005 \mathrm{E}-01 \\
k_{2}=3.23577 \mathrm{E}-01
\end{array}
\end{aligned}
$$




\section{APPENDIX B}

Maple program to calculate the elastic properties of chopped strand mat from unidirectional composite properties obtained from CADEC

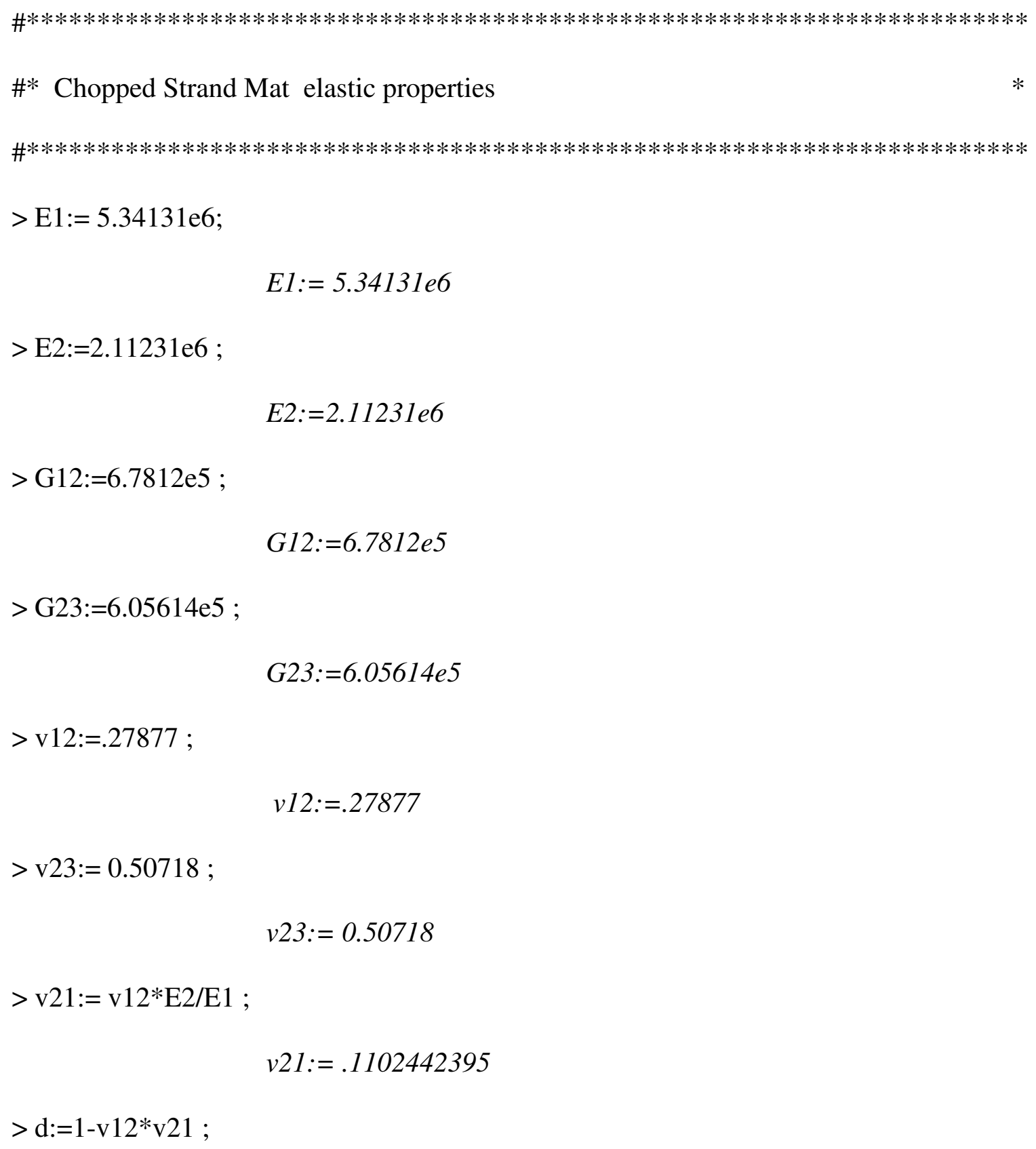




$$
d:=.9692672134
$$

$>$ Echsm: $=\left(\mathrm{E} 1{ }^{\wedge} 2+4 * \mathrm{E} 1 * \mathrm{G} 12 * \mathrm{~d}+2 * \mathrm{E} 1 * \mathrm{E} 2+8 * \mathrm{v} 12 * \mathrm{E} 2 * \mathrm{G} 12 * \mathrm{~d}-\right.$

$\left.4 * \mathrm{v} 12^{\wedge} 2 * \mathrm{E} 2 \wedge 2+4 * \mathrm{E} 2 * \mathrm{G} 12 * \mathrm{~d}+\mathrm{E} 2{ }^{\wedge} 2\right) / \mathrm{d} /(3 * \mathrm{E} 1+2 * \mathrm{v} 12 * \mathrm{E} 2+3 * \mathrm{E} 2+4 * \mathrm{G} 12 * \mathrm{~d})$

$$
\text { Echsm: }=.303043046910^{7}
$$

$>$ Gchsm: $=(\mathrm{E} 1-2 * \mathrm{v} 12 * \mathrm{E} 2+\mathrm{E} 2+4 * \mathrm{G} 12 * \mathrm{~d}) / 8 / \mathrm{d}$

$$
\text { Gchsm: }=.114842435810^{7}
$$

$>$ vchsm: $=(\mathrm{E} 1+6 * \mathrm{v} 12 * \mathrm{E} 2+\mathrm{E} 2-4 * \mathrm{G} 12 * \mathrm{~d}) /(3 * \mathrm{E} 1+2 * \mathrm{v} 12 * \mathrm{E} 2+3 * \mathrm{E} 2+4 * \mathrm{G} 12 * \mathrm{~d})$

$$
\text { vchsm: }=.3193861869
$$

$>$ dchsm: $=1-$ vchsm$^{\wedge} 2$;

$$
\text { dchsm: }=.8979924636
$$

$>$ Q11:=Echsm/dchsm ;

$$
Q 11:=.337467249710^{7}
$$

$>$ Q12:=vchsm*Echsm/dchsm;

$$
Q 12:=.107782378110^{7}
$$

>Q21:=Q12 ;

$$
Q 21:=.107782378110^{7}
$$

$>$ Q22:= Echsm/dchsm ;

$$
Q 22:=.33746729710^{7}
$$

$>$ Q66:= Gchsm;

$$
Q 66:=.114842435810^{7}
$$

> A11:=Q11*0.09;

$$
A 11:=303720.5247
$$

$>\mathrm{A} 22:=\mathrm{Q} 22 * 0.09$; 


$$
A 22:=303720.5247
$$

>A12:=Q12*0.09;

$$
\text { A12:=97004.14029 }
$$

> A66:= Gchsm*0.09;

$$
\text { A66: }=103358.1922
$$

$>\mathrm{t}:=0.09$

$$
t:=0.09
$$

$>\mathrm{Ex}:=\left(\mathrm{A} 11^{*} \mathrm{~A} 22-\mathrm{A} 12^{\wedge} 2\right) / \mathrm{t} / \mathrm{A} 22 ;$

$$
E x:=.303043046910^{7}
$$

$>\mathrm{Ey}:=\left(\mathrm{A} 11^{*} \mathrm{~A} 22-\mathrm{A} 12^{\wedge} 2\right) / \mathrm{t} / \mathrm{A} 11$;

$$
E y:=.303043046910^{7}
$$

$>$ Gxy:=A66/t;

$$
G x y:=.114842435810^{7}
$$

$>$ Gxz:= G23;

$$
G x z:=605614
$$

> Gyz:=Gxz;

$$
G y z:=605614 \text {. }
$$

> vxy:=A12/A22;

$$
v x y:=.3193861870
$$

$>$ vyz:=v23;

$$
v y z:=.50718
$$

$>\mathrm{vxz}:=\mathrm{vyz}$

$$
v x z:=.50718
$$




\section{APPENDIX C}

Mathematica program to calculate the In-plane equivalent properties of the sinusoidal core plate.

Note: All values are in SI units and are converted into FPS units before using the properties in finite element modeling

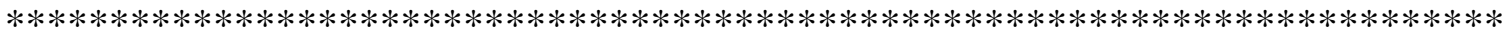

IN-plane properties of Sinusoidal core plate

$* * * * * * * * * * * * * * * * * * * * * * * * * * * * * * * * * * * * * * * * * * * * * * * * * * * * * * * * * * * * * * * * * * * * * * * * * * * *$

$\mathrm{h}=0.0254$

$b=0.0508$

$t 1=0.001524$

$t 2=t 1$

$E 1=20.894 * 10^{\wedge} 9$

E2 = E1

$\mathrm{G} 12=7.91 * 10^{\wedge} 9$

$\mathrm{am}=12 /\left(\mathrm{E} 1 * \mathrm{t} 2^{\wedge} 3\right)$

aml $=12 /\left(\mathrm{E1} * \mathrm{t1} 1^{\wedge} 3\right)$

an $=1 /(\mathrm{E} 1 *$ t2 $)$

av $=1 /(5 / 6 * G 12 * t 2)$

$\operatorname{av1}=1 /(5 / 6 * G 12 * t 1)$

0.0254

0.0508

0.001524 
0.001524

$2.0894 \times 10^{10}$

$2.0894 \times 10^{10}$

$7.91 \times 10^{9}$

0.162257

0.162257

$3.14046 \times 10^{-8}$

$9.95451 \times 10^{-8}$

$9.95451 \times 10^{-8}$

$\mathrm{c}=1 / \sqrt{1+(\mathrm{h} * \pi / \mathrm{b}) \wedge 2 *(\operatorname{Sin}[\pi * \mathrm{x} / \mathrm{b}])^{\wedge} 2}$

$\mathbf{s}=(\mathrm{h} * \pi / \mathrm{b}) *(\operatorname{Sin}[\pi * \mathrm{x} / \mathrm{b}]) / \sqrt{1+(\mathrm{h} * \pi / \mathrm{b}) \wedge 2 *(\operatorname{Sin}[\pi * \mathrm{x} / \mathrm{b}])^{\wedge} 2}$

$j=\sqrt{1+(h * \pi / b) \wedge 2 *(\operatorname{Sin}[\pi * x / b])^{\wedge} 2}$

$\frac{1}{\sqrt{1+2.4674 \operatorname{Sin}[61.8424 x]^{2}}}$

$\frac{1.5708 \operatorname{Sin}[61.8424 x]}{\sqrt{1+2.4674 \operatorname{Sin}[61.8424 x]^{2}}}$

$\sqrt{1+2.4674 \operatorname{Sin}[61.8424 x]^{2}}$

$M=-P * X+F * h *(1-\operatorname{Cos}[\pi * \mathbf{X} / b])+M 0$

$\mathrm{Na}=\mathbf{F} * \mathbf{C}+\mathrm{P} * \mathbf{S}$

$\mathrm{V}=\mathrm{P} * \mathbf{C}-\mathbf{F} * \mathbf{S}$

$\mathrm{M} 0-\mathrm{Px}+0.0254 \mathrm{~F}(1-\operatorname{Cos}[61.8424 \mathrm{x}])$

$\frac{F}{\sqrt{1+2.4674 \operatorname{Sin}[61.8424 x]^{2}}}+\frac{1.5708 P \operatorname{Sin}[61.8424 x]}{\sqrt{1+2.4674 \operatorname{Sin}[61.8424 x]^{2}}}$

$\frac{\mathrm{P}}{\sqrt{1+2.4674 \operatorname{Sin}[61.8424 \mathrm{x}]^{2}}}-\frac{1.5708 \mathrm{~F} \operatorname{Sin}[61.8424 \mathrm{x}]}{\sqrt{1+2.4674 \operatorname{Sin}[61.8424 \mathrm{x}]^{2}}}$ 


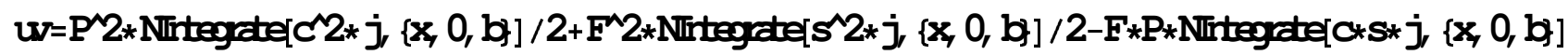

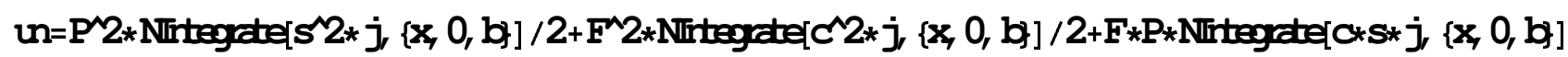

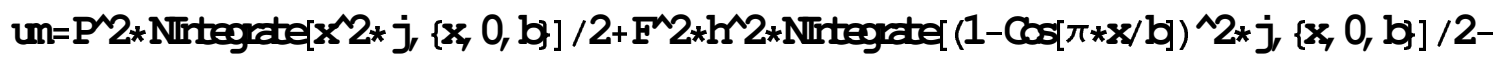

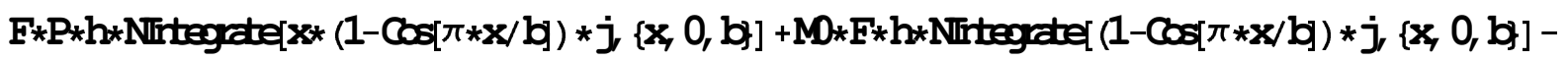
$M * P * N$ integrte $[x * j ;\{x, 0, b\}]+M D * N$ Irtegrate $[j,\{x, 0, b\}] / 2$

$0.0190041 F^{2}-0.0324659 F P+0.0181738 P^{2}$

$0.0181738 F^{2}+0.0324659 F P+0.0190041 P^{2}$

$0.0000342329 \mathrm{~F}^{2}+0.00188864 \mathrm{FMD}+0.0371779 \mathrm{MO}^{2}-0.0000642351 \mathrm{FP}-0.00188864 \mathrm{MD} \mathrm{P}+0.0000305376 \mathrm{P}^{2}$

$U=u v * a v+u n * a n+u m * a m+a n * F^{\wedge} 2 * b$

$1.59535 \times 10^{9} \mathrm{~F}^{2}+0.162257\left(0.0000342329 \mathrm{~F}^{2}+0.00180864 \mathrm{FM}+0.0371779 \mathrm{M}^{2}-0.0000642351 \mathrm{FP}-0.00188364 \mathrm{MP}+0.0000305376 \mathrm{P}^{2}\right)+$ $9.95451 \times 10^{8}\left(0.0190011 \mathrm{~F}^{2}-0.0324659 \mathrm{FP}+0.0181738 \mathrm{P}^{2}\right)+3.14046 \times 10^{8}\left(0.0181738 \mathrm{~F}^{2}+0.0324659 \mathrm{FP}+0.0190041 \mathrm{P}^{2}\right)$

$* * * * * * * * * * * * * * * * * * * * * * * * * * * * * * * * * * * * * * * * * * * * * * * * * * * * * * * * * * * * * * * * * * * * * * * * *$

\section{E22 and V21}

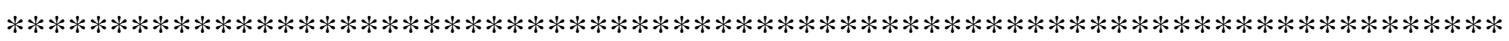

$\delta \mathrm{y}=0.0001$

0.0001

$P=$.

$\mathrm{Eq} 1=\partial_{\mathrm{M}} \mathrm{U}==0$

$\mathrm{E} Q \mathbf{Q}=\partial_{\mathrm{P}} \mathrm{U}==\delta \mathrm{Y}$

$\mathrm{Eq3}=\partial_{\mathrm{F}} \mathrm{U}-2 * \mathrm{~F} * \mathrm{~b} / \mathrm{E} 1 / \mathrm{t} 1==0$

$\delta \mathbf{X}=2 * \mathrm{~F} * \mathrm{~b} / \mathrm{E} \mathbf{1} / \mathrm{t} 1$

$0.162257(0.00188864 \mathrm{~F}+0.0743557 \mathrm{M} 0-0.00188864 \mathrm{P})==0$ 
$0.162257(-0.0000642351 \mathrm{~F}-0.00188864 \mathrm{MD}+0.0000610753 \mathrm{P})+$

$9.95451 \times 10^{-8}(-0.0324659 \mathrm{~F}+0.0363475 \mathrm{P})+3.14046 \times 10^{-8}(0.0324659 \mathrm{~F}+0.0380082 \mathrm{P})=0.0001$

$0 . \mathrm{F}+9.95451 \times 10^{-8}(0.0380082 \mathrm{~F}-0.0324659 \mathrm{P})+$

$0.162257(0.0000684657 \mathrm{~F}+0.00188864 \mathrm{MD}-0.0000642351 \mathrm{P})+3.14046 \times 10^{-8}(0.0363475 \mathrm{~F}+0.0324659 \mathrm{P})=0$

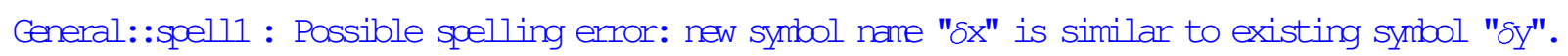

$3.19071 \times 10^{-9} \mathrm{~F}$

Solve $[$ Eq1, Eq2, Eq 3$\},\{M 0, P, F\}]$

$\{\{\mathrm{MO} \rightarrow 14.4202, \mathrm{P} \rightarrow 2743.43, \mathrm{~F} \rightarrow 2175.71\}\}$

$\mathrm{Stb}=\left\{\left\{\mathrm{MD} \rightarrow 23.7085583328231042^{\prime}, \mathrm{P} \rightarrow 4497.08793815037655^{\prime}, \mathrm{F} \rightarrow 3563.68012984153859^{\prime}\right\}\right\}$

$\{\{\mathrm{MO} \rightarrow 23.7086, \mathrm{P} \rightarrow 4497.09, \mathrm{~F} \rightarrow 3563.68\}\}$

$\delta \mathbf{x} /$. Sub

$\{0.0000113707\}$

$\mathrm{E} 22=\mathrm{P} * 2 * \mathrm{~h} /(\mathrm{b} * \delta \mathrm{y}) / . \mathrm{Sub}$

$v 21=\delta x * 2 * h /(2 * b * \delta y) /$. Sub

$\left\{4.49709 \times 10^{7}\right\}$

$\{0.0568533\}$

E22 / E1

$\{0.00215233\}$ 


\section{E11 and V12}

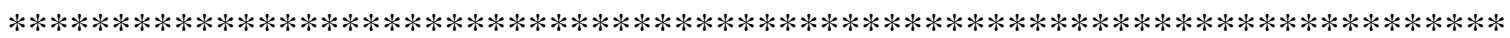

$\delta \mathbf{x}=0.001$

$\delta \mathrm{y}=$.

0.001

$E q 4=\partial_{M} \mathrm{U}==0$

$\operatorname{Eq} 5=\partial_{\mathrm{P}} \mathrm{U}==\delta \mathrm{Y}$

Eq $6=\partial_{F} \mathrm{U}==\delta \mathbf{x}$

$0.162257(0.00188864 \mathrm{~F}+0.0743557 \mathrm{M} 0-0.00188864 \mathrm{P})==0$

$0.162257(-0.0000642351 \mathrm{~F}-0.00188864 \mathrm{M} 0+0.0000610753 \mathrm{P})+$

$9.95451 \times 10^{-8}(-0.0324659 \mathrm{~F}+0.0363475 \mathrm{P})+3.14046 \times 10^{-8}(0.0324659 \mathrm{~F}+0.0380082 \mathrm{P})==\delta \mathrm{Y}$

$3.19071 \times 10^{-9} \mathrm{~F}+9.95451 \times 10^{-8}(0.0380082 \mathrm{~F}-0.0324659 \mathrm{P})+$

$0.162257(0.0000684657 \mathrm{~F}+0.00188864 \mathrm{MD}-0.0000642351 \mathrm{P})+3.14046 \times 10^{-8}(0.0363475 \mathrm{~F}+0.0324659 \mathrm{P})=0.001$

Solve $\{$ Eq4, Eq5, Eq6 $\},\{M 0, F, \delta y\}]$

$\left\{\left\{\mathrm{MD} \rightarrow 631562 \cdot\left(0.0120648(-0.001-0.0000104248 \mathrm{P})+9.39087 \times 10^{-8} \mathrm{P}\right)+0.0254 \mathrm{P}\right.\right.$, $\mathrm{F} \rightarrow-2.48647 \times 10^{7}\left(0.0120648(-0.001-0.0000104248 \mathrm{P})+9.39087 \times 10^{-8} \mathrm{P}\right)$ ， $\left.\left.\delta \mathrm{Y} \rightarrow 2.06093 \times 10^{9}\left(3.18646 \times 10^{-8}\left(0.0120648(-0.001-0.0000104248 \mathrm{P})+9.39087 \times 10^{-8} \mathrm{P}\right)+1.03401 \times 10^{-15} \mathrm{P}\right)\right\}\right\}$

$P=0$

0

$\delta y=$

$1.3384734100231029 * 10$

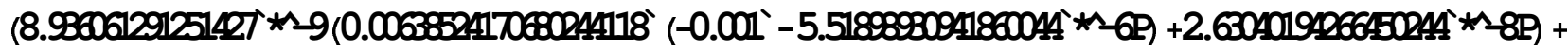
$8.16863505153326 * 2-17 \mathrm{P}$ 
$-0.000790749$

$v 12=-\delta y * b /(\delta x * 2 * h)$

General::spell1 : Possible spelling error: new symbol name "v12" is similar to existing symbol "v21".

0.790749

$\mathrm{E} 11=\mathrm{E} 22 * v 12 / v 21$

$\left\{6.25481 \times 10^{8}\right\}$

\section{E11/ E1}

$\{0.0299359\}$

$* * * * * * * * * * * * * * * * * * * * * * * * * * * * * * * * * * * * * * * * * * * * * * * * * * * * * * * * * * * * * * * * * * * * * * * * * *$

G12

$* * * * * * * * * * * * * * * * * * * * * * * * * * * * * * * * * * * * * * * * * * * * * * * * * * * * * * * * * * * * * * * * * * * * * * * * * *$

$\delta \mathbf{x}=.001$

$\delta y=0$

$\mathrm{P}=$.

0.001

0

$\mathrm{U} 1=u v * a v+u n * a n+u m * a m+2 * a n * F^{\wedge} 2 * b$

$3.19071 \times 10^{9} \mathrm{~F}^{2}+0.16257\left(0.0000322329 \mathrm{~F}^{2}+0.00180864 \mathrm{FM}+0.0371779 \mathrm{M}^{2}-0.0000612351 \mathrm{FP}-0.00180864 \mathrm{MOP}+0.0000305376 \mathrm{P}^{2}\right)+$ $9.95451 \times 10^{8}\left(0.0190041 \mathrm{~F}^{2}-0.0324659 \mathrm{FP}+0.0181738 \mathrm{P}^{2}\right)+3.14046 \times 10^{8}\left(0.0181738 \mathrm{~F}^{2}+0.0324659 \mathrm{FP}+0.0190041 \mathrm{P}^{2}\right)$

$\mathrm{Eq} 7=\partial_{\mathrm{MO}} \mathrm{U1}==0$

Eq $8=\partial_{P} \mathbb{U}==0$

$\operatorname{Eq} 9=\partial_{F} U 1==\delta \mathbf{x}$ 
$0.162257(0.00188864 \mathrm{~F}+0.0743557 \mathrm{M} 0-0.00188864 \mathrm{P})==0$

$0.162257(-0.0000642351 \mathrm{~F}-0.00188864 \mathrm{M0}+0.0000610753 \mathrm{P})+$ $9.95451 \times 10^{-8}(-0.0324659 \mathrm{~F}+0.0363475 \mathrm{P})+3.14046 \times 10^{-8}(0.0324659 \mathrm{~F}+0.0380082 \mathrm{P})==0$

$6.38142 \times 10^{-9} \mathrm{~F}+9.95451 \times 10^{-8}(0.0380082 \mathrm{~F}-0.0324659 \mathrm{P})+$

$0.162257(0.0000684657 \mathrm{~F}+0.00188864 \mathrm{MD}-0.0000642351 \mathrm{P})+3.14046 \times 10^{-8}(0.0363475 \mathrm{~F}+0.0324659 \mathrm{P})=0.001$

Solve $\{$ Eq7, Eq8, Eq9 $\},\{M 0, P, F\}]$

$\{\{\mathrm{MO} \rightarrow 95.9815, \mathrm{P} \rightarrow 19565.3, \mathrm{~F} \rightarrow 15786.5\}\}$

$\mathrm{Sub1}=\left\{\left\{\mathrm{MD} \rightarrow 142.470736828005843^{\prime}, \mathrm{P} \rightarrow 29264.4069210505097^{\prime}, \mathrm{F} \rightarrow 23655.3227944257216^{\prime}\right\}\right\}$

$\{\{\mathrm{MO} \rightarrow 142.471, \mathrm{P} \rightarrow 29264.4, \mathrm{~F} \rightarrow 23655.3\}\}$

$\mathrm{G} 121=\mathbf{F} / \delta \mathbf{x} / . \mathrm{Sub} 1$

G121 / E1

$\left\{2.36553 \times 10^{7}\right\}$

$\{0.00113216\}$ 


\section{APPENDIX D}

\section{Maple program to calculate the material properties of the face sheet and out-of-} plane equivalent properties of the sinusoidal core plate

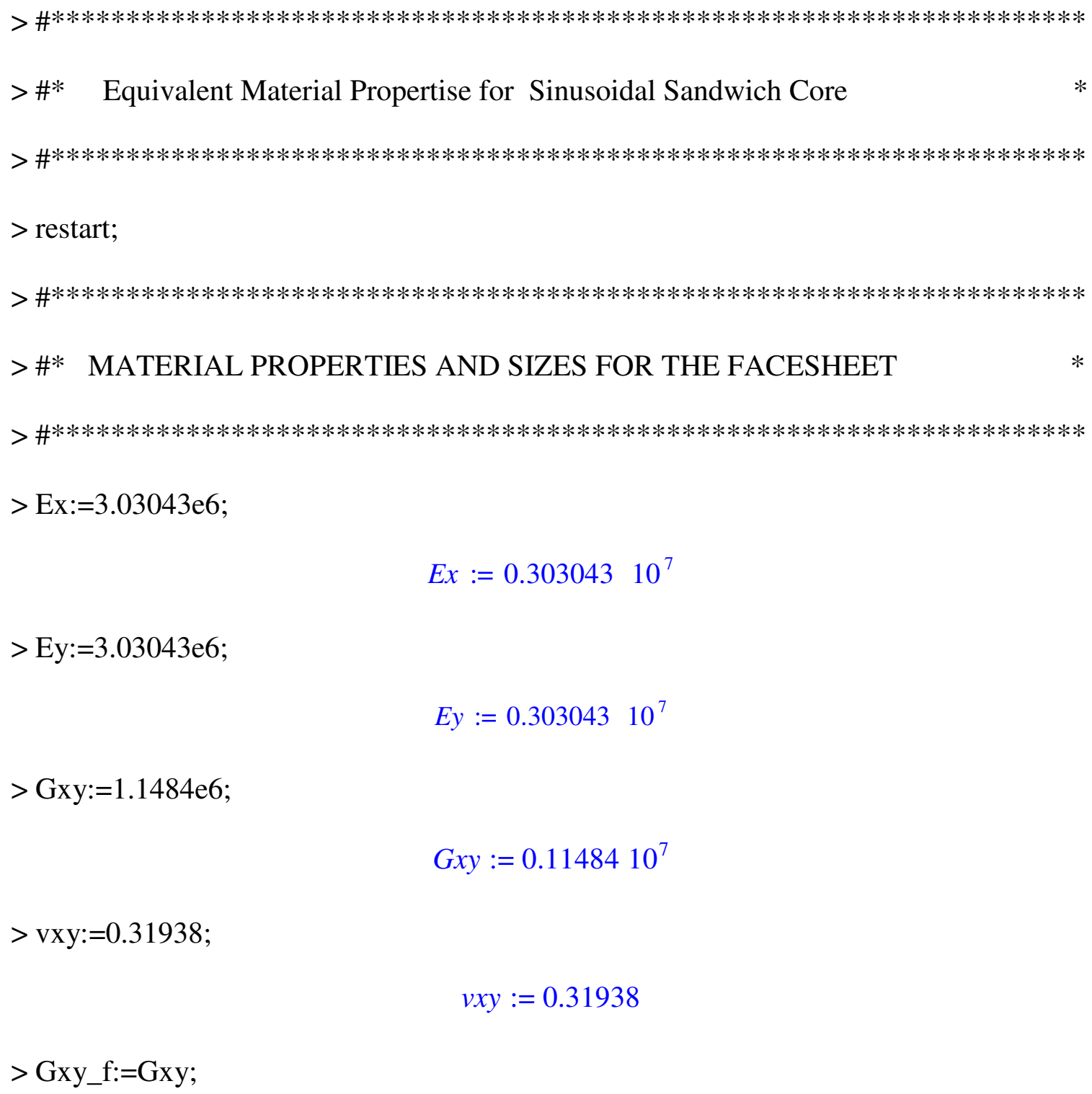


$>$ Gxz_f:=605614;

$G x z \_:=605614$

$>$ Gyz_f:=605614;

$G y z \_:=605614$

$>\# * * * * * * * * * * * * * * * * * * * * * * * * * * * * * * * * * * * * * * * * * * * * * * * * * * * * * * * * * * * * * * * * * * * * *$ > \#* MATERIAL PROPERTIES FOR CORE WALL AND SIZES $\quad *$

$>\# * * * * * * * * * * * * * * * * * * * * * * * * * * * * * * * * * * * * * * * * * * * * * * * * * * * * * * * * * * * * * * * * * * * * *$

> \#Note:2h-sinusoidal core height; 1-core length for RVE

$>$ t2-corruted wall thickness;t1-flat wall thickness

> \# hc-height of core; Ht-Total height of the panel

> \# L-the width of the panel;H-the height of core RVE

$>$ k-transverse shear factor $(5 / 6)$

$>\mathrm{E} 1:=3.0304 \mathrm{e} 6$

$$
E 1:=0.3030410^{7}
$$

$>\mathrm{E} 2:=\mathrm{E} 1$

$$
E 2:=0.3030410^{7}
$$

$>$ G12:=1.1484e6;

$$
G 12:=0.1148410^{7}
$$

> G23:=0.605614e6;

$$
G 23:=605614
$$

$>\mathrm{G} 13:=\mathrm{G} 23$;

$$
G 13:=605614
$$


> v12:=0.3194;

$$
v 12:=0.3194
$$

> v23:=0.50718;

$$
v 23:=0.50718
$$

> v13:=v23;

$$
v 13:=0.50718
$$

$>\mathrm{h}:=1$;

$$
h:=1
$$

$>1:=4$

$$
l:=4
$$

$>\mathrm{t} 1:=0.06$;

$$
t 1:=0.06
$$

$>\mathrm{t} 2:=0.06$;

$$
t 2:=0.06
$$

$>\mathrm{k}:=5 / 6$;

$$
k:=\frac{5}{6}
$$

$>\mathrm{H}:=4 * \mathrm{~h}+2 * \mathrm{t} 1+2 * \mathrm{t} 2$;

$$
H:=4.24
$$

$>\mathrm{S}:=2.927$;

$$
S:=2.927
$$

> pai:=3.1415926;

$$
\text { pai }:=3.1415926
$$


$>\# * * * * * * * * * * * * * * * * * * * * * * * * * * * * * * * * * * * * * * * * * * * * * * * * * * * * * * * * * * * * * * * * * * * * *$ > \#* CALCULATION OF EQUIVALENT CORE MATERIAL PROPERTIES ～*

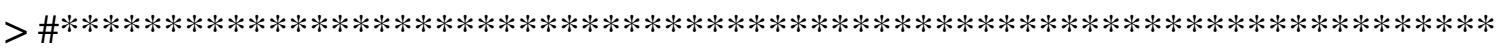

$>$ Gxy_c: $=16 * \mathrm{t} 2 \wedge 3 /\left(1 * \mathrm{~h}^{\wedge} 2 * 12 *\left(6+5 * \mathrm{pai}^{\wedge} 2 *(\mathrm{~h} / \mathrm{l})^{\wedge} 2\right)\right) * \mathrm{E} 1$

$$
G x y \_c:=24.01835809
$$

$>\mathrm{Gxz}_{-} \mathrm{c}:=(2 * \mathrm{t} 1+\mathrm{t} 2 * 1 /(\mathrm{S})) / \mathrm{H} * \mathrm{G} 12$

$$
G x z \_c:=54710.21397
$$

$>$ Gyz_c:=16*t2*h^2/H/1/S*G12;

$$
G y z_{-} c:=22208.32715
$$

$>$ Ey_c $1:=2337.82 * \mathrm{H}^{*} \mathrm{t} 2{ }^{\wedge} 3 *\left(\left(29.6088 * \mathrm{~h}^{\wedge} 4+6 * \mathrm{~h}^{\wedge} 2 * 1 \wedge 2\right) * \mathrm{t} 1-2 * 1 \wedge 2 * \mathrm{t} 2 \wedge 3\right)^{\wedge} 2$

$$
\text { Ey_cl }:=121.3881616
$$

$>$ Ey_c2:=h^ $4 *\left(6892.6 * \mathrm{~h}^{\wedge} 6+9616.51 * \mathrm{~h}^{\wedge} 4 * 1^{\wedge} 2+2416.66 * \mathrm{~h}^{\wedge} 2^{*} \mathrm{l}^{\wedge} 4+152.181 * 1^{\wedge} 6\right)^{*} \mathrm{t} 1^{\wedge} 2$

$$
\text { Ey_c2 :=5049.918346 }
$$

$>$ Ey_c $3:=\mathrm{h}^{\wedge} 2 * 1 \wedge 2 *\left(65566.8 * \mathrm{~h}^{\wedge} 2+29209 * \mathrm{~h}^{\wedge} 2 * 1 \wedge 2+3354.55^{*} \mathrm{1}^{\wedge} 4\right) * \mathrm{t} 1 * \mathrm{t} 2{ }^{\wedge} 3$;

$$
\text { Ey_c3 }:=288.5778524
$$

$>$ Ey_c4:=1^4*(4523.22* $\left.\mathrm{h}^{\wedge} 2+1168.91 * 1 \wedge 2\right) * t 2^{\wedge} 6$;

$$
\text { Ey_c4 := } 0.2774072299
$$

$>$ Ey_c:=Ey_c1*E1/(1^2*(Ey_c2+Ey_c3+Ey_c4) $)$;

$$
E y_{-} c:=4306.404338
$$

$>\mathrm{Ex} \_\mathrm{c}:=2 * \mathrm{t} 1 / \mathrm{H}^{*} \mathrm{E} 1$

$$
E x \_c:=85766.03776
$$

$>\mathrm{Ez}_{-} \mathrm{c}:=(2 * \mathrm{t} 1 * 1+4 * \mathrm{t} 2 * \mathrm{~S}) /(1 * \mathrm{H}) * \mathrm{E} 1$

$$
E z_{-} c:=211284.6340
$$


$>$ Vyx_c1:=315.827* $\mathrm{h}^{*} \mathrm{H}^{*}\left(39.4784 * \mathrm{~h}^{\wedge} 2+9 * 1 \wedge 2\right)^{*} \mathrm{t} 2{ }^{\wedge} 3 *\left(3 *\left(9.8696 * \mathrm{~h}^{\wedge} 4+2 * \mathrm{~h}^{\wedge} 2 * 1 \wedge 2\right) * \mathrm{t} 1-\right.$ $2 * 1 \wedge 2 *(2 \wedge 3)$

$$
V y x \_c 1:=399.6010637
$$

$>$ Vyx_c2:=h^4* $4\left(6892.6 * \mathrm{~h}^{\wedge} 6+9616.5 * \mathrm{~h}^{\wedge} 4 * 1^{\wedge} 2+2416.66 * \mathrm{~h}^{\wedge} 2 * 1^{\wedge} 4+152.181^{*} \mathrm{l}^{\wedge} 6\right)^{*} \mathrm{t} 1^{\wedge} 2$

$$
V y x \_c 2:=5049.917770
$$

$>$ Vyx_c3:=4*h^2*1^2*(16391.7*h^4+7302.24*h^2*1^2+838.636*1^4)*t1*t2^3;

$$
V y x \_c 3:=288.5774012
$$

$>$ Vyx_c4:=1168.91*1^4*(3.8696*h^2+1^2)*t2^6;

$$
\text { Vyx_c4 }:=0.2774071598
$$

$>V y x \_c:=V y x \_c 1 /\left(V y x \_c 2+V y x \_c 3+V y x \_c 4\right)$

$$
V y x \_c:=0.07484886420
$$

$>V x y \_c:=V y x \_c * E x \_c / E y \_c ;$

$$
V x y \_c:=1.490684573
$$

$>\# * * * * * * * * * * * * * * * * * * * * * * * * * * * * * * * * * * * * * * * * * * * * * * * * * * * * * * * * * * * * * * * * * * * * *$ $>$ \#* OVERWRITING THE VALUES OF Ex_c and Ey_c FROM APPENDIX C *

$>\# * * * * * * * * * * * * * * * * * * * * * * * * * * * * * * * * * * * * * * * * * * * * * * * * * * * * * * * * * * * * * * * * * * * * *$ $>$ Ex_c:=90721.1;

$$
E x \_c:=90721.1
$$

$>$ Ey_c:=22208.33;

$$
E y \_c:=6522.347
$$

$>V x z \_c:=E x \_c / E z \_c * v 13$

$$
V x z_{-} c:=0.217772
$$


$>V y z \_c:=E y \_c / E z \_c * v 23 ;$

$$
V y z \_c:=0.0156566
$$

$>$ Vzx_c:=v13;

$$
V z x \_c:=0.50718
$$

>Vzy_c:=v23;

$$
V z y_{-} c:=0.50718
$$

